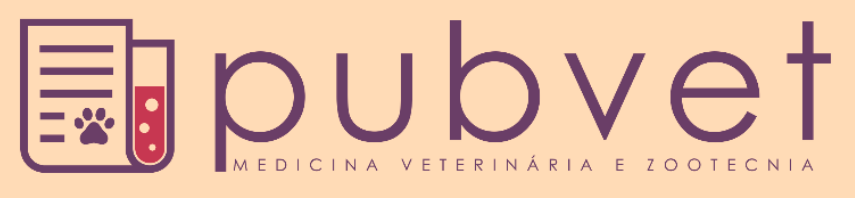

https://doi.org/10.31533/pubvet.v13n8a391.1-7

\title{
Identificação in silico de potenciais alvos antigênicos de Corynebacterium pseudotuberculosis
}

\author{
Andressa Souza Marques ${ }^{1,3} \bullet$, Bruno Lopes Bastos $^{2}{ }^{\ominus}$, José Tadeu Raynal Filho ${ }^{1,3} \bullet$, Antônio \\ Pedro Fróes de Farias ${ }^{1,3} \bullet$, Roberto José Meyer Nascimento ${ }^{1,3 *} \bullet$
}

\begin{abstract}
${ }^{1}$ Laboratório de Imunologia e Biologia Molecular - Instituto de Ciências da Saúde - Universidade Federal da Bahia.
${ }^{2}$ Instituto Multidisciplinar de Saúde - Campus Anísio Teixeira (IMS-CAT), Universidade Federal da Bahia (UFBA), rua Rio de Contas, $n$ 58, bloco 17, Lote 58, Candeias, Vitória da Conquista, BA, Código Postal: 45029-094, Brasil

${ }^{3}$ Instituto de Ciências da Saúde, Universidade Federal da Bahia. Av. Reitor Miguel Calmon S/N, Vale do Canela, Salvador, Ba. 40.110-100, Brasil * Correspondência para o autor, Laboratório de Imunologia e Biologia Molecular, Instituto de Ciências da Saúde, Universidade Federal da Bahia. Avenida Reitor Miguel Calmon, S/N, Vale do Canela, Salvador, Bahia, Brazil. CEP: 40.110-100. Phone: +55 (71)3332-3341 Fax: +55(71)3235-9682.E-mail: rmeyer@ufba.br; meyer.roberto@gmail.com
\end{abstract}

Resumo. Corynebacterium pseudotuberculosis é uma bactéria Gram-positiva causadora da linfadenite caseosa. A linfadenite caseosa acomete principalmente pequenos ruminantes como caprinos e ovinos. O controle da doença é muito difícil, uma vez que a doença já está estabelecida no rebanho. Objetivo: O proteoma do Corynebacterium pseudotuberculosis foi submetido a avaliação in silico da localização subcelular e topologia proteica. A predição in silico dos epítopos lineares de células B foi efetuada e realizada a análise de conservação desses epítopos em outros proteomas do C. pseudotuberculosis depositada na base de dados do UNIPROT. Resultados: 111 proteínas foram selecionadas a partir da avaliação subcelular e topologia proteica, com a posterior submissão dessas proteínas a uma predição de epítopos lineares de células B e análise de conservação desses em outros proteomas de $C$. pseudotuberculosis, resultando em 9 proteínas com uma ou mais regiões de epítopos conservados numa mesma proteína. Conclusão: Regiões conservadas favorecem um reconhecimento maior de antígenos quando avaliados. Além disso, neste trabalho é fornecida uma lista de epítopos que podem ser sintetizados e testados in vitro.

Palavras chave: Corynebacterium pseudotuberculosis, epítopos, imunoinformática

\section{In silico identification of potential antigenic targets of Corynebacterium pseudotuberculosis}

Abstract: Corynebacterium pseudotuberculosis is a gram-positive bacterium that causes
caseous lymphadenitis. Caseous lymphadenitis mainly affects small ruminants such as
goats and sheep. Controlling the disease is very difficult, since the disease is already
established in the herd. Objective: The protease of Corynebacterium pseudotuberculosis
was subjected to in silico evaluation of subcellular localization and protein topology. The
in silico prediction of linear B cell epitopes was performed and the conservation analysis
of these epitopes was performed on other $C$. pseudotuberculosis proteomes deposited in
the UNIPROT database. Results: 111 proteins were selected from the subcellular
evaluation and protein topology, with the subsequent submission of these proteins to a
prediction of linear B cell epitopes and their conservation analysis in other proteases of $C$.
pseudotuberculosis, resulting in 9 proteins with one or more regions of epitopes conserved
in the same protein. Conclusion: Conserved regions favor a greater recognition of antigens 
when evaluated. In addition, a list of epitopes that can be synthesized and tested in vitro is provided in this paper.

Key words: Corynebacterium pseudotuberculosis, epitopes, immunoinformatic

\title{
Identificación in silico de posibles objetivos antigénicos de Corynebacterium pseudotuberculosis
}

\begin{abstract}
Resumen. Corynebacterium pseudotuberculosis es una bacteria gram-positiva causante de la linfadenitis caseosa. La linfadenitis caseosa afecta principalmente a pequeños rumiantes como los caprinos y los ovinos. El control de la enfermedad es muy difícil, ya que la enfermedad ya está establecida en el rebaño. Objetivo: El proteoma del Corynebacterium pseudotuberculosis fue sometido a la evaluación in silico de la localización subcelular y topología proteica. La predicción in silico de los epítopos lineales de células B fue efectuada y realizada el análisis de conservación de estos epítopos en otros proteomas de la $C$. pseudotuberculosis depositada en la base de datos del UNIPROT. Resultados: 111 proteínas fueron seleccionadas a partir de la evaluación subcelular y topología proteica, con la posterior sumisión de esas proteínas a una predicción de epítopos lineales de células B y análisis de conservación de estos en otros proteomas de C. pseudotuberculosis, resultando en 9 proteínas con una o más regiones de epítopos conservados en una misma proteína. Conclusión: Las regiones conservadas favorecen un mayor reconocimiento de antígenos cuando se los evalúan. Además, en este trabajo se proporciona una lista de epítopos que pueden ser sintetizados y probados in vitro.
\end{abstract}

Palabras clave: Corynebacterium pseudotuberculosis, epítopos, imunoinformática

\section{Introdução}

Corynebacterium pseudotuberculosis (Cp) é uma bactéria bacilar Gram-positiva, intracelular facultativa, imóvel, não esporulada e com capacidade fermentativa que causa a linfadenite caseosa em pequenos ruminantes, principalmente em caprinos e ovinos (Brum et al., 2017; Zhou et al., 2019). A linfadenite caseosa é caracterizada pelo aparecimento de granulomas contendo material caseoso nos linfonodos superficiais ou em vísceras (Corrêa et al., 2018; Eckersall \& Bell, 2010; Santos Junior \& Gomes, 2014). Como relatado na literatura, a transmissão pode ocorrer pelo material caseoso contaminado, tendo a via oral, nasal e cutâneas como vias de transmissão (Othman et al., 2016; VarelaCastro et al., 2017).

O controle da linfadenite caseosa é de extrema importância para evitar perdas econômicos em muitos países, incluindo o Brasil (Batey, 1986; Nairn \& Robertson, 1974). Entretanto, o tratamento existente ainda é pouco eficiente e se baseia na drenagem do abscesso e cauterização química, ou tratamento com antibiótico, este por sua vez possui custo elevado e muitas vezes o antibiótico não consegue alcançar as bactérias devido a sua localização, dentro dos piogranulomas (Batey, 1986; Brum et al., 2017; Nairn \& Robertson, 1974). Abordagens recentes estão sendo desenvolvidas para a confecção de novos testes de diagnósticos mais sensíveis e específicos para a linfadenite caseosa. Essas novas abordagens envolvem o uso da bioinformática, enriquecendo ainda mais os novos estudos e os estudos existentes para os potenciais alvos terapêuticos, como proteínas com fator de virulência, mapas gênicos, dentre outros (Guimarães et al., 2011; Sobrinho Santos et al., 2018). A maioria dos determinantes genéticos de virulência do $C p$ é, até o momento, pouco caracterizados, podendo ter as proteínas em sua maioria como um fator de virulência ou até mesmo serem codificadoras dos fatores de virulência (Dorella et al., 2006). O principal fator de virulência é atribuído à exotoxina Fosfolipase D (PLD), se fazendo necessário para a comunidade científica a descoberta de proteínas e genes que tenham a função de líderes na virulência do $C p$ (Fontaine \& Baird, 2008; Merchant \& Packer, 1975; Muckle \& Gyles, 1982; Songer et al., 1988; Souza et al., 2011; Sutherland et al., 1996).

O objetivo deste estudo foi identificar in silico os principais epítopos como potenciais antigênicos de proteínas de Corynebacterium pseudotuberculosis C231 a partir de base de dados públicas. 


\section{Materiais e métodos}

\section{Obtenção dos proteomas}

Foi utilizado o proteoma completo da cepa de C. pseudotuiberculosis C231 do UNIPROT (http://www.uniprot.org/) sendo arquivada em formato FASTA. Esta cepa possui 2090 proteínas. Em etapas posteriores do trabalho, também foram utilizados outros 70 proteomas $C$. pseudotuberculosis depositados na base de dados do UNIPROT, todos foram arquivados em formato FASTA.

\section{Avaliação in silico de localização subcelular}

Nesta etapa, o proteoma da cepa C231 de C. pseudotuberculosis foi submetido à análise de localização sub-celular no software público online CELLO2GO (http://cello.life.nctu.edu.tw). Com base nas sequências das proteínas, a plataforma online identifica a ontologia gênica de cada proteínas, ou seja, o local em que cada proteína do proteoma se encontra.

\section{Avaliação in silico da topologia proteica}

As topologias de proteínas foram avaliadas usando o software TOPCONS (http://topcons.cbr.su.se/). Esse software suporta sequências de aminoácidos formatada em FASTA ou um arquivo com múltiplas sequências, tendo os resultados apresentados aos usuários graficamente na tela, tendo a opção do download em formato de texto simples e também receber os resultados por email, caso fornecidos. Com base na sequência de aminoácidos de cada proteína, o algoritmo do programa identifica a presença de peptídeo sinal e hélices transmembrana, sendo mapeadas as proteínas exportadas para o ambiente extracelular e as proteínas ancoradas na membrana e parede celular. Moléculas que apresentam exposição extracelular são acessíveis às células do sistema imunológico, constituindo potenciais alvos para uso como antígenos em ensaios de imunodiagnóstico.

\section{Predição in silico de epítopos lineares de células $B$}

As proteínas selecionadas nas etapas anteriores foram submetidas ao mapeamento in silico de epítopos lineares de células B, utilizando diferentes modelos preditivos: Bepipred, LBtope, Método Chou \& Fasman Beta, Emini Surface Accessibility, Karplus \& Schulz Flexibility e Parker para a identificação de padrões de hidrofilicidade dos aminoácidos e estruturas secundárias das proteínas, prever e projetar epítopos lineares de células B, calcular a probabilidade de um trecho de resíduos de aminoácidos fazer parte da estrutura secundária $\beta$-turn (alças- $\beta)$, calcular a acessibilidade à superfície da proteína e a probabilidade dos aminoácidos estarem expostos nessa superfície, avaliar a flexibilidade e mobilidade dos segmentos proteicos e avaliar em escalas de hidrofilicidade dos conjuntos de resíduos de aminoácidos em uma proteína, respectivamente.

Foram considerados potencialmente antigênicos aqueles peptídeos que apresentaram afinidade de ligação por anticorpos em todos os modelos preditivos utilizados. Desta forma, foi confeccionado um novo arquivo FASTA contendo todos os epítopos selecionados para posterior utilização.

\section{Análise de conservação dos epítopos no proteoma de outras cepas de C. pseudotuberculosis}

Os epítopos selecionados foram submetidos a uma análise de conservação entre os diferentes proteomas de C. pseudotuberculosis depositados na base de dados do UNIPROT. Foi utilizado o software "Epitope Conservancy Analysis" (http://tools.iedb.org/conservancy/) para calcular o grau de conservação dos epítopo dentro de um determinado grupo de sequências de proteínas em diferentes graus de identidade.

Além da análise de conservação, os epítopos preditos também foram submetidos a uma análise de sobreposição de sequências, por meio do programa online Epitope Cluster Analysis (http://tools.immuneepitope.org/cluster/). Posterior aos alinhamentos dos peptídeos, foram identificados os epítopos que compartilham sequências de aminoácidos idênticas em uma de suas extremidades, sendo agrupados em clusters de acordo com essas sobreposições, permitindo em momento futuro a confecção de uma sequência consenso, que contenha os diferentes epítopos simultaneamente. Os epítopos 
conservados e presentes em todos os proteomas de C. pseudotuberculosis podem ser selecionados para uma etapa de síntese química e posterior validação experimental da antigenicidade.

\section{Resultados}

A predição da análise da localização subcelular de proteínas e anotações sobre a função molecular e a função que cada gene tem no processo biológico do proteoma da cepa de Corynebacterium pseudotuberculosis C231 ao software público CELLO2GO (http://cello.life.nctu.edu.tw/) teve como resultado 315 proteínas extracelulares (Anexo 1), tendo o proteoma um total de 2090 proteínas. As proteínas extracelulares correspondem a aproximadamente 15,07\% do proteoma total (Figura 1).

\section{Localização Subcelular}

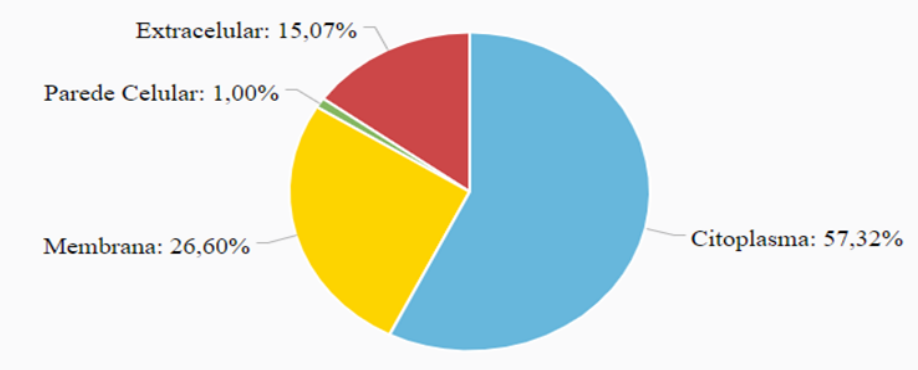

Figura 1. Análise da localização subcelular. O software mostra a localização e a quantidade de proteínas que existe em cada compartimento, além do gráfico com proporções em porcentagem de cada proteína de acordo com a localização. O Corynevacterium pseudotuberculosis C231 possui, aproximadamente, $15,07 \%$ de proteínas extracelulares; $57,32 \%$ de proteínas citoplasmáticas; $26,60 \%$ de proteínas de membrana; e $1 \%$ de proteínas de parede celular.

\section{Avaliação da topologia proteica}

A plataforma online TOPCONS foi utilizada para a previsão e avaliação da topologia de cada proteína e avaliação da presença de peptídeo sinal nas 315 proteínas que o CELLO2GO sinalizou como proteínas extracelulares. O algoritmo do TOPCONS sinalizou 205 proteínas como extracelulares e possuíam o peptídeo sinal (Anexo 1). Foram selecionadas apenas proteínas que foram positivas aos dois softwares, ou seja, que eram proteínas extracelulares e que possuíam peptídeo sinal, totalizado um total de 111 proteínas selecionadas (Anexo 1).

\section{Predição de epítopos de células $B$}

As proteínas extracelulares selecionadas na etapa anterior foram submetidas ao mapeamento in silico de epítopos lineares de células B e as regiões com afinidade de ligação ao epítopo em todos os testes foram selecionadas, ou seja, regiões comuns a todas as proteínas, dessa forma, 76 proteínas foram selecionadas. Algumas dessas proteínas continham mais de um epítopo de 10 aminoácidos (Anexo 2).

\section{Análise da conservação de epítopos}

A conservação dos 76 epítopos foi avaliada em outros 75 proteomas existentes do $C$. pseudotuberculosis. Foram consideradas regiões de epítopos com grau de identidade acima de $97 \%$ para a análise de conservação dos epítopos em questão, resultando em nove proteínas com uma ou mais regiões de epítopos conservados (Tabela 1).

A análise da função gênica, função molecular e dos processos biológicos que cada proteína participa foi realizada, dessa forma, foi efetuada a comparação da similaridade que as mesmas possuem com as cepas do $C p$ e outras bactérias. Partindo desses critérios, foram selecionados 4 melhores epítopos para ser sintetizados individualmente para serem confrontados de acordo a sua eficiência no reconhecimento do antígeno (Tabela 2). 
Tabela 1. Seleção dos epítopos no software Epitope Conservancy Analysis. Foram consideradas regiões que continham uma sequência de 10 aminoácidos, entretanto, em algumas proteínas foram selecionadas regiões contendo de 12-16 aminoácidos. O grau de conservação dessas regiões varia de 97,1 a $98,6 \%$ de conservação dentro dos proteomas.

\begin{tabular}{|c|c|c|}
\hline Entrada da proteína no UNIRPROT & Região Conservada & \\
\hline D9QBT2 & PQVDAGTVAL & \\
\hline \multirow{2}{*}{ D9QAT6 } & GKEDQRPAWL & \\
\hline & PAFSKDKLDP & \\
\hline D9QCX3 & AKPTPGESFS & \\
\hline D9Q954 & VDDAQNYAAA & \\
\hline D9Q9L5 & TRTPAKDFSS & \\
\hline \multirow{7}{*}{ D9QBC2 } & SSNPPKTRHP & KSSDTPPVERAI \\
\hline & KSSDTPPVER & \\
\hline & SDTPPVERAI & KQGTFNPTAPSGGEV \\
\hline & KQGTFNPTAP & \\
\hline & QGTFNPTAPS & \\
\hline & FNPTAPSGGE & \\
\hline & NPTAPSGGEV & \\
\hline \multirow{8}{*}{ D9QBZ2 } & GNKSNQQIES & \\
\hline & PLEGQRQAGK & \\
\hline & PQATPDTPNY & PQATPDTPNYYPGGMV \\
\hline & QATPDTPNYY & \\
\hline & ATPDTPNYYP & \\
\hline & TPDTPNYYPG & \\
\hline & PDTPNYYPGG & \\
\hline & TPNYYPGGMV & \\
\hline \multirow{2}{*}{ D9QCZ5 } & TWKDDQGKIT & \\
\hline & TPSLEQQDTH & \\
\hline \multirow{4}{*}{ D9QBC3 } & SSDDKGSSSS & \\
\hline & DAAAQPPAPD & DAAAQPPAPDAPAA \\
\hline & AAQPPAPDAP & \\
\hline & QPPAPDAPAA & \\
\hline
\end{tabular}

Tabela 2. Epítopos selecionados. 4 epítopos foram selecionados de três proteínas diferentes com base na conservação dessas sequências de aminoácidos em 69 dos 75 proteomas analisados, dois epítopos estavam presentes numa mesma proteína. Esses epítopos foram selecionados para o uso em estudos posteriores.

\begin{tabular}{|c|c|c|c|c|c|}
\hline $\begin{array}{l}\text { Código da } \\
\text { Proteína no } \\
\text { UNIPROT }\end{array}$ & $\begin{array}{l}\text { Sequência } \\
\text { Epítopo }\end{array}$ & ${ }^{\mathrm{o}}$ Gene & Função Molecular & Processo biológico & $\begin{array}{l}\text { Similaridade } \\
\text { microrganismos }\end{array}$ \\
\hline D9QAT6 & GKEDQRPAWL & CPC231_1186 & $\begin{array}{l}\text { Atividade da } \\
\text { oxirredutase; } \\
\text { Ligação de íon }\end{array}$ & $\begin{array}{l}\text { Transporte; resposta ao } \\
\text { estresse; processo } \\
\text { homeostático }\end{array}$ & $\begin{array}{l}\text { C. ulcerans; C. } \text { ulcerans } \\
\text { NCTC } \quad 12077 ; \\
\text { pseudotuberculosis; } \\
\text { Pseudomonas Aeruginosa }\end{array}$ \\
\hline D9QAT6 & PAFSKDKLDP & CPC231_1186 & $\begin{array}{l}\text { Atividade da } \\
\text { oxirredutase; } \\
\text { Ligação de íon }\end{array}$ & $\begin{array}{l}\text { Transporte; resposta ao } \\
\text { estresse; processo } \\
\text { homeostático }\end{array}$ & $\begin{array}{l}\text { C. ulcerans; C. ulcerans } \\
\text { NCTC } \quad 12077 ; \\
\text { pseudotuberculosis; } \\
\text { Pseudomonas }\end{array}$ \\
\hline D9Q954 & VDDAQNYAAA & rpfA & $\begin{array}{l}\text { Ligação de proteínas; } \\
\text { Atividade de } \\
\text { hidrolase }\end{array}$ & $\begin{array}{l}\text { Patogênese; simbiose } \\
\text { (abrangendo o mutualismo } \\
\text { através do parasitismo); } \\
\text { processo catabólico; } \\
\text { organização da parede } \\
\text { celular ou biogênese }\end{array}$ & $\begin{array}{l}\text { Mycobacterium } \\
\text { tuerculosis; M. bovis; } \\
\text { Macacine betaherpesvirus }\end{array}$ \\
\hline D9Q9L5 & TRTPAKDFSS & оррА3 & $\begin{array}{l}\text { Atividade } \\
\text { transportadora } \\
\text { transmembrana; } \\
\text { Ligação de íon }\end{array}$ & $\begin{array}{l}\text { Transporte; diferenciação } \\
\text { celular; formação de } \\
\text { estrutura anatômica } \\
\text { envolvida na morfogênese; } \\
\text { desenvolvimento de } \\
\text { estrutura anatômica; } \\
\text { locomoção }\end{array}$ & $\begin{array}{l}\text { C. ulcerans; C. ulcerans } \\
\text { NCTC 12077; } \\
\text { pseudotuberculosis; } \\
\text { Pseudomonas Aeruginosa }\end{array}$ \\
\hline
\end{tabular}




\section{Discussão}

Os resultados mostram que a combinação de algoritmos de análises de bioinformática podem ser ferramentas úteis e muito importantes para a identificação de epítopos como potenciais alvos de antigenicidade a partir de genomas já sequenciados. O sequenciamento de genomas de patógenos tornou possível conhecer e analisar os principais antígenos que estão relacionados à doença com uma maior rapidez e menor custo, como é o caso do Corynebacterium pseudotuberculosis (Droppa-Almeida et al., 2018). Essas análises fornecem informações teóricas muito importantes para testar a hipótese em laboratório.

Dentre as 315 das proteínas extracelulares, o que equivale a 15,1\% do proteoma da $C p C 231$ (Figura 1), 191 delas são proteínas não caracterizada e não possuíam função experimental estudada (Anexo 1). Sendo a localização subcelular das proteínas uma informação importante para a evidência da função biológica, isso pode realizado de forma rápida e precisa (Spetale et al., 2018; Yu et al., 2004).

A partir da predição de epítopos in silico de células B realizada neste trabalho, foi gerada uma lista de epítopos (Anexo 2) que podem ser sintetizados quimicamente e testada a sua antigenicidade. Estudos já realizados demonstram que a descoberta de novos antígenos levou ao desenvolvimento de novas estratégias para o desenho de novas vacinas (Duthie et al., 2016; Koff et al., 2014). Estudos também mostram a importância de epítopos conservados em vários isolados diferentes (Marana et al., 2009). A escolha dos epítopos (Tabela 2) com base no grau de conservação dessas regiões em outros proteomas do Corynebacterium pseudotuberculosis pode fornecer um maior reconhecimento imunogênico quando testados in vitro.

Em conclusão, vale ressaltar que é de extrema importância a identificação dessas regiões em proteínas determinantes para o estabelecimento da linfadenite caseosa. O presente trabalho também pode contribuir com a academia para o desenvolvimento de novos testes de imunodiagnóstico com resultados mais satisfatórios, tendo então uma especificidade e sensibilidade maior.

\section{Referências bibliográficas}

Batey, R. G. (1986). Aspects of pathogenesis in a mouse model of infection by Corynebacterium pseudotuberculosis. Australian Journal of Experimental Biology and Medical Science, 64(3):237249.

Brum, A. A., Rezende, A. F. S., Brilhante, F. S., Collares, T., Begnine, K., Seixas, F. K., . . Santos, A. (2017). Recombinant esterase from Corynebacterium pseudotuberculosis in DNA and subunit recombinant vaccines partially protects mice against challenge. Journal of Medical Microbiology, 66(5):635-642.

Corrêa, J. I., Stocker, A., Trindade, S. C., Vale, V., Bastos, B., Raynal, J. T., . . Costa, L. M. (2018). Avaliação da expressão de seis possíveis fatores de virulência de C. pseudotuberculosis em macrófagos murinos. PUBVET, 12(a237):1-8.

Dorella, F. A., Pacheco, L. G. C., Oliveira, S. C., Miyoshi, A. \& Azevedo, V. (2006). Corynebacterium pseudotuberculosis: microbiology, biochemical properties, pathogenesis and molecular studies of virulence. Veterinary Research, 37(2):201-218.

Droppa-Almeida, D., Franceschi, E. \& Padilha, F. F. (2018). Biotechnological potential of the use of synthetic peptides in vaccine formulations against Caseous Lymphadenits. Revista GEINTECGestão, Inovação e Tecnologias, 8(4):4684-4696.

Duthie, M. S., Favila, M., Hofmeyer, K. A., Tutterrow, Y. L., Reed, S. J., Laurance, J. D., . . Vallur, A. C. (2016). Strategic evaluation of vaccine candidate antigens for the prevention of Visceral Leishmaniasis. Vaccine, 34(25):2779-2786.

Eckersall, P. D. \& Bell, R. (2010). Acute phase proteins: Biomarkers of infection and inflammation in veterinary medicine. The Veterinary Journal, 185(1):23-27.

Fontaine, M. C. \& Baird, G. J. (2008). Caseous lymphadenitis. Small Ruminant Research, 76(1-2):4248. 
Guimarães, A. S., Carmo, F. B., Pauletti, R. B., Seyffert, N., Ribeiro, D., Lage, A. P., . . Gouveia, A. M. G. (2011). Caseous lymphadenitis: epidemiology, diagnosis, and control. The IIOAB Journal, 2(11):33-43.

Koff, W. C., Gust, I. D. \& Plotkin, S. A. (2014). Toward a human vaccines project. Nature Immunology, 15(7):589-592.

Marana, E. R. M., Kano, F. S., Vicentini, J. C., Spurio, R. S., Ribeiro, M., Coelho, A. L. M., . . Vidotto, O. (2009). Clonagem, expressão, caracterização molecular da proteína de superfície MSP5 da amostra PR1 de Anaplasma marginale e sua aplicação em um teste de ELISA por competição. Revista Brasileira de Parasitologia Veterinária, 18(2):5-12.

Merchant, I. A. \& Packer, R. A. (1975). Bacteriología e Virolgía Veterinarias. Zagaroza, Spain: Aciribia.

Muckle, C. A. \& Gyles, C. L. (1982). Characterization of strains of Corynebacterium pseudotuberculosis. Canadian Journal of Comparative Medicine, 46(2):206.

Nairn, M. E. \& Robertson, J. P. (1974). Corynebacterium pseudotuberculosis infection of sheep: role of skin lesions and dipping fluids. Australian Veterinary Journal, 50(12):537-542.

Othman, A. M., Abba, Y., Jesse, F. F. A., Ilyasu, Y. M., Saharee, A. A., Haron, A. W., . . Lila, M. A. M. (2016). Reproductive pathological changes associated with experimental subchronic corynebacterium pseudotuberculosis infection in nonpregnant boer does. Journal of Pathogens, 2016(ID 4624509):1-7.

Santos Junior, M. L. \& Gomes, A. A. B. (2014). Determinação do estresse osmótico do Corynebacterium pseudotuberculosis, agente etiológico da linfadenite caseosa. Revista Científica de Produção Animal, 14(1):5-8.

Sobrinho Santos, E. M., Almeida, A. C., Santos, H. O., Cangussu, A. R., Almeida, D. A. \& Costa, K. S. (2018). Leader gene of Corynebacterium pseudotuberculosis may be useful in vaccines against caseous lymphadenitis of goats: a bioinformatics approach. Journal of Veterinary Medical Science, 80(8):1317-1324.

Songer, J. G., Beckenbach, K., Marshall, M. M., Olson, G. B. \& Kelley, L. (1988). Biochemical and genetic characterization of Corynebacterium pseudotuberculosis. American Journal of Veterinary Research, 49(2):223-226.

Souza, M. d. F., Carvalho, A. Q., Garino Júnior, F. \& Riet-Correa, F. (2011). Linfadenite caseosa em ovinos deslanados abatidos em um frigorífico da Paraíba. Pesquisa Veterinária Brasileira, 31(3):224-230.

Spetale, F. E., Tapia, E., Murillo, J., Krsticevic, F., Ponce, S., Angelone, L. \& Bulacio, P. (2018). Proper integration of feature subsets boosts GO subcellular localization predictions. Revista Argentina de Bioingeniería, 22(1):3-6.

Sutherland, S. S., Hart, R. A. \& Buller, N. B. (1996). Genetic differences between nitrate-negative and nitrate-positive $C$. pseudotuberculosis strains using restriction fragment length polymorphisms. Veterinary Microbiology, 49(1-2):1-9.

Varela-Castro, L., Lara-Vergara, J., Ortega, N., Salinas, J., Colom-Cadena, A., Lavín, S., . . . Mentaberre, G. (2017). Endemic caseous lymphadenitis in a wild Caprinae population. Veterinary Record, 180(16):405-405.

Yu, C. S., Lin, C. J. \& Hwang, J. K. (2004). Predicting subcellular localization of proteins for Gramnegative bacteria by support vector machines based on n-peptide compositions. Protein Science, 13(5):1402-1406.

Zhou, Z., Yang, H., Li, H., Li, X., Li, X., Wu, B., . . Hu, S. (2019). Sodium butyrate ameliorates Corynebacterium pseudotuberculosis infection in RAW264. 7 macrophages and C57BL/6 mice. Microbial Pathogenesis, 131144-149.

Recebido: 10 de junho, 2019.

Aprovado: 9 de julho, 2019.

Publicado: 20 de setembro, 2019.

Licenciamento: Este artigo é publicado na modalidade Acesso Aberto sob a licença Creative Commons Atribuição 4.0 (CCBY 4.0), a qual permite uso irrestrito, distribuição, reprodução em qualquer meio, desde que o autor e a fonte sejam devidamente creditados. 


\section{Anexo 1}

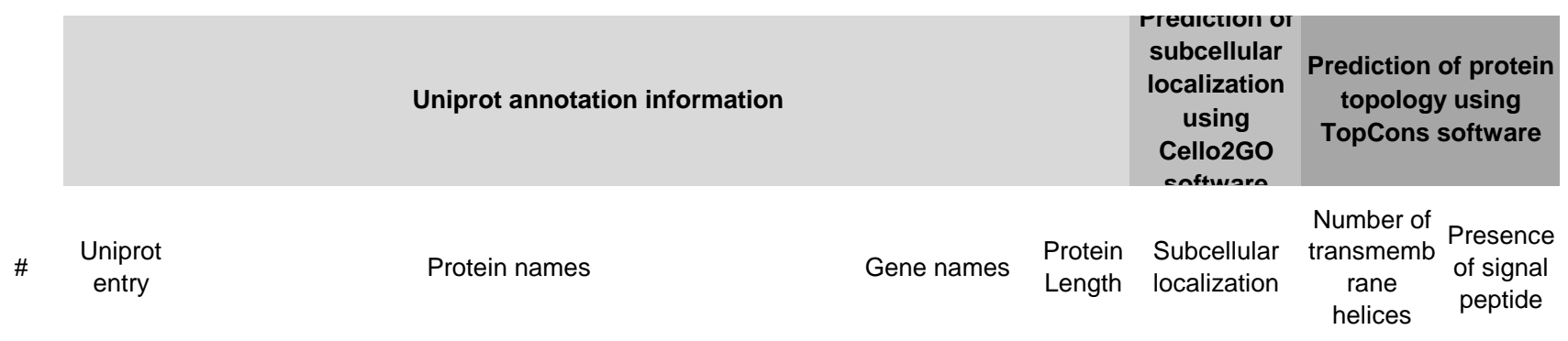

1 P48288 Protein RecA

2 P96749 3-dehydroquinate synthase

3 P96750 3-dehydroquinate dehydratase

4 D9QB58 ATP-dependent protease

5 D9QBM2 Glutamine synthetase II

6 D9Q957 Glutamine cyclotransferase

7 D9QE99 Response regulator

8 D9Q919 Uncharacterized protein

9 D9Q9T7 Diaminopimelate decarboxylase

10 D9QDD3 Uncharacterized protein

11 D9QCR0 Uncharacterized protein

12 D9QCG6 tRNA(Ile)-lysidine synthase

13 D9Q9Z8 Uncharacterized protein

14 D9QA49 Phenylalanine--tRNA ligase beta subunit

15 D9QB41 Mycothione/glutathione reductase

16 D9QCV5 Arabinofuranosyltransferase

17 D9QEN4 NIpC/P60 family protein

18 D9QCN6 Orotate phosphoribosyltransferase

19 D9QAT2 Lipid A biosynthesis lauroyl acyltransferase

20 D9QEA8 30 S ribosomal protein S7

21 D9Q9Y2 Iron(3+)-hydroxamate import ATP-binding protein FhuC

22 D9QBD7 UDP-N-acetylmuramoylalanine--D-glutamate ligase

23 D9QCZ9 Amidase

24 D9QDH0 Magnesium transporter mgtE

25 D9QCK8 Uncharacterized protein

26 D9QCl3 Uncharacterized protein

27 D9Q9R8 Uncharacterized protein

28 D9Q995 Glucose-6-phosphate isomerase

29 D9QDA2 Formamidopyrimidine-DNA glycosylase

30 D9QCP8 ABC transporter domain-containing ATP-binding subunit

31 D9QES4 Uncharacterized protein

32 D9QCQ6 ATP-bindingABC transporter domain-containing protein

33 D9Q981 Oligopeptide transport system permease protein oppB

34 D9QB42 Cobyric acid synthase

35 D9QCK2 ABC transporter glutamine-binding protein $\mathrm{glnH}$

36 D9QA05 Menaquinone-specific isochorismate synthase

37 D9QEM7 Endonuclease/Exonuclease/phosphatase family

38 D9QEL2 Manganese ABC transporter membrane protein

39 D9QB01 Competence-damage inducible protein

40 D9QE48 Porphobilinogen deaminase

41 D9Q960 tRNA/rRNA methyltransferase, SpoU

42 D9QEG2 30 S ribosomal protein S4

43 D9QAU5 1-deoxy-D-xylulose-5-phosphate synthase

44 D9QD64 DNA gyrase subunit A

45 D9Q9M2 Uncharacterized protein

46 D9QEB9 50 S ribosomal protein L3

47 D9QBV3 Uncharacterized protein

48 D9QDI0 Choline transport system permease protein

49 D9QA51 Arginine biosynthesis bifunctional protein ArgJ

50 D9QE29 UDP-N-acetylenolpyruvoylglucosamine reductase

51 D9QD00 Uncharacterized protein

52 D9QEV3 Uncharacterized protein

53 D9Q9Q4 2-oxoglutarate dehydrogenase E1 component

54 D9QDJ3 Abhydrolase domain-containing protein 6

55 D9Q9T3 Lactate utilization protein B

\begin{tabular}{|c|c|c|c|}
\hline RecA & 369 Cytoplasmic: & 0 & TV \\
\hline aroB & 359 Cytoplasmic; & 0 & No \\
\hline $\operatorname{aroQ}$ & 146 Cytoplasmic; & 0 & 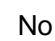 \\
\hline CpC231_1312 & 645 Membrane; & 0 & \\
\hline$g \ln A 2$ & 446 Cytoplasmic; & 0 & $\mathrm{~N}$ \\
\hline СpC231_0598 & 313 Cytoplasmic; & 1 & $\mathrm{~N}$ \\
\hline $\operatorname{cst} A$ & 234 Cytoplasmic; & 0 & \\
\hline CpC231_0733 & 213 Extracellular; & 0 & \\
\hline IysA & 443 Cytoplasmic; & 0 & \\
\hline CpC231_2069 & 59 Cytoplasmic; & 0 & \\
\hline CpC231_1882 & 364 Membrane; & 0 & \\
\hline tils & 280 Cytoplasmic; & 0 & \\
\hline CpC231_0895 & 522 Membrane; & 0 & \\
\hline phet & 836 Cytoplasmic; & 0 & \\
\hline CpC231_1293 & 463 Membrane; & 0 & $\mathrm{~N}$ \\
\hline CpC231_1930 & 1087 Membrane; & 15 & $\mathrm{~N}$ \\
\hline CpC231_0470 & 288 Membrane; & 0 & \\
\hline pyrE & 181 Cytoplasmic; & 0 & $\mathrm{~N}$ \\
\hline CpC231_1182 & 305 Cytoplasmic; & 0 & $\mathrm{~N}$ \\
\hline rpsG & 155 Cytoplasmic; & 0 & $\mathrm{~N}$ \\
\hline fhuC & 255 Membrane; & 0 & \\
\hline murD & 461 Cytoplasmic; & 0 & \\
\hline CpC231_1974 & 385 Cytoplasmic; & 0 & $\mathrm{~N}$ \\
\hline mgtE1 & 460 Membrane; & 5 & $\mathrm{~N}$ \\
\hline CpC231_1828 & 389 Cytoplasmic; & 0 & $\mathrm{Nc}$ \\
\hline CpC231_1803 & 779 Extracellular; & 0 & \\
\hline CpC231_0812 & 139 Membrane; & 1 & $\mathrm{~N}$ \\
\hline pgi & 547 Cytoplasmic; & 0 & $\mathrm{~N}$ \\
\hline mutM2 & 273 Cytoplasmic; & 0 & $\mathrm{~N}$ \\
\hline CpC231_1869 & 268 Membrane; & 0 & No \\
\hline CpC231_0510 & 133 Cytoplasmic; & 0 & No \\
\hline CpC231_1878 & 244 Cytoplasmic; & 0 & $\mathrm{Nc}$ \\
\hline орpB2 & 318 Membrane; & 6 & $\mathrm{Nc}$ \\
\hline cobQ & 481 Cytoplasmic; & 0 & $Y \in$ \\
\hline glnH & 323 Membrane; & 0 & \\
\hline menF & 372 Cytoplasmic; & 0 & No \\
\hline CpC231_0463 & 299 Extracellular; & 0 & No \\
\hline $\mathrm{mnt} \overline{\mathrm{D}}$ & 269 Membrane; & 9 & $\mathrm{Nc}$ \\
\hline $\operatorname{cin} A$ & 171 Cytoplasmic; & 0 & $\mathrm{Nc}$ \\
\hline hemC & 296 Cytoplasmic; & 0 & No \\
\hline spoU & 290 Cytoplasmic; & 0 & $\mathrm{Nc}$ \\
\hline rpsD & 201 Cytoplasmic; & 0 & $\mathrm{~N}$ \\
\hline$d x s$ & 640 Membrane; & 0 & $\mathrm{Nc}$ \\
\hline gyrA & 854 Cytoplasmic; & 0 & No \\
\hline СpC231_0766 & 236 Extracellular; & 0 & $\mathrm{Ye}$ \\
\hline rplC & 218 Cytoplasmic; & 0 & $\mathrm{Nc}$ \\
\hline CpC231_1567 & 197 Membrane; & 1 & $\mathrm{~N}$ \\
\hline opuBB & 220 Membrane; & 5 & $\mathrm{~N}$ \\
\hline $\arg \mathrm{J}$ & 386 Membrane; & 0 & $\mathrm{~N}$ \\
\hline murB & 379 Cytoplasmic; & 0 & $\mathrm{Nc}$ \\
\hline CpC231_1975 & 253 Membrane; & 7 & $\mathrm{~N}$ \\
\hline CpC231_0539 & 401 Extracellular; & 1 & $\mathrm{~N}$ \\
\hline odhA & 1228 Cytoplasmic; & 0 & $\mathrm{~N}$ \\
\hline CpC231_0067 & 286 Cytoplasmic; & 0 & $\mathrm{~N}$ \\
\hline lutB & 514 Cytoplasmic; & 0 & \\
\hline
\end{tabular}




\section{Anexo 1}

56 D9QCP7 Chaperone protein ClpB

57 D9QAX1 Transcriptional repressor NrdR

58 D9QAS3 Crossover junction endodeoxyribonuclease RuvC

59 D9QEF6 Adenylate kinase

60 D9QEK9 Manganese ABC transporter substrate-binding protein

61 D9QDZ1 GSPII

62 D9QCD8 DNA repair protein RadA

63 D9QDE2 Anthranilate phosphoribosyltransferase

64 D9QBJ9 Uncharacterized protein

65 D9QEC5 30 S ribosomal protein S3

66 D9QAU0 Uncharacterized protein

67 D9QE27 Uncharacterized protein

68 D9QAK5 Glyceraldehyde-3-phosphate dehydrogenase

69 D9QA35 Phosphotransferase system II Component

70 D9QDW8 Uncharacterized protein

71 D9QDE1 Anthranilate synthase component II

72 D9QD58 DNA replication and repair protein RecF

73 D9QCP3 Sortase B

74 D9QAl2 Uncharacterized protein

75 D9QB99 Uncharacterized protein

76 D9QDN8 Manganese/zinc/iron transport system

77 D9QCP0 Uncharacterized protein

78 D9QDN3 GtrA-like integral membrane protein

79 D9QCT9 Urease subunit alpha

80 D9QAP4 Putative pre-16S rRNA nuclease

81 D9QDT3 2-isopropylmalate synthase

82 D9QE83 50 S ribosomal protein L11

83 D9QDR3 Glutamyl-tRNA synthetase

84 D9QAW4 Proteasome assembly chaperones 2 (PAC2)

85 D9QAL4 Riboflavin biosynthesis protein RibD

86 D9QCT2 Iron(III) dicitrate transport permease-like protein yusV

87 D9Q9D5 Methionine--tRNA ligase

88 D9QBT9 ABC-type dipeptide transport system, periplasmic compon

89 D9QBJ7 Uncharacterized protein

90 D9QAN5 Elongation factor $P$

91 D9QBY7 Endopeptidase Clp

92 D9QEP1 Pyruvate carboxylase

93 D9QCF5 Choline dehydrogenase

94 D9QBW5 Probable nicotinate-nucleotide adenylyltransferase

95 D9QC89 Phosphate transport system permease protein

96 D9QE79 FAD-linked oxidoreductase

97 D9QBJ8 DNA methylase

98 D9QDF0 Branched-chain amino acid permease

99 D9QB53 Elongation factor Ts

100 D9QAV8 Methyltransferase

101 D9QD90 PP2C-family Ser/Thr phosphatase

102 D9QEL5 Bifunctional protein FolD

103 D9Q9W2 Alpha-1,4-glucan:maltose-1-phosphate maltosyltransferası

104 D9QAI9 FeS cluster assembly protein sufB

105 D9Q938 Inositol-1-monophosphatase ImpA

106 D9QD54 Universal stress protein UspA

107 D9QA32 DNA polymerase I

108 D9QCL9 Tetratricopeptide TPR

109 D9QB60 Ribonuclease HII

110 D9QES5 Phosphomannomutase ManB

111 D9QA61 Haloacid dehalogenase (HAD) superfamily hydrolase

112 D9QE40 DNA-binding (Excisionase) protein

113 D9QCM4 Uncharacterized protein

114 D9QDF1 Uncharacterized protein

115 D9QD68 Uncharacterized protein

116 D9QAL3 Riboflavin synthase alpha chain

117 D9QE08 dTDP-glucose 4,6-dehydratase

118 D9QBR0 Uncharacterized protein

119 D9Q9J1 Drug transport membrane protein

120 D9QC58 Ribonucleoside-diphosphate reductase subunit beta

121 D9QCQ4 Uncharacterized protein

122 D9QCZ3 Serine--tRNA ligase

\begin{tabular}{|c|c|c|}
\hline clpB & 849 Cytoplasmic; & 0 \\
\hline $\mathrm{nrdR}$ & 151 Cytoplasmic; & 0 \\
\hline ruvC & 193 Cytoplasmic; & 0 \\
\hline adk & 181 Cytoplasmic; & 0 \\
\hline CpC231_0443 & 318 Extracellular; & 0 \\
\hline gspE & 373 Cytoplasmic; & 0 \\
\hline $\operatorname{rad} A$ & 467 Membrane; & 0 \\
\hline $\operatorname{trpD}$ & 341 Cytoplasmic; & 0 \\
\hline CpC231_1458 & 543 Cytoplasmic; & 0 \\
\hline $\mathrm{rps} \overline{\mathrm{C}}$ & 248 Cytoplasmic; & 0 \\
\hline CpC231_1190 & 435 Membrane; & 12 \\
\hline CpC231_0256 & 275 Cytoplasmic; & 0 \\
\hline gap & 334 Cytoplasmic; & 0 \\
\hline ptsG & 670 Membrane; & 10 \\
\hline CpC231_0196 & 468 Extracellular; & 0 \\
\hline $\operatorname{trp} \bar{G}$ & 215 Cytoplasmic; & 0 \\
\hline recF & 404 Cytoplasmic; & 0 \\
\hline srtB & 319 Membrane; & 2 \\
\hline CpC231_1082 & 709 Extracellular; & 1 \\
\hline CpC231_1354 & 430 Membrane; & 12 \\
\hline $\mathrm{mntC}$ & 175 Membrane; & 6 \\
\hline СpC231_1861 & 773 Extracellular; & 0 \\
\hline CpC231_0108 & 152 Extracellular; & 4 \\
\hline ure $\bar{C}$ & 565 Cytoplasmic; & 0 \\
\hline CpC231_1144 & 197 Cytoplasmic; & 0 \\
\hline $\operatorname{leu} \bar{A}$ & 605 Cytoplasmic; & 0 \\
\hline rplk & 143 Cytoplasmic; & 0 \\
\hline gltX & 270 Cytoplasmic; & 0 \\
\hline pac2 & 337 Cytoplasmic; & 0 \\
\hline ribD & 353 Membrane; & 0 \\
\hline phuC & 256 Membrane; & 0 \\
\hline metG & 610 Cytoplasmic; & 0 \\
\hline oppA5 & 513 Extracellular; & 0 \\
\hline CpC231_1455 & 70 Cytoplasmic; & 0 \\
\hline efp & 187 Cytoplasmic; & 0 \\
\hline clpP & 199 Cytoplasmic; & 0 \\
\hline pyc & 1141 Cytoplasmic; & 0 \\
\hline betA & 582 Cytoplasmic; & 0 \\
\hline $\operatorname{nadD}$ & 218 Cytoplasmic; & 0 \\
\hline pstC & 343 Membrane; & 6 \\
\hline CpC231_0308 & 425 Extracellular; & 0 \\
\hline CpC231_1456 & 656 Cytoplasmic; & 0 \\
\hline azI $\bar{C}$ & 238 Membrane; & 6 \\
\hline tsf & 275 Cytoplasmic; & 0 \\
\hline CpC231_1209 & 508 Cytoplasmic; & 0 \\
\hline pstP & 503 Cytoplasmic; & 1 \\
\hline fold & 281 Cytoplasmic; & 0 \\
\hline$g \lg E$ & 671 Cytoplasmic; & 0 \\
\hline sufB & 484 Cytoplasmic; & 0 \\
\hline impA & 294 Cytoplasmic; & 0 \\
\hline uspA4 & 325 Membrane; & 0 \\
\hline polA & 886 Cytoplasmic; & 0 \\
\hline CpC231_1839 & 241 Cytoplasmic; & 1 \\
\hline $\operatorname{rnh} \bar{B}$ & 240 Cytoplasmic; & 0 \\
\hline $\operatorname{manB}$ & 459 Cytoplasmic; & 0 \\
\hline nag $D$ & 327 Cytoplasmic; & 0 \\
\hline xis & 63 Cytoplasmic; & 0 \\
\hline CpC231_1844 & 366 Membrane; & 5 \\
\hline CpC231_2087 & 198 Membrane; & 0 \\
\hline CpC231_0013 & 86 Extracellular; & 0 \\
\hline $\mathrm{rib} \overline{\mathrm{E}}$ & 213 Cytoplasmic; & 0 \\
\hline $\mathrm{rmlB}$ & 334 Cytoplasmic; & 0 \\
\hline CpC231_1520 & 366 Membrane; & 5 \\
\hline CpC231_0735 & 524 Membrane; & 14 \\
\hline nrdF2 & 328 Membrane; & 0 \\
\hline CpC231_1875 & 174 Membrane; & 4 \\
\hline sers & 419 Cytoplasmic; & 0 \\
\hline
\end{tabular}




\section{Anexo 1}

123 D9QEG0 30S ribosomal protein S13

rpsM

122 Cytoplasmic;

480 Cellwall;

124 D9QCP4 Collagen-binding surface protein Cna-like, B-type domain । CpC231 1865

125 D9QDT1 UDP-N-acetylmuramoylalanine--D-glutamate ligase

murD

126 D9QB97 1-(5-phosphoribosyl)-5-[(5-phosphoribosylamino)methylide

hisA

127 D9QED1 Oligopeptide transport system permease protein oppC

oppC1

128 D9QA38 UvrABC system protein B

uvrB

129 D9QAJ6 Transketolase

130 D9Q9P4 Glycosyl transferase

131 D9QBR4 Pyridoxal kinase PdxY

tkt

$\operatorname{glg} A$

$\mathrm{pdx} Y$

132 D9QBT0 Uncharacterized protein

CpC231_1541

133 D9QD13 Uncharacterized protein

CpC231_1989

134 D9QBA6 Uncharacterized protein

135 D9Q9D8 Ribosomal RNA small subunit methyltransferase A

136 D9QDF6 RNA polymerase sigma factor sigM

137 D9QBV5 PemK-like protein

138 D9QB83 Glutamate dehydrogenase

139 D9QAF9 Uncharacterized protein

140 D9QAL1 6,7-dimethyl-8-ribityllumazine synthase

141 D9Q9W7 Electron transfer flavo protein subunit alpha

142 D9QC65 NH(3)-dependent NAD(+) synthetase

143 D9QEP9 Uncharacterized protein

144 D9QD21 Two-component system sensor kinase protein

CpC231_1361

rsmA

sigM

CpC231_1569

gdh

CpC231_1059

ribH

etfA

nadE

CpC231_0485

tcsS

145 D9QER8 dTDP-Rha:alpha-D-GlcNAc-pyrophosphate polyprenol, alp

wbbl

fhuG

147 D9QAZ3 Regulatory protein RecX

148 D9QAT1 GDP-mannose-dependent alpha-(1-2)-phosphatidylinositol

149 D9Q9J7 Exodeoxyribonuclease 7 large subunit

150 D9QEK3 Methionine import system permease protein metl

151 D9QA73 Uncharacterized transporter yclF

152 D9QC13 Copper resistance D domain-containing protein/Cytochrom

153 D9QA41 Metallo-beta-lactamase superfamily protein

154 D9QEG5 tRNA pseudouridine synthase $A$

155 D9QCH4 Mycosubtilin synthase subunit B

156 D9QAD8 M18 family aminopeptidase

157 F9Y364 Phosphoribosyl-ATP pyrophosphatase

158 D9QBW2 DegV family protein

159 D9Q9Y5 Aspartyl/glutamyl-tRNA(Asn/Gln) amidotransferase subuni

160 D9QEC0 50 S ribosomal protein L4

161 D9QD40 Cation-transporting P-type ATPase A

162 D9QCM5 Uncharacterized protein

163 D9QCH0 Aerobic C4-dicarboxylate transport protein

164 D9QBS6 Peptidyl-dipeptidase

165 D9QAG3 Methylmalonyl-CoA mutase small subunit

166 D9QBQ3 Uncharacterized protein

167 D9QD98 UPF0176 protein CpC231

168 D9QAX3 LexA repressor

169 D9QEE5 30 S ribosomal protein S5

170 D9QA06 Glutamate--tRNA ligase

171 D9QCK3 Serine/threonine-protein kinase PknG

172 D9QEG3 DNA-directed RNA polymerase subunit alpha

173 D9QDU0 Serine-aspartate repeat-containing protein

174 D9QCT3 Iron(III) dicitrate transport system permease fecD

175 D9Q951 UvrABC system protein B

176 D9QCA7 Glutathione peroxidase

177 D9QBA3 Histidinol dehydrogenase

178 D9QER2 Maltose transport system permease protein malG

179 D9QE00 OPT family protein

180 D9QCA8 Protease II

181 D9QDR1 Uncharacterized protein

182 D9QAF0 Prolipoprotein LppL

183 D9QCE5 Uncharacterized protein

184 D9QAJ5 Protoheme IX farnesyltransferase

185 D9QEU9 Anti-sigma factor

186 D9Q9W1 1,4-alpha-glucan branching enzyme GlgB

187 D9QAR2 Thiol peroxidase

188 D9QDX4 Penicillin binding protein transpeptidase

189 D9QDZ0 Pilus assembly protein CpaE

recX

pimA

xseA

metl

yclF

copD

CpC231_0939

truA

mycB

pepC2

hisE

CpC231_1576

gatB

rpID

ctpA

CpC231_1845

$\operatorname{dct} A$

dcp

mutA

CpC231_1513

CpC231_2034

IexA

rpsE

gltX1

pknG

rpoA

sdrC

CpC231_1907

uvrB

CpC231_1723

hisD

malG

opt

ptrB

$\mathrm{mmpL} 11$

IppL

CpC231_1764

ctaB

431 Cytoplasmic;

242 Cytoplasmic;

346 Membrane;

699 Cytoplasmic;

697 Cytoplasmic;

390 Cytoplasmic;

283 Cytoplasmic;

516 Cytoplasmic;

403 Membrane;

219 Extracellular;

290 Cytoplasmic;

222 Cytoplasmic;

184 Cytoplasmic;

448 Cytoplasmic;

317 Cytoplasmic;

157 Cytoplasmic;

318 Membrane;

276 Cytoplasmic;

138 Cytoplasmic;

441 Membrane;

316 Extracellular;

344 Membrane;

201 Cytoplasmic;

366 Cytoplasmic;

413 Cytoplasmic;

225 Membrane;

501 Membrane;

681 Membrane;

242 Cytoplasmic;

291 Cytoplasmic;

1276 Cellwall;

438 Cytoplasmic;

87 Cytoplasmic;

276 Cytoplasmic;

501 Cytoplasmic;

217 Cytoplasmic;

790 Membrane;

375 Cytoplasmic;

480 Membrane;

692 Cytoplasmic;

603 Cytoplasmic;

690 Extracellular;

337 Cytoplasmic;

235 Cytoplasmic;

208 Cytoplasmic;

475 Cytoplasmic;

749 Cytoplasmic;

338 Cytoplasmic;

723 Cellwall;

355 Membrane;

549 Cytoplasmic;

157 Cytoplasmic;

441 Cytoplasmic;

278 Membrane;

657 Membrane;

708 Cytoplasmic;

795 Membrane;

340 Extracellular;

228 Membrane;

310 Membrane;

CpC231_0535

glgB

93 Cytoplasmic;

732 Extracellular;

tpx

pbpB

168 Cytoplasmic;

790 Extracellular;

$\mathrm{cpaE}$

342 Cytoplasmic;

0 No

1 Yes

0 Yes

0 No

6 No

$\begin{array}{ll}0 & \text { No } \\ 0 & \text { No }\end{array}$

0 No

0 No

0 No

12 No

0 Yes

0 No

0 No

0 No

0 No

0

0 No

0 No

O No

$0-N$

10 No

0 No

0 No

$0 \quad$ No

14 No

16 No

0 No

0 No

$10 \quad$ No

0 No

0 No

0 No

0 No

8 No

0 Yes

10 No

0 No

1

0 Yes

$0 \quad$ No

0 No

0 No

0 No

0 No

0 Yes

10 No

$\begin{array}{ll}0 & \text { No } \\ 0 & \text { No }\end{array}$

0 No

6 No

18 No

0 No

11 Yes

0 Yes

6 No

9 No

0 No

0 No

$0 \quad$ No

0 No 


\section{Anexo 1}

190 D9QD73 Peptidyl-prolyl cis-trans isomerase

191 D9QD24 Sortase-like protein

192 D9QBU0 Oligopeptide transport system permease protein oppB

193 D9Q9A4 Glutamate-binding protein GluB

194 D9QBA1 Imidazoleglycerol-phosphate dehydratase

195 D9QAZ2 tRNA-2-methylthio-N(6)-dimethylallyladenosine synthase

196 D9QCF0 Lysine--tRNA ligase

197 D9Q9L5 Oligopeptide-binding protein oppA

198 D9QA16 Glycerol-3-phosphate dehydrogenase [NAD(P)+]

199 D9QDD1 Uncharacterized protein

200 D9QBL4 Uncharacterized protein

201 D9QBP7 DNA primase

202 D9QB13 Polyribonucleotide nucleotidyltransferase

203 D9QE84 50 S ribosomal protein L1

204 D9QD09 L-lactate dehydrogenase

205 D9QER7 Transcriptional regulator lytR

206 D9QC11 Uncharacterized protein

207 D9QCZ4 GntR family transcriptional regulator

208 D9Q932 Methylmalonyl-CoA carboxyltransferase 5S subunit

209 D9QB28 Uncharacterized protein

210 D9QEJ6 GMP synthase [glutamine-hydrolyzing]

211 D9Q946 Periplasmic binding protein

212 D9QB24 Translation initiation factor IF-2

213 D9QBR8 Ribosomal RNA small subunit methyltransferase E

214 D9QD56 Chromosomal replication initiator protein DnaA

215 D9QDU1 Serine-aspartate repeat-containing protein $D$

216 D9QEB0 Elongation factor Tu

217 D9QB04 YCll-related domain protein

218 D9QBC6 Isoleucine--tRNA ligase

219 D9QAY2 FMN-dependent NADPH-azoreductase

220 D9QC07 Lantibiotic dehydratase, $\mathrm{N}$ terminus/C terminus family

221 D9QEC3 30S ribosomal protein S19

222 D9QD70 Ribose transport system permease protein rbsC

223 D9QEC8 30S ribosomal protein S17

224 D9QEI6 Uncharacterized protein

225 D9QA67 Uncharacterized protein

226 D9QCA5 Phosphoribosylformylglycinamidine synthase subunit PurC

227 D9QEF3 FNT family formate-nitrite transporter

228 D9QA36 Dephospho-CoA kinase

229 D9Q9E8 Glyceraldehyde-3-phosphate dehydrogenase

230 D9QDR2 Queuine tRNA-ribosyltransferase

231 D9QAA6 Thioesterase

232 D9QA95 Hydrolase alpha/beta superfamily

233 D9QA39 Stress related protein

234 D9QED8 Serine transporter

235 D9Q9W3 Ferric enterobactin transport ATP-binding protein FepC

236 D9Q9R6 Galactokinase

237 D9QB29 Proline--tRNA ligase

238 D9QAA3 Hemolysin-related protein

239 D9Q965 Peptidyl-prolyl cis-trans isomerase

240 D9QB57 Rossmann-fold nucleotide-binding protein/SMF

241 D9QBW3 Phosphoglycerate mutase

242 D9QAl6 Cysteine desulfurase

243 D9QD49 Uncharacterized protein

244 D9QB40 Lysophospholipase L2

245 D9QE88 50 S ribosomal protein L7/L12

246 D9Q9B8 Serine protease

247 D9QDB3 Uncharacterized protein

248 D9QCZ1 HAD-family hydrolase

249 D9QBK0 DNA helicase

250 D9QA96 Protein translocase subunit SecA

251 D9QBE9 Acetyltransferase

252 D9QEP2 Lincomycin resistance protein

253 D9QC35 Two component transcriptional regulator

254 D9QDJ7 Uncharacterized iron-regulated membrane protein

255 F9Y379 Uncharacterized protein

256 D9QEI9 $10 \mathrm{kDa}$ chaperonin

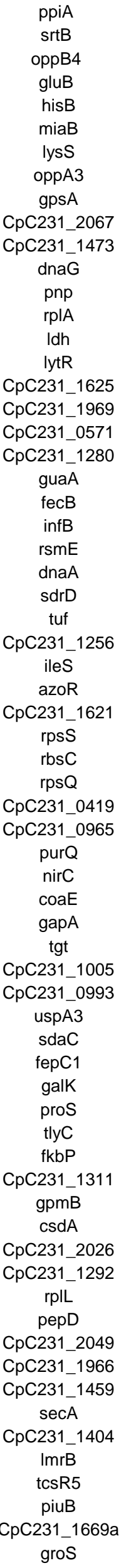

178 Cytoplasmic;

295 Membrane;

316 Membrane;

293 Extracellular;

202 Cytoplasmic;

512 Cytoplasmic;

518 Cytoplasmic;

526 Extracellular;

338 Cytoplasmic;

212 Membrane;

69 Cytoplasmic;

638 Cytoplasmic;

767 Cytoplasmic;

236 Cytoplasmic;

316 Cytoplasmic;

522 Extracellular;

252 Membrane;

257 Cytoplasmic;

493 Cytoplasmic;

308 Extracellular;

525 Cytoplasmic;

330 Cytoplasmic;

976 Cytoplasmic;

256 Cytoplasmic;

603 Cytoplasmic;

367 Extracellular;

396 Cytoplasmic;

97 Extracellular;

1052 Cytoplasmic;

277 Membrane;

867 Membrane;

92 Cytoplasmic;

361 Membrane;

92 Cytoplasmic;

224 Cytoplasmic;

317 Extracellular;

223 Cytoplasmic;

265 Membrane;

204 Cytoplasmic;

476 Cytoplasmic;

413 Cytoplasmic;

166 Membrane;

395 Cytoplasmic;

146 Cytoplasmic;

447 Membrane;

282 Cytoplasmic;

407 Cytoplasmic;

585 Cytoplasmic;

467 Membrane;

119 Cytoplasmic;

391 Cytoplasmic;

247 Extracellular;

429 Cytoplasmic;

511 Membrane;

332 Cytoplasmic;

127 Cytoplasmic;

484 Extracellular;

773 Cellwall;

271 Cytoplasmic;

297 Cytoplasmic;

765 Cytoplasmic;

202 Cytoplasmic;

485 Membrane;

208 Cytoplasmic;

492 Membrane;

211 Extracellular;

98 Cytoplasmic;

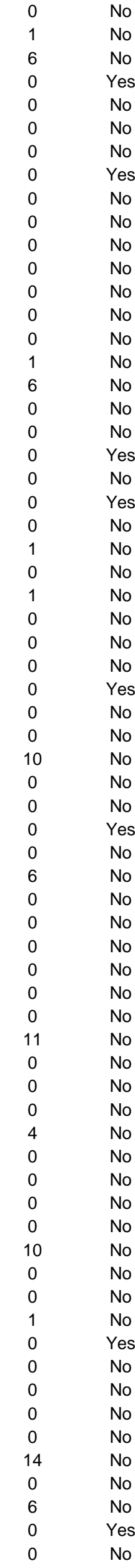




\section{Anexo 1}

257 D9QAR0 Histidine--tRNA ligase

his

CpC231_1401

ispB

murA

260 D9QC72 UDP-N-acetylglucosamine 1-carboxyvinyltransferase

261 D9QBP9 Guanyl-specific ribonuclease Sa3

262 D9QD41 MFS family major facilitator transporter

263 D9QAA5 6-phosphogluconate dehydrogenase, decarboxylating

264 D9QA60 Tetratricopeptide TPR2

265 D9QAE8 Undecaprenyl-diphosphatase

266 D9QD20 Two-component system transcriptional regulatory protein

267 D9QDC4 Oligopeptide transport ATP-binding protein OppD

268 D9QEV9 DNA helicase, UvrD/REP type

269 D9QD07 Cytidine deaminase

270 D9QB55 M23 peptidase domain-containing protein

271 D9QEN8 Phosphoglucomutase/phosphomannomutase

272 D9QAG2 Methylmalonyl-CoA mutase large subunit

273 D9QDH1 Oligo-1,6-glucosidase 1

274 D9QEF0 Maltose transport system permease protein

275 D9QCU1 Urease subunit gamma

276 D9Q998 ATP-dependent DNA helicase

277 D9QCW1 Phosphoenolpyruvate carboxykinase [GTP]

278 D9QAW5 Uncharacterized protein

279 D9QEQ4 Propionyl CoA carboxylase beta chain 1

280 D9QED5 50 S ribosomal protein L14

281 D9QDG0 Uncharacterized protein

282 D9QDA4 Glycopeptide antibiotics resistance protein

283 D9QB45 4-hydroxy-3-methylbut-2-en-1-yl diphosphate synthase (fla 284 D9QC83 ATP-binding/permease protein cydC

285 D9QDK4 Uncharacterized protein

286 D9QB07 DNA translocase ftsK

287 D9QBG4 Ubiquinol-cytochrome $C$ reductase cytochrome $B$ subunit

288 D9QB33 CobW/HypB/UreG, nucleotide-binding domain protein

289 D9QBE0 UDP-N-acetylmuramoyl-L-alanyl-D-glutamate--2,6-diamino

290 D9QBS3 4-alpha-glucanotransferase

291 D9QAI5 NifU

292 D9QE57 Phosphoglycerate mutase

293 D9QE37 Uncharacterized protein

294 D9Q9Q0 Iron-sulfur cluster carrier protein

295 D9Q9N1 Aromatic amino acid transport protein

296 D9QB94 Phosphoribosyl-AMP cyclohydrolase

297 D9QBQ1 Deoxyguanosinetriphosphate triphosphohydrolase-like pro

298 D9QEU5 3-phosphoshikimate 1-carboxyvinyltransferase

299 D9QC53 Transposase for IS3511a

300 D9QCA2 Ribonucleoside-diphosphate reductase beta chain 2

301 D9QAN0 Aspartate carbamoyltransferase

302 D9Q9U4 Release factor glutamine methyltransferase

303 D9QAG6 SPFH domain, band 7 integral membrane protein

304 D9QAQ1 SNF2 family DNA/RNA helicase

305 D9Q9W0 Thioredoxin TrxA

306 D9QE61 Methyltransferase

307 D9Q948 ABC transporter iron (III)

308 D9QAK2 Phosphoenolpyruvate carboxylase

309 D9Q9J8 4-hydroxy-3-methylbut-2-enyl diphosphate reductase

310 D9QDF7 Thioredoxin reductase

311 D9QDD6 $\mathrm{Na}+/ \mathrm{H}+$-dicarboxylate symporter

312 D9QDA3 ADP-dependent (S)-NAD(P)H-hydrate dehydratase

313 D9QEG8 Subtilisin-like serine protease

314 D9QB91 Prolipoprotein diacylglyceryl transferase

315 D9Q982 Oligopeptide transport system permease protein oppC

316 D9QB90 Pyruvate kinase

317 D9QEP0 Flavoprotein disulfide reductase

318 D9QET4 Sensor histidine kinase mtrB

319 D9QEI2 Alanine racemase

320 D9QB08 Uncharacterized protein

321 D9QCF4 Betaine aldehyde dehydrogenase

322 D9QDG1 Chromosome partitioning protein ParB

323 D9QEX2 Uncharacterized protein
CpC231_1509

CpC231_2018

gnd

CpC231_0958

uppP

tcsR

oppCD2

uvrD

cdd

CpC231_1309

manB

$\mathrm{sbm}$

malL

malF

ureA

pcrA

pckG

CpC231_1216

pccB1

rpIN

CpC231_2096

CpC231_2040

isp $G$

cydC

CpC231_0079

$\mathrm{ftsK}$

qcrB

CpC231_1285

murE

malQ

nifU

gpmB

CpC231_0266

mrp

aroP1

hisl

dgt

aroA

CpC231_1667

nrdF

pyrB

hemK

CpC231_1066

CpC231_1151

trxA

CpC231_0290

fecC

ppc

ispH

trxB

CpC231_2072

nnrD

mycP

lgt

oppC2

pyk

IpdA

mtrB

alr

CpC231_1260

gbs A

parB

CpC231_0558
423 Cytoplasmic;

131 Membrane;

339 Cytoplasmic;

418 Cytoplasmic;

175 Extracellular;

450 Membrane;

498 Cytoplasmic;

405 Cytoplasmic;

295 Membrane;

212 Cytoplasmic;

677 Membrane;

1074 Cytoplasmic;

156 Cytoplasmic;

187 Extracellular;

533 Cytoplasmic;

735 Cytoplasmic;

532 Extracellular;

468 Membrane;

100 Cytoplasmic;

846 Membrane;

645 Cytoplasmic;

846 Cytoplasmic;

543 Cytoplasmic;

122 Cytoplasmic;

199 Cytoplasmic;

173 Membrane;

391 Cytoplasmic;

521 Membrane;

198 Extracellular; 1045 Membrane;

540 Membrane;

371 Cytoplasmic;

503 Cytoplasmic;

728 Cytoplasmic;

149 Cytoplasmic;

202 Cytoplasmic;

368 Cytoplasmic;

380 Cytoplasmic;

469 Membrane;

118 Cytoplasmic;

424 Cytoplasmic;

424 Extracellular;

167 Cytoplasmic;

340 Extracellular;

313 Cytoplasmic;

272 Cytoplasmic;

403 Membrane;

920 Cytoplasmic;

297 Cytoplasmic;

253 Cytoplasmic;

352 Membrane;

893 Cytoplasmic;

341 Cytoplasmic;

315 Cytoplasmic;

439 Membrane;

500 Extracellular;

392 Membrane;

300 Membrane;

258 Membrane;

472 Cytoplasmic;

489 Cytoplasmic;

524 Membrane;

370 Cytoplasmic;

220 Cytoplasmic;

501 Cytoplasmic;

350 Cytoplasmic;

328 Cytoplasmic;
No

No

Yes

No

No

No

No

No

No

No

No

Yes

No

No

No

No

No

No

No

No

No

No

No

No

No

No

Yes

No

No

No

No

No

No

No

No

No

No

No

No

No

No

No

No

No

No

No

No

No

No

No

No

No

No

No

Yes

No

No

No

No

No

No

No

No

No

No 
Anexo 1

324 D9QDH4 Uncharacterized protein

325 D9QC32 Fatty acid synthase

326 D9Q9L0 HMP/thiamine permease protein ykoE

327 D9QBM6 Galactokinase

328 D9Q977 Diaminopimelate decarboxylase

329 D9QCQ3 Oxidoreductase

330 D9Q9W8 Cysteine desulfurase

331 D9QAK6 Putative sporulation transcription regulator WhiA

332 D9QED6 50 S ribosomal protein L24

333 D9Q9L6 Oligopeptide transport system permease protein oppB

334 D9QBI0 Aminomethyltransferase

335 D9QCU4 Aminotransferase AlaT

336 D9QER5 Maltose/maltodextrin transport system substrate-binding p।

337 D9QD55 Uncharacterized protein

338 D9QB78 Formamidopyrimidine-DNA glycosylase

339 D9QEG1 30S ribosomal protein S11

340 D9Q978 Ornithine cyclodeaminase

341 D9QA59 Tyrosine--tRNA ligase

342 D9QEW8 Uncharacterized protein

343 D9QDY2 Thioredoxin-related protein

344 D9QBC7 Uncharacterized protein

345 D9QBP6 Thiamine biosynthesis protein $X$

346 D9Q9Q9 Uncharacterized protein

347 D9QBQ2 Uncharacterized protein

348 D9QCG2 Dihydropteroate synthase

349 D9QBU1 Oligopeptide transport system permease protein oppC

350 D9QBL3 Inosine 5-monophosphate dehydrogenase

351 D9QDC9 Uncharacterized protein

352 D9QC94 UPF0678 fatty acid-binding protein-like protein $\mathrm{CpC231}$

353 D9QE14 Dihydrolipoyl dehydrogenase

354 D9Q9A6 Glutamate transport system permease protein gluD

355 D9QDM8 Decaprenylphosphoryl-beta-D-ribose oxidase

356 D9QDH7 Uncharacterized protein

357 D9QBV0 MFS-type drug efflux transporter

358 D9QBK7 ABC transporter ATP-binding protein

359 D9Q9A1 Phosphoribosylglycinamide formyltransferase

360 D9QD67 Uncharacterized protein

361 D9QEU2 Stearoyl-CoA 9-desaturase electron transfer partner

362 D9QEG9 Uncharacterized protein

363 D9QAC1 Precorrin-8X methyl mutase

364 D9QEK4 Methionine import ATP-binding protein MetN

365 D9QAS9 8-amino-7-oxononanoate synthase/2-amino-3-ketobutyrat $\epsilon$

366 D9QCN7 Uncharacterized protein

367 D9QEK1 Uncharacterized protein

368 D9Q9G0 Bifunctional protein GlmU

369 D9QAW3 Uncharacterized protein

370 D9QER3 Maltose transport system permease protein malF

371 D9QAE7 L-cysteine:1D-myo-inositol 2-amino-2-deoxy-alpha-D-glucc

372 D9Q9K1 Ribosome-binding ATPase YchF

373 D9QCD2 2-C-methyl-D-erythritol 2,4-cyclodiphosphate synthase

374 D9QBD2 Cell division protein FtsZ

375 D9QB88 Alpha-1,4 glucan phosphorylase

376 D9QE32 2,3-bisphosphoglycerate-dependent phosphoglycerate mu

377 D9QCB0 Phosphoribosylaminoimidazole-succinocarboxamide synth

378 D9Q9N8 Glycosyl transferase group 2

379 D9QBF5 Phospho-2-dehydro-3-deoxyheptonate aldolase

380 D9QBA2 Histidinol-phosphate aminotransferase

381 D9QDV6 Spermidine/putrescine transport system permease protein

382 D9Q9S5 Exonuclease, SbcD-family

383 D9QBI4 Lipoyl synthase

384 D9Q996 Succinate-semialdehyde dehydrogenase [NADP+]

385 D9QBH1 Iron-sulfur cluster insertion protein erpA

386 D9QBY2 Malate dehydrogenase

387 D9QDV5 Spermidine/putrescine import ATP-binding protein PotA

388 D9QEJ5 Uncharacterized protein

389 D9QE17 Succinate dehydrogenase flavoprotein subunit

390 D9QDE6 Iron-sulfur protein

CpC231_0048
fas
ykoE
CpC231_1486
lysA
CpC231_1874
nifS
whiA
rplX
oppB3
gcvT
aspC
malE

CpC231_2032

mutM1

rpsk

$\operatorname{arcB}$

tyrS

CpC231_0554

CpC231_0211

CpC231_1382

thi $\bar{X}$

CpC231_0803

CpC231_1512

folP1

oppC4

CpC231_1472

CpC231_2065

CpC231_1710

Ipd

gluD

dprE1

CpC231_0051

CpC231_1564

CpC231_1466

purN

CpC231_0012

CpC231_0528

CpC231_0402

$\mathrm{cobH}$

metN

bioF

CpC231_1857

CpC231_0435 glmU

CpC231_1214

malF

$\mathrm{mshC}$

ychF

ispF

$\mathrm{ftsZ}$

glgP

gpmA

purC

CpC231_0782

aroG

hisC

potC

$\mathrm{sbcD}$

$\operatorname{lip} A$

gabD

CpC231_1426

mdh

potA

CpC231_0429

sdhA

CpC231_2082
69 Cytoplasmic; 3032 Cellwall;

204 Membrane;

429 Cytoplasmic;

452 Extracellular;

378 Cytoplasmic;

375 Cytoplasmic;

329 Cytoplasmic;

104 Cytoplasmic;

308 Membrane;

377 Cytoplasmic;

428 Cytoplasmic;

419 Extracellular;

222 Membrane;

285 Cytoplasmic;

134 Cytoplasmic;

328 Membrane;

426 Cytoplasmic;

167 Cytoplasmic;

201 Membrane;

62 Membrane;

193 Extracellular;

263 Cytoplasmic;

258 Membrane;

260 Cytoplasmic;

287 Membrane;

477 Cytoplasmic;

88 Extracellular;

214 Cytoplasmic;

469 Cytoplasmic;

312 Membrane;

488 Extracellular;

97 Extracellular;

410 Membrane;

236 Membrane;

208 Cytoplasmic;

171 Extracellular;

352 Cytoplasmic;

478 Membrane;

216 Cytoplasmic;

340 Cytoplasmic;

342 Membrane;

332 Cytoplasmic;

210 Extracellular;

487 Cytoplasmic;

355 Cytoplasmic;

361 Membrane;

416 Cytoplasmic;

361 Cytoplasmic;

159 Cytoplasmic;

409 Cytoplasmic;

802 Cytoplasmic;

248 Cytoplasmic;

297 Cytoplasmic;

244 Cytoplasmic;

462 Cytoplasmic;

371 Cytoplasmic;

466 Membrane;

372 Cytoplasmic;

348 Cytoplasmic;

495 Cytoplasmic;

115 Extracellular;

326 Cytoplasmic;

350 Membrane;

617 Membrane;

671 Cytoplasmic;

116 Membrane;
No

No

No

No

No

No

No

No

No

No

No

No

Yes

No

No

No

No

No

No

Yes

No

Yes

No

No

No

No

No

No

No

No

No

No

Yes

No

No

No

Yes

No

No

No

No

No

No

Yes

Yes

No

No

No

No

No

No

No

No

No

No

No

No

No

No

No

No

No

No

No

No

No

Yes 


\section{Anexo 1}

391 D9QAF8 ABC transporter ATP-binding protein 392 D9QED2 Oligopeptide transport system permease protein oppB 393 D9QD76 Uncharacterized protein 394 D9QCM2 Adenylosuccinate synthetase 395 D9QB15 30S ribosomal protein S15 396 D9QDM1 Metalloendopeptidase 397 D9Q9B0 30S ribosomal protein S18 398 D9QDU8 Catalase 399 D9QC49 Nicotinate phosphoribosyltransferase 400 D9QA57 Argininosuccinate lyase 401 D9QB37 Magnesium chelatase subunit D 402 D9QB20 Calcineurin-like phosphoesterase 403 D9QBY5 Para-aminobenzoate synthase component I 404 D9QDP5 Cysteine desulfurase 405 D9QEW2 DNA helicase 406 D9Q970 Enoyl-CoA hydratase echA6 407 D9QAT0 Uncharacterized protein 408 D9Q9F0 Proline iminopeptidase 409 D9QET1 Adenosylhomocysteinase

CpC231_1058
oppB1
CpC231_0021
purA
rpsO
pepO
rpsR
katA
pncB
argH

CpC231_1272

410 D9QEI4 AspT/YidE/YbjL antiporter duplication domain-containing p CpC231_0417

411 D9Q9X1 Uncharacterized protein

412 D9Q9H2 Ppx/GppA phosphatase family

413 D9Q9T6 Arginine--tRNA ligase

414 D9QCR5 Chaperone protein DnaJ

415 D9Q9G2 C4-dicarboxylate transporter/malic acid transport protein

416 D9QB67 Ribosome maturation factor RimM

417 D9QET8 Protein translocase subunit SecA

418 D9Q9H8 Mycothiol S-conjugate amidase

419 D9QAA9 NADH dehydrogenase

420 D9QE15 HTH-type transcriptional regulator

421 D9QBR7 Phosphate starvation-inducible protein $\mathrm{PhoH}$

422 D9QEB1 Uncharacterized protein

423 D9QAB4 Uncharacterized protein

424 D9QAX4 Galactitol utilization operon repressor

425 D9QAC8 ATP-dependent DNA helicase

426 D9Q9L7 Oligopeptide transport system permease protein oppC

427 D9QAP8 Phosphotransferase enzyme family protein

428 D9QD63 Uncharacterized protein

429 D9QA45 50 S ribosomal protein L20

430 D9QA88 Siderophore biosynthesis related protein

431 D9QB56 Tyrosine recombinase XerC

432 D9QCT4 ABC transporter domain-containing permease component

433 D9QDK0 Multiple antibiotic resistance protein marR

434 D9QEP8 O-acetyltransferase OatA

435 D9QCX1 Long-chain-fatty-acid--AMP ligase FadD32

436 D9QDN9 Manganese/zinc/iron transport system permease protein

437 D9QBD6 Cell division protein $\mathrm{ftsW}$

438 D9QCY8 ABC-type cobalamin/Fe3+-siderophores transport system,

439 D9QCE1 A/G-specific DNA glycosylase

440 D9QCS2 Oligopeptide transport system permease protein oppC

441 D9QAB7 Apolipoprotein N-acyltransferase

442 D9QA71 Segregation and condensation protein A

443 D9QAI0 Archaeal ATPase

444 D9Q9P5 Glucose-1-phosphate adenylyltransferase

445 D9Q9J9 Uncharacterized protein

446 D9QDN4 UDP-galactofuranosyl transferase GlfT1

447 D9QCF3 $\mathrm{Na}+/ \mathrm{H}+$-dicarboxylate symporter

448 D9QAB9 Cobaltochelatase

449 D9QEL1 Manganese ABC transporter membrane protein

450 D9QDT2 DNA polymerase III subunit epsilon

451 D9QDN7 Manganese/zinc/iron transport system ATP-binding proteir

452 D9QE73 o-succinylbenzoate synthase

453 D9QEQ1 Ribokinase

454 D9QA84 Iron ABC transporter substrate-binding protein

455 D9QB79 Ribonuclease 3

456 D9QBS0 Oxygen-independent coproporphyrinogen-III oxidase-like $p$

457 D9QAJ1 Uncharacterized protein

oppCD1 chll

pabB

csd

uvrD

echA6

CpC231_1180

pip

ahcY

CpC231_0866

gppA2

argS

dnaJ

tehA

rimM

secA

mca

ndh

CpC231_0244

phoH

CpC231_0342

CpC231_1013

gatR

helY

oppC3

CpC231_1148

CpC231_0008

rpIT

ciue

xerC

91 Cytoplasmic;

327 Membrane;

115 Cytoplasmic;

428 Cytoplasmic;

89 Cytoplasmic;

623 Cytoplasmic;

77 Cytoplasmic;

512 Extracellular;

452 Membrane;

477 Cytoplasmic;

254 Cytoplasmic;

291 Cytoplasmic;

934 Cytoplasmic;

397 Cytoplasmic;

683 Cytoplasmic;

228 Cytoplasmic;

152 Membrane;

339 Cytoplasmic;

479 Cytoplasmic;

535 Membrane;

323 Cytoplasmic;

323 Cytoplasmic;

550 Cytoplasmic;

396 Cytoplasmic;

379 Membrane;

167 Cytoplasmic;

847 Cytoplasmic;

296 Cytoplasmic

452 Cytoplasmic;

475 Cytoplasmic;

345 Cytoplasmic;

209 Cytoplasmic;

108 Cytoplasmic

258 Membrane;

918 Cytoplasmic;

319 Membrane;

443 Cytoplasmic;

70 Cytoplasmic;

127 Cytoplasmic;

1129 Cytoplasmic;

293 Cytoplasmic;

336 Extracellular;

138 Cytoplasmic;

704 Membrane;

fadD32

mntD

ftsW1

CpC231_1963

mutY

Int

scpA

CpC231_1080 glg $\bar{C}$

CpC231_0743

glfT1

CpC231_1772

cobN

$\mathrm{mntC}$

dnaQ1

$\mathrm{mntB}$

menC

rbsK

ciuA

rnc

hemN

CpC231_1091

615 Cytoplasmic;

291 Membrane;

544 Membrane;

347 Membrane;

295 Cytoplasmic;

509 Membrane;

518 Membrane;

272 Cytoplasmic;

369 Cytoplasmic;

429 Cytoplasmic;

267 Membrane;

300 Cytoplasmic;

429 Membrane;

1204 Cytoplasmic;

280 Membrane;

348 Cytoplasmic;

241 Membrane;

345 Cytoplasmic;

300 Cytoplasmic;

301 Membrane;

249 Membrane;

384 Cytoplasmic;

612 Membrane;

\begin{tabular}{|c|c|c|}
\hline 0 & & No \\
\hline 6 & & No \\
\hline 0 & & No \\
\hline 0 & & No \\
\hline 0 & & No \\
\hline 0 & & No \\
\hline 0 & & No \\
\hline 0 & & No \\
\hline 0 & & No \\
\hline 0 & & No \\
\hline 0 & & No \\
\hline 0 & & No \\
\hline 0 & & No \\
\hline 0 & & No \\
\hline 0 & & No \\
\hline 0 & & No \\
\hline 1 & & No \\
\hline 0 & & No \\
\hline 0 & & No \\
\hline 12 & & No \\
\hline 0 & & No \\
\hline 0 & & No \\
\hline 0 & & No \\
\hline 0 & & No \\
\hline 10 & & No \\
\hline 0 & & No \\
\hline 0 & & No \\
\hline 0 & & No \\
\hline 3 & & No \\
\hline 0 & & No \\
\hline 0 & & No \\
\hline 0 & & No \\
\hline 0 & & No \\
\hline 0 & & No \\
\hline 0 & & No \\
\hline 6 & & No \\
\hline 0 & & No \\
\hline 0 & & No \\
\hline 0 & & No \\
\hline 0 & & No \\
\hline 0 & & No \\
\hline 0 & & Yes \\
\hline 0 & & No \\
\hline 11 & & No \\
\hline 0 & & No \\
\hline 9 & & No \\
\hline 10 & & No \\
\hline 10 & & No \\
\hline 0 & & No \\
\hline 4 & & No \\
\hline 8 & & No \\
\hline 0 & & No \\
\hline 0 & & No \\
\hline 0 & & No \\
\hline 2 & & $\mathrm{No}$ \\
\hline 0 & & $\mathrm{No}$ \\
\hline 9 & & $\mathrm{No}$ \\
\hline 0 & & No \\
\hline 9 & & No \\
\hline 0 & & No \\
\hline 0 & & No \\
\hline 0 & & No \\
\hline 0 & & No \\
\hline 0 & & Ye \\
\hline 0 & & No \\
\hline 0 & & No \\
\hline 14 & & No \\
\hline
\end{tabular}




\section{Anexo 1}

458 D9Q9Y8 LysR family transcriptional regulator 459 D9QDA5 ABC-2 type transporter family protein 460 D9QBM1 Heme oxygenase 461 D9QEQ2 Ribose operon repressor

462 D9QCN8 Glycerol-3-phosphate dehydrogenase

463 D9QAM2 DNA-directed RNA polymerase subunit omega

464 D9Q959 Xanthine permease

$465 \mathrm{D} 9 \mathrm{QCH} 960 \mathrm{kDa}$ chaperonin

466 D9QAD6 AAA ATPase forming ring-shaped complexes

467 D9QB96 Inositol monophosphate phosphatase

468 D9QE97 DNA-directed RNA polymerase subunit beta;

469 D9QCM6 Uncharacterized protein

470 D9QD83 Uncharacterized protein

471 D9QC56 Cytochrome $c$ oxidase subunit 1

472 D9QD82 Iron-enterobactin transporter

473 D9Q9U8 ATP synthase subunit a

474 D9QCS3 Oligopeptide transport system permease protein oppB 475 D9QBT8 Auxin Efflux Carrier

476 D9QDM6 Arabinofuranosyl transferase A

477 D9Q9A3 Glutamate ABC transporter domain-containing ATP-bindin

478 D9QE74 2-succinyl-5-enolpyruvyl-6-hydroxy-3-cyclohexene-1-carbo 479 D9QCR7 Chaperone protein DnaK

$480 \mathrm{D} 9 \mathrm{QCl} 4 \mathrm{Na}(+) / \mathrm{H}(+)$ antiporter subunit $\mathrm{A}$

481 D9QBQ6 Glycine--tRNA ligase

482 D9QBZ7 Small-conductance mechanosensitive channel

483 D9QB11 Flavin-dependent thymidylate synthase

484 D9Q9Z0 Uncharacterized protein

485 D9QBL0 Cell-surface hemin receptor

486 D9QE47 Glutamyl-tRNA reductase

487 D9QAZ9 Phage shock protein A (IM30)

488 D9QB31 Uroporphyrinogen-III methylase

489 D9Q989 Thymidylate synthase

490 D9Q9V1 ATP synthase subunit delta

491 D9QAQ3 Uncharacterized protein

492 D9QC91 Mycothiol acetyltransferase

493 D9QD31 Ribosomal pseudouridine synthase

494 D9QCC2 Acetolactate synthase large subunit IlvB1

495 D9QB86 Galactose-1-phosphate uridylyltransferase

496 D9QBE4 Transcriptional regulator MraZ

497 D9QBC0 Pseudouridine synthase

498 D9Q9J2 TetR family transcriptional regulator

499 D9QDE5 Tryptophan synthase alpha chain

500 D9QBD8 Phospho-N-acetylmuramoyl-pentapeptide-transferase

501 D9QDC6 Dihydrodipicolinate synthase

502 D9QAK3 Triosephosphate isomerase

503 D9QEX3 UvrABC system protein B

504 D9QD71 Ribose import ATP-binding protein RbsA

505 D9Q9K9 2-dehydropantoate 2-reductase

506 D9QAM7 Carbamoyl-phosphate synthase large chain

507 D9QBY8 Trigger factor

508 D9QBR9 Chaperone protein DnaJ

509 D9QCV1 Aldehyde dehydrogenase

510 D9Q988 Dihydrofolate reductase

511 D9Q9X6 Glutamyl-tRNA(GIn) amidotransferase subunit A

512 D9QE54 Protoporphyrinogen oxidase

513 D9Q9F3 Peptidyl-tRNA hydrolase

514 D9Q913 Serine hydroxymethyltransferase

515 D9QAX6 Glycerol-3-phosphate regulon repressor

516 D9QCS9 Protein fadF

517 D9QDD7 Phytoene synthase

518 D9Q9E7 Uncharacterized protein

519 D9QE56 Glutamate-1-semialdehyde 2,1-aminomutase

520 D9QBB1 RelA/SpoT domain-containing protein

521 D9QCT6 Urease accessory protein UreG

522 D9QB35 Hydrogenobyrinate a,c-diamide synthase

523 D9QDF5 Uncharacterized protein

524 D9QBC1 Lipoprotein signal peptidase

\begin{tabular}{|c|c|c|c|}
\hline lysG & 296 Cytoplasmic; & 0 & No \\
\hline CpC231_2041 & 633 Membrane; & 6 & No \\
\hline $\mathrm{hmuO}$ & 212 Cytoplasmic; & 0 & No \\
\hline rbsR & 354 Cytoplasmic; & 0 & No \\
\hline glpD & 573 Cytoplasmic; & 0 & No \\
\hline rpoz & 95 Cytoplasmic; & 0 & No \\
\hline pbuX & 492 Membrane; & 13 & No \\
\hline groL & 546 Cytoplasmic; & 0 & No \\
\hline arc & 526 Cytoplasmic; & 0 & No \\
\hline impA & 260 Cytoplasmic; & 0 & No \\
\hline rрoC & 1350 Cytoplasmic; & 0 & No \\
\hline CpC231_1846 & 384 Membrane; & 6 & No \\
\hline $\operatorname{fag} \bar{A}$ & 355 Membrane; & 9 & No \\
\hline $\mathrm{ctaD}$ & 573 Membrane; & 12 & No \\
\hline fagB & 328 Membrane; & 10 & No \\
\hline atpB & 261 Membrane; & 7 & No \\
\hline oppB5 & 331 Membrane; & 6 & No \\
\hline CpC231_1550 & 306 Membrane; & 10 & No \\
\hline aftA & 691 Membrane; & 13 & No \\
\hline gluA & 252 Cytoplasmic; & 0 & No \\
\hline menD & 537 Cytoplasmic; & 0 & No \\
\hline dnaK & 610 Cytoplasmic; & 0 & No \\
\hline mrpA1 & 952 Membrane; & 23 & Yes \\
\hline glys & 461 Cytoplasmic; & 0 & No \\
\hline CpC231_1611 & 224 Membrane; & 2 & No \\
\hline thyX & 252 Cytoplasmic; & 0 & No \\
\hline CpC231_0885 & 474 Extracellular; & 5 & No \\
\hline CpC231_1469 & 733 Extracellular; & 1 & No \\
\hline hemA & 456 Cytoplasmic; & 0 & No \\
\hline $\mathrm{pspA}$ & 280 Cytoplasmic; & 0 & No \\
\hline cobA & 250 Cytoplasmic; & 0 & No \\
\hline thyA & 265 Cytoplasmic; & 0 & No \\
\hline atpH & 273 Cytoplasmic; & 0 & No \\
\hline CpC231_1153 & 270 Cytoplasmic; & 0 & No \\
\hline $\mathrm{mshD}$ & 304 Cytoplasmic; & 0 & No \\
\hline rluc & 327 Cytoplasmic; & 0 & No \\
\hline ilvB1 & 578 Cytoplasmic; & 0 & No \\
\hline CpC231_1341 & 447 Cytoplasmic; & 0 & No \\
\hline mraZ & 143 Cytoplasmic; & 0 & No \\
\hline rulD & 307 Cytoplasmic; & 0 & No \\
\hline tetR3 & 216 Cytoplasmic; & 0 & No \\
\hline $\operatorname{trpA}$ & 279 Cytoplasmic; & 0 & No \\
\hline mraY & 366 Membrane; & 10 & No \\
\hline nanL & 307 Cytoplasmic; & 0 & No \\
\hline tpiA & 259 Cytoplasmic; & 0 & No \\
\hline uvrB & 1648 Cellwall; & 0 & No \\
\hline rbsA & 257 Cytoplasmic; & 0 & No \\
\hline panE & 294 Cytoplasmic; & 0 & No \\
\hline carB & 1120 Cytoplasmic; & 0 & No \\
\hline tig & 450 Cytoplasmic; & 0 & No \\
\hline dnaJ1 & 378 Cytoplasmic; & 0 & No \\
\hline СpC231_1926 & 463 Cytoplasmic; & 0 & No \\
\hline folA & 175 Membrane; & 0 & No \\
\hline gat $A$ & 494 Cytoplasmic; & 0 & No \\
\hline hemY & 461 Cytoplasmic; & 0 & Yes \\
\hline pth & 217 Cytoplasmic; & 0 & No \\
\hline glyA & 429 Cytoplasmic; & 0 & No \\
\hline glpR & 267 Cytoplasmic; & 0 & No \\
\hline fadF & 887 Membrane; & 5 & No \\
\hline crtB & 397 Membrane; & 0 & No \\
\hline CpC231_0691 & 416 Cytoplasmic; & 0 & No \\
\hline hemL & 441 Cytoplasmic; & 0 & No \\
\hline CpC231_1366 & 338 Cytoplasmic; & 0 & No \\
\hline ure $\bar{G}$ & 204 Cytoplasmic; & 0 & No \\
\hline cobB & 457 Cytoplasmic; & 0 & Yes \\
\hline CpC231_2091 & 1157 Cellwall; & 15 & No \\
\hline Isp $\bar{A}$ & 186 Membrane; & 4 & No \\
\hline
\end{tabular}




\section{Anexo 1}

525 D9QA91 Uncharacterized protein

526 D9QCD0 SpoU rRNA Methylase family protein

527 D9QEN2 Adenosine deaminase

528 D9QAG5 DNA-binding protein

529 D9QB95 Imidazole glycerol phosphate synthase subunit HisF

530 D9QDD2 UPF0371 protein CpC231

531 D9QE86 N-ethylmaleimide reductase

532 D9QEN1 D-alanyl-D-alanine carboxypeptidase dacA

533 D9Q9Z5 Ketol-acid reductoisomerase (NADP $(+))$

534 D9QEY0 Uncharacterized protein

535 D9QB19 4-phosphopantetheinyl transferase entD

536 D9QDY8 Phosphoserine phosphatase

537 D9Q9C1 Large-conductance mechanosensitive channel

538 D9QC38 Uncharacterized protein

539 D9QC51 Ribosomal-protein-alanine acetyltransferase

540 D9QBR6 Endoribonuclease YbeY

541 D9QDY1 Endonuclease III

542 D9QDF9 N-Acetymuramyl-L-Alanine Amidase

543 D9QEA3 Permease

544 D9Q9A2 Bifunctional purine biosynthesis protein $\mathrm{PurH}$

545 D9QCK5 Phosphotransacetylase

546 D9Q9N6 Cytokinin riboside 5;

547 D9QE05 Secreted hydrolase

548 D9QEA7 30S ribosomal protein $\mathrm{S} 12$

549 D9QAC4 Precorrin-4 C11-methyltransferase

550 D9QDX9 CRP/FNR family transcriptional regulator

551 D9Q9P9 Sec-independent protein translocase protein TatB

552 D9QEV8 DNA helicase

553 D9QB62 50 S ribosomal protein L19

554 D9QDB6 Uncharacterized protein

555 D9QB27 Ribosome maturation factor RimP

556 D9QC08 Uncharacterized protein

557 D9QCA4 Phosphoribosylformylglycinamidine synthase subunit PurL

558 D9QCQ9 UPF0012 hydrolase

559 D9QC46 Rhomboid family protein

560 D9QB22 DHH subfamily 1 protein

561 D9QA29 ABC transporter domain-containing protein

562 D9Q9F9 Ribose-phosphate pyrophosphokinase

563 D9QDL8 Glycerol kinase

564 F9Y365 Haloacid dehalogenase-like hydrolase

565 D9QDV3 Uncharacterized protein

566 D9QBF4 Serine/threonine protein kinase

567 D9Q947 FecCD family membrane transport protein

568 D9QBH0 Asparagine synthetase

569 D9QEA2 Uncharacterized protein

570 D9QBN9 Alpha/beta hydrolase

571 D9QBJ5 Uncharacterized protein

572 D9QDI1 Choline transport system permease protein opuBD

573 D9QC74 Transcriptional regulator, LuxR family

574 D9QEJ2 Uncharacterized protein

575 D9Q9Z6 Cadmium, cobalt and zinc/ $\mathrm{H}(+)-\mathrm{K}(+)$ antiporter

576 D9QE07 dTDP-4-dehydrorhamnose reductase

577 D9QBZ6 Aminopeptidase N

578 D9Q9V0 ATP synthase subunit b

579 D9QB39 Probable malate:quinone oxidoreductase

580 D9QE87 50 S ribosomal protein L10

581 D9QAR1 Metallo-beta-lactamase superfamily protein

582 D9QA83 Uncharacterized protein

583 D9QD25 Uncharacterized protein

584 D9QEP4 Acyl coenzyme A carboxylase

585 D9QA14 7,8-dihydro-8-oxoguanine-triphosphatase

586 D9QBB8 RarD protein

587 D9QEC6 50 S ribosomal protein L16

588 D9QDW7 Uncharacterized protein

589 D9QBA8 Glycogen debranching protein

590 D9QB84 Glycerate kinase

591 D9QET6 Phosphoribosyl transferase

\begin{tabular}{|c|c|c|c|}
\hline СpC231_0989 & 523 Extracellular; & 0 & Yes \\
\hline CpC231_1749 & 313 Cytoplasmic; & 0 & No \\
\hline add & 296 Cytoplasmic; & 0 & No \\
\hline СpC231_1065 & 190 Cytoplasmic; & 0 & No \\
\hline his $\bar{F}$ & 264 Cytoplasmic; & 0 & No \\
\hline CpC231_2068 & 497 Cytoplasmic; & 0 & No \\
\hline nemA & 357 Cytoplasmic; & 0 & No \\
\hline dacA & 404 Extracellular; & 1 & Yes \\
\hline ilvC & 337 Cytoplasmic; & 0 & No \\
\hline СpC231_0566 & 455 Membrane; & 10 & No \\
\hline ent $\bar{D}$ & 223 Cytoplasmic; & 0 & No \\
\hline serB & 290 Membrane; & 1 & No \\
\hline $\mathrm{mscL}$ & 140 Membrane; & 2 & No \\
\hline СpC231_1652 & 109 Extracellular; & 0 & Yes \\
\hline СpC231_1665 & 165 Membrane; & 0 & No \\
\hline$y b e \bar{Y}$ & 196 Cytoplasmic; & 0 & No \\
\hline nth & 268 Cytoplasmic; & 0 & No \\
\hline cwIM & 398 Cytoplasmic; & 0 & No \\
\hline CpC231_0334 & 320 Membrane; & 11 & No \\
\hline purH & 525 Cytoplasmic; & 0 & No \\
\hline eutD & 462 Cytoplasmic; & 0 & No \\
\hline CpC231_0780 & 263 Cytoplasmic; & 0 & No \\
\hline CpC231_0234 & 269 Extracellular; & 0 & Yes \\
\hline $\operatorname{rps} \bar{L}$ & 128 Cytoplasmic; & 0 & No \\
\hline cobM & 257 Cytoplasmic; & 0 & No \\
\hline$g \mid x R$ & 227 Cytoplasmic; & 0 & No \\
\hline tatB & 147 Cytoplasmic; & 1 & No \\
\hline uvrD & 1062 Cytoplasmic; & 0 & No \\
\hline rplS & 113 Cytoplasmic; & 0 & No \\
\hline CpC231_2052 & 1135 Cellwall; & 1 & Yes \\
\hline $\operatorname{rim} \bar{P}$ & 184 Cytoplasmic; & 0 & No \\
\hline CpC231_1622 & 337 Extracellular; & 0 & No \\
\hline purL & 766 Cytoplasmic; & 0 & No \\
\hline CpC231_1881 & 278 Cytoplasmic; & 0 & No \\
\hline CpC231_1660 & 272 Membrane; & 6 & No \\
\hline CpC231_1274 & 330 Cytoplasmic; & 0 & No \\
\hline CpC231_0926 & 318 Membrane; & 6 & No \\
\hline $\operatorname{prs} \bar{A}$ & 326 Cytoplasmic; & 0 & No \\
\hline glpK & 509 Cytoplasmic; & 0 & No \\
\hline СpC231_1044 & 234 Cytoplasmic; & 0 & No \\
\hline СpC231_0181 & 207 Cytoplasmic; & 0 & No \\
\hline pknL & 752 Membrane; & 1 & No \\
\hline fecCD & 321 Membrane; & 10 & No \\
\hline asnB & 640 Cytoplasmic; & 0 & No \\
\hline CpC231_0333 & 241 Membrane; & 3 & No \\
\hline CpC231_1499 & 321 Cytoplasmic; & 0 & No \\
\hline CpC231_1452 & 377 Cytoplasmic; & 0 & No \\
\hline opuBD & 212 Membrane; & 5 & No \\
\hline CpC231_1689 & 279 Cytoplasmic; & 0 & No \\
\hline CpC231_0425 & 293 Extracellular; & 0 & No \\
\hline $\mathrm{czc} \overline{\mathrm{D}}$ & 361 Membrane; & 6 & No \\
\hline rmID & 460 Extracellular; & 0 & No \\
\hline pepN & 871 Cytoplasmic; & 0 & No \\
\hline atpF & 188 Cytoplasmic; & 1 & No \\
\hline mqo & 499 Cytoplasmic; & 0 & No \\
\hline rplJ & 171 Cytoplasmic; & 0 & No \\
\hline gloB1 & 182 Cytoplasmic; & 0 & No \\
\hline СpC231_0981 & 898 Membrane; & 12 & No \\
\hline oxaA & 415 Membrane; & 6 & No \\
\hline $\mathrm{accBC}$ & 591 Cytoplasmic; & 0 & No \\
\hline mutT2 & 333 Cytoplasmic; & 0 & No \\
\hline $\operatorname{rarD}$ & 294 Membrane; & 10 & No \\
\hline rpIP & 138 Cytoplasmic; & 0 & No \\
\hline CpC231_0195 & 477 Extracellular; & 5 & Yes \\
\hline $\operatorname{glg} \bar{X}$ & 745 Cytoplasmic; & 0 & No \\
\hline glxK & 396 Extracellular; & 0 & No \\
\hline СpC231_0522 & 201 Cytoplasmic; & 0 & \\
\hline
\end{tabular}




\section{Anexo 1}

592 D9QEL3 DtxR family transcriptional regulator 593 D9QCN2 Sdr family related adhesin 594 D9QAK9 UvrABC system protein C 595 D9Q9B7 Two component system sensor kinase protein 596 D9QBK8 ABC transporter inner membrane protein 597 D9QAI7 FeS assembly ATPase SufC

598 D9QAS4 Probable transcriptional regulatory protein $\mathrm{CpC} 231$

599 D9QE04 Acetyl-coenzyme A synthetase

600 D9QED7 50 S ribosomal protein L5

601 D9Q9R5 Galactose-1-phosphate uridylyltransferase

602 D9QD29 Universal stress protein A

603 D9QEG4 50S ribosomal protein L17

604 D9QE18 Succinate dehydrogenase iron-sulfur subunit

605 D9QCC7 Trehalose 6-phosphate phosphatase

606 D9QCN4 Glycoside hydrolase family 76 protein

607 D9QAJ0 Iron-sulfur cluster biosynthesis transcriptional regulator Su

608 D9QCD3 2-C-methyl-D-erythritol 4-phosphate cytidylyltransferase

609 D9QE43 Thiol:disulfide interchange protein DsbA

610 D9Q9X8 Multidrug resistance protein B

611 D9QC96 Glycine cleavage T protein

612 D9QC31 Holo-[acyl-carrier-protein] synthase

613 D9QCE6 Permease, major facilitator family

614 D9QBF0 Methylenetetrahydrofolate reductase

615 D9Q9A5 Glutamate transport system permease protein gluC

616 D9QE20 Uncharacterized protein yjiN

617 D9QCS0 Predicted permease

618 D9Q9H3 HTH-type transcriptional repressor of iron protein A

619 D9Q9Z2 Small-conductance mechanosensitive channel

620 D9QCJ0 Uncharacterized protein

621 D9Q997 Chorismate mutase

622 D9QES8 Uncharacterized protein

623 D9Q972 Cation/acetate symporter ActP

624 D9Q9M5 1D-myo-inositol 2-acetamido-2-deoxy-alpha-D-glucopyran

625 D9QDS5 3-hydroxyisobutyrate dehydrogenase

626 D9Q9R3 Sodium/solute symporter

627 D9QET2 Thymidylate kinase

628 D9QC42 dITP/XTP pyrophosphatase

629 D9Q9U6 Undecaprenyl-phosphate alpha-N-acetylglucosaminyl 1-ph

630 D9QCZ6 Uncharacterized protein

631 D9QBU6 Uncharacterized protein

632 D9QAD0 Sec-independent protein translocase protein TatA

633 D9QDR9 Aspartate transaminase

634 D9Q9D2 Glycine betaine transporter

635 D9QCP9 Transport protein

636 D9QAU6 RNA methyltransferase, TrmA family

637 D9QDG8 $\mathrm{Fe}(3+)$ dicitrate transport ATP-binding protein FecE

638 D9QEH1 ESX-3 secretion system protein eccC3

639 D9QAR8 Protein-export membrane protein SecF

640 D9Q9V7 Endonuclease NucS

641 D9Q9S6 ATP-binding protein

642 D9QDJ8 Uncharacterized protein

643 D9QCB4 Phosphoribosylamine--glycine ligase

644 D9QA37 Coenzyme PQQ synthesis protein E

645 D9QEQ9 N5-carboxyaminoimidazole ribonucleotide mutase

646 D9QAX9 PTS system fructose-specific EIIABC component

647 D9QAC5 Precorrin-6Y C5,15-methyltransferase

648 D9QA42 UvrABC system protein A

649 D9QEP7 Uncharacterized protein

650 D9QBY4 ATP-dependent Clp protease ATP-binding subunit CIpX

651 D9QBH3 Bifunctional adenosylcobalamin biosynthesis protein Cobl

652 D9QA43 Translation initiation factor IF-3

653 D9QC88 Phosphate import ATP-binding protein PstB

654 D9QE38 Pyrroline-5-carboxylate reductase

655 D9Q9C6 Ribosomal-protein-alanine acetyltransferase

656 D9QE60 Cytochrome $C$ biosynthesis protein ResB

657 D9QC84 Succinyl-CoA Coenzyme A transferase

658 D9QAl3 ABC transporter ATP-binding protein

\begin{tabular}{|c|c|c|c|}
\hline mntR & 213 Cytoplasmic; & 0 & No \\
\hline CpC231_1852 & 1269 Cellwall; & 2 & Yes \\
\hline uvrC & 675 Cytoplasmic; & 0 & No \\
\hline $\operatorname{tcs} S 4$ & 514 Membrane; & 2 & No \\
\hline СpC231_1467 & 484 Membrane; & 10 & No \\
\hline sufC & 252 Cytoplasmic; & 0 & No \\
\hline СpC231_1174 & 250 Cytoplasmic; & 0 & No \\
\hline $\operatorname{acs} \bar{A}$ & 548 Membrane; & 0 & No \\
\hline rplE & 187 Cytoplasmic; & 0 & No \\
\hline galT & 371 Cytoplasmic; & 0 & No \\
\hline uspA & 299 Cytoplasmic; & 0 & No \\
\hline rplQ & 161 Cytoplasmic; & 0 & No \\
\hline $\operatorname{sdh} B$ & 249 Cytoplasmic; & 0 & No \\
\hline otsB & 241 Cytoplasmic; & 0 & No \\
\hline CpC231_1854 & 380 Cytoplasmic; & 0 & No \\
\hline suf' $\bar{R}$ & 257 Cytoplasmic; & 0 & No \\
\hline ispD & 245 Membrane; & 0 & No \\
\hline dsbA & 293 Membrane; & 0 & Yes \\
\hline emrB & 482 Membrane; & 14 & No \\
\hline CpC231_1712 & 376 Cytoplasmic; & 0 & No \\
\hline $\operatorname{acpS}$ & 129 Cytoplasmic; & 0 & No \\
\hline CpC231_1765 & 467 Membrane; & 14 & No \\
\hline metF & 327 Cytoplasmic; & 0 & No \\
\hline gluC & 228 Membrane; & 5 & No \\
\hline yjiN & 435 Membrane; & 3 & No \\
\hline CpC231_1894 & 453 Membrane; & 10 & No \\
\hline ripA & 368 Membrane; & 0 & No \\
\hline $\operatorname{mscS}$ & 564 Membrane; & 4 & No \\
\hline CpC231_1810 & 430 Membrane; & 12 & No \\
\hline $\mathrm{csm}$ & 100 Cytoplasmic; & 0 & No \\
\hline СpC231_0514 & 255 Extracellular; & 1 & No \\
\hline $\operatorname{act} \bar{P}$ & 547 Membrane; & 13 & No \\
\hline $\mathrm{mshB}$ & 294 Cytoplasmic; & 0 & No \\
\hline $\mathrm{mmsB}$ & 302 Cytoplasmic; & 0 & Yes \\
\hline СpC231_0807 & 552 Membrane; & 14 & No \\
\hline tmk & 206 Cytoplasmic; & 0 & No \\
\hline СpC231_1656 & 207 Cytoplasmic; & 0 & No \\
\hline rfe & 384 Membrane; & 11 & No \\
\hline СpC231_1971 & 115 Cytoplasmic; & 0 & No \\
\hline CpC231_1558 & 440 Membrane; & 9 & No \\
\hline $\operatorname{tat} A$ & 92 Cytoplasmic; & 1 & No \\
\hline aspB & 451 Cytoplasmic; & 0 & No \\
\hline betP & 663 Membrane; & 12 & No \\
\hline CpC231_1870 & 528 Membrane; & 5 & No \\
\hline $\operatorname{trm} A$ & 439 Cytoplasmic; & 0 & No \\
\hline fecE & 256 Membrane; & 0 & No \\
\hline eccC3 & 1283 Cytoplasmic; & 1 & No \\
\hline secF & 373 Membrane; & 6 & No \\
\hline nucs & 227 Cytoplasmic; & 0 & No \\
\hline СpC231_0820 & 857 Cytoplasmic; & 0 & No \\
\hline CpC231_0073 & 356 Cytoplasmic; & 0 & No \\
\hline purD & 422 Cytoplasmic; & 0 & No \\
\hline pqqE & 412 Cytoplasmic; & 0 & No \\
\hline purE & 166 Membrane; & 0 & No \\
\hline fruA & 38 Extracellular; & 0 & No \\
\hline cobL & 422 Membrane; & 0 & No \\
\hline uvrA & 954 Cytoplasmic; & 0 & No \\
\hline CpC231_0483 & 356 Cytoplasmic; & 0 & No \\
\hline $\operatorname{clp} \bar{X}$ & 428 Cytoplasmic; & 0 & No \\
\hline cobU & 184 Cytoplasmic; & 0 & No \\
\hline infC & 148 Cytoplasmic; & 0 & No \\
\hline pstB & 257 Cytoplasmic; & 0 & No \\
\hline proC & 267 Membrane; & 0 & No \\
\hline rimJ & 238 Cytoplasmic; & 0 & No \\
\hline $\operatorname{ccs} B$ & 535 Membrane; & 4 & No \\
\hline cat1 & 501 Cytoplasmic; & 0 & No \\
\hline СpC231_1083 & 543 Cytoplasmic; & 0 & No \\
\hline
\end{tabular}


Anexo 1

659 D9QBV1 ABC-type oligopeptide transport system 660 D9Q9U9 ATP synthase subunit C 661 D9QBI3 Octanoyltransferase

662 D9QDS1 DNA polymerase III subunit gamma/tau

663 D9QAH4 Aconitate hydratase

664 D9QBR3 GTPase Era

665 D9QBX8 Ornithine cyclodeaminase

666 D9QCX0 Phthiocerol synthesis polyketide synthase type I PpsA

667 D9Q950 Uncharacterized protein

668 D9QBD3 Cell division protein FtsQ

669 D9QAQ9 CaiB/baiF CoA-transferase family protein

670 D9QD16 Uncharacterized protein

671 D9QEE8 Uncharacterized protein

672 D9QBX0 Glutamate 5-kinase

673 D9QBL8 Threonine synthase

674 D9Q9E4 Transcriptional regulatory protein PvdS

675 D9QAL2 Riboflavin biosynthesis protein RibBA

676 D9QA75 ATP-dependent dethiobiotin synthetase BioD

677 D9QEE1 PAP2 superfamily protein

678 D9QCR9 Fimbrial associated sortase-like protein

679 D9QDK8 ATP-dependent RNA helicase hrpB

680 D9QAK0 6-phosphogluconolactonase

681 D9QEF5 Protein translocase subunit SecY

682 D9Q9Y9 Uncharacterized protein

683 D9QB74 Uncharacterized protein

684 D9QAX7 1-phosphofructokinase

685 D9QA21 Dihydroxyacetone kinase 2

686 D9QAK4 Phosphoglycerate kinase

687 D9QDS7 2-hydroxyhepta-2,4-diene-1,7-dioatesomerase

$688 \mathrm{D} 9 \mathrm{QBL} 5 \mathrm{Na}+\mathrm{H}+$ antiporter $\mathrm{NhaC}$

689 D9QA50 N-acetyl-gamma-glutamyl-phosphate reductase

690 D9QA77 Pseudouridine synthase

691 D9Q9Y4 ATP-dependent 6-phosphofructokinase

692 D9QBH9 Glycine dehydrogenase (aminomethyl-transferring)

693 D9QAW8 Transcriptional activator protein lysR

694 D9QA85 Iron ABC transporter domain-containing permease protein 695 D9QBY6 ATP-dependent Clp protease proteolytic subunit

696 D9QEE3 50 S ribosomal protein L6

697 D9QE26 Formate acetyltransferase 1

698 D9QDW0 Sensor-like histidine kinase senX3

699 D9QBA4 Uncharacterized protein

700 D9Q9A0 Uncharacterized protein

701 D9QBP8 Glutamine--fructose-6-phosphate aminotransferase [isome

702 D9QBH4 Nicotinate-nucleotide--dimethylbenzimidazole phosphoribo

703 D9QES6 Uncharacterized protein

704 D9QD01 LytR family transcriptional regulator

705 D9QD72 Uncharacterized protein

706 D9QBD9 UDP-N-acetylmuramoyl-tripeptide--D-alanyl-D-alanine liga:

707 D9QBX7 Nucleoside diphosphate kinase

708 D9QDV2 Uncharacterized protein

709 D9Q9R7 ATP-dependent RNA helicase DeaD

710 D9QE03 Uncharacterized protein

711 D9QEA1 ABC transporter inner membrane protein

712 D9QE45 Haloacid dehalogenase-like hydrolase

713 D9QCR6 Protein GrpE

714 D9QEX6 Uncharacterized protein

715 D9QEH6 30S ribosomal protein S9

716 D9QD61 Uncharacterized protein

717 D9QDT8 Phosphoglucosamine mutase

718 D9QD43 Glycoside hydrolase 15-related protein

719 D9QCB7 Sensor histidine kinase mtrB

720 D9QA74 Adenosylmethionine-8-amino-7-oxononanoate aminotrans

721 D9QEA6 Uncharacterized protein

722 D9QB63 Transcriptional accessory protein

723 D9QEQ7 Uncharacterized protein

724 D9QC95 4-Amino-4-deoxychorismate lyase

725 D9QEJ0 $60 \mathrm{kDa}$ chaperonin

$\begin{array}{cr}\text { CpC231_1565 } & 235 \text { Membrane; } \\ \text { atpE } & 79 \text { Cytoplasmic; } \\ \text { lipB } & 251 \text { Cytoplasmic; } \\ \text { dnaX } & 849 \text { Cytoplasmic; } \\ \text { acnA } & 939 \text { Cytoplasmic; } \\ \text { era } & 305 \text { Cytoplasmic; } \\ \text { arcB } & 316 \text { Membrane; }\end{array}$

ppsA

CpC231_0591

$\mathrm{fts} \mathrm{Q}$

CpC231_1159

CpC231_1993

CpC231_0379

proB

thrC

pvdS

ribA

bioD

CpC231_0372

srtA

hrpB

pgl

$\sec Y$

CpC231_0884

CpC231_1328

fruK

dak2

pgk

hpaF

CpC231_1474

$\arg \overline{\mathrm{C}}$

rluB

pfkA

gcvP

lysR1

ciuB

clpP

rplF

pfIB

senX3

CpC231_1359

CpC231 0643

glms

cobT

CpC231_0512

lytR

CpC231_0017

murF

ndk

CpC231_0180

deaD1

CpC231_0232

CpC231_0332

CpC231_0274

grpE

CpC231_0562

rpsl

CpC231_0006

pmmB

CpC231_2020

$\mathrm{mtr} B$

bioA

CpC231_0337

CpC231_1317

CpC231_0493

pabC

groL
1611 Cellwall;

213 Membrane;

218 Membrane;

379 Cytoplasmic;

452 Membrane;

151 Cytoplasmic;

417 Cytoplasmic;

480 Cytoplasmic;

287 Cytoplasmic;

451 Cytoplasmic;

229 Membrane;

410 Extracellular;

291 Cytoplasmic;

818 Membrane;

236 Cytoplasmic;

440 Membrane;

273 Extracellular;

1201 Membrane;

326 Extracellular;

571 Cytoplasmic;

404 Cytoplasmic;

282 Cytoplasmic;

456 Membrane;

347 Membrane;

373 Cytoplasmic;

342 Cytoplasmic;

951 Cytoplasmic;

313 Cytoplasmic;

322 Membrane;

209 Cytoplasmic;

178 Cytoplasmic;

698 Cytoplasmic;

261 Membrane;

401 Membrane;

579 Membrane;

624 Cytoplasmic;

354 Cytoplasmic;

328 Membrane;

427 Extracellular;

223 Cytoplasmic;

516 Cytoplasmic;

136 Cytoplasmic;

244 Extracellular;

650 Cytoplasmic;

78 Extracellular;

253 Membrane;

347 Cytoplasmic;

214 Cytoplasmic;

350 Membrane;

177 Cytoplasmic;

144 Cytoplasmic;

554 Cytoplasmic;

654 Cytoplasmic;

501 Membrane;

432 Cytoplasmic;

146 Cytoplasmic;

767 Cytoplasmic;

156 Membrane;

305 Cytoplasmic;

540 Cytoplasmic;
No

No

No

No

No

No

No

No

No

No

No

No

Yes

No

No

No

No

Yes

Yes

No

No

No

No

Yes

No

No

No

No

No

No

No

No

No

No

No

No

No

No

No

Yes

No

No

No

No

No

No

No

No

No

No

No

No

No

No

No

No

No

No

No

No

No

No

No

No

No

No

No 
Anexo 1

726 D9QDQ4 HTH-type pyridoxine biosynthesis transcriptional regulator 727 D9QB77 $\mathrm{Na}+$ /alanine symporter family

728 D9QE10 Serine proteases of the peptidase family S9A

729 D9QER0 Uncharacterized protein

730 D9QEY1 Non-ribosomal peptide synthetase

731 D9QB43 Methionine aminopeptidase

732 D9QEC1 50 S ribosomal protein L23

733 D9Q994 Uncharacterized protein

734 D9QDZ7 DEAD-box ATP dependent DNA helicase

735 D9QA20 Uracil-DNA glycosylase

736 D9QBW6 Gamma-glutamyl phosphate reductase

737 D9QBI7 Glutamine synthetase

738 D9QAE5 Methionine synthase

739 D9QA64 NAD kinase

740 D9QCD5 Lipoprotein LpqE

741 D9QDI2 Choline transport ATP-binding protein OpuBA

742 D9QE35 Uncharacterized protein

743 D9QDA6 Leucine--tRNA ligase

744 D9QEC9 Oligopeptide-binding protein oppA

745 D9QDP7 Putative phenylalanine aminotransferase

746 D9QAB3 Protein ycel

747 D9QDX8 Metallo-beta-lactamase superfamily protein

748 D9QEL7 Uncharacterized protein

749 D9QAM9 Dihydroorotase

750 D9QA33 SAM-dependent methyltransferase

751 D9QBF6 3;

752 D9QE09 Peptidase family M1 containing protein

753 D9QCK7 Acetyltransferase

754 D9QA10 Guanosine-3;

755 D9QAH0 Ferrochelatase

756 D9QEM2 Hemin import ATP-binding protein HmuV

757 D9QCB1 Adenylosuccinate lyase

758 D9Q952 Uncharacterized protein

759 D9QE64 Membrane permease protein

760 D9QDK5 Probable membrane transporter protein

761 D9QAV9 D-aminoacyl-tRNA deacylase

762 D9QA11 IcIR family transcriptional regulator

763 D9QAU9 Deoxyuridine 5;

764 D9QAM0 S-adenosylmethionine synthase

765 D9Q912 Pantothenate kinase

766 D9QA44 50S ribosomal protein L35

767 D9QCK1 Uncharacterized protein

768 D9QE93 Manganese transport system membrane protein mntD

769 D9QEM9 Tryptophan--tRNA ligase

770 D9QDC3 Oligopeptide transport system permease protein oppB

771 D9QEV2 Secreted hydrolase

772 D9QAY8 tRNA dimethylallyltransferase

773 D9QBG6 Ubiquinol-cytochrome $\mathrm{C}$ reductase cytochrome $\mathrm{C}$ subunit

774 D9Q9D4 Ribosomal RNA small subunit methyltransferase I

775 D9QCL4 Uncharacterized protein

776 D9QDB5 ChrA, CheY/winged-helix DNA-binding domain-containing

777 D9QAL7 Methionyl-tRNA formyltransferase

778 D9QEQ8 N5-carboxyaminoimidazole ribonucleotide synthase

779 D9QBU5 Pyridoxal phosphate homeostasis protein

780 D9QC79 Glycerol dehydrogenase

781 D9QE85 Aminopeptidase C

782 D9QEJ3 Inosine-5;

783 D9QCL8 Cytochrome $\mathrm{c}$ biogenesis protein resB

784 D9QDZ9 DNA topoisomerase 1

785 D9QEY3 Uncharacterized protein

786 D9Q9X3 DNA ligase

787 D9QDM0 Alpha/beta hydrolase family protein

788 D9QE52 Cation-transporting P-type ATPase A

789 D9QC23 Dihydrodipicolinate synthase

790 D9Q9F4 Nitronate monooxygenase

791 D9QB10 4-hydroxy-tetrahydrodipicolinate synthase

792 D9QEM1 Hemin import ATP-binding protein
pdxR

CpC231 1331

CpC231_0239

CpC231_0496

CpC231_0567

map

rplW

CpC231_0637

CpC231_0226

ung

proA

$g \ln A$

metH

nadK

lpqE

opuBA

CpC231_0264

leuS

oppA1

pat

ycel

CpC231_0207

CpC231_0451

pyrC

CpC231_0930

CpC231_1411

CpC231_0238

CpC231 1827

spoT

hemH

hmuV

purB

CpC231_0593

CpC231_0293

CpC231_0080

dtd

ItbR

dut

metK

coaA

rpml

CpC231_182

mntD

trps

oppB6

CpC231_0538

miaA

qcrC

rsml

CpC231_1834

chrA

fmt

purK

CpC231_1557

gldA

pepC1

guaB

res $B$

topA

CpC231_0569

$\operatorname{lig} A$

CpC231_0095

$\operatorname{ctp} A$

dapA1

yrpB

dapA

hmuU
464 Membrane;

488 Membrane;

693 Cytoplasmic;

155 Membrane;

1332 Cellwall;

297 Cytoplasmic;

101 Cytoplasmic;

137 Membrane;

785 Membrane;

207 Cytoplasmic;

428 Cytoplasmic;

478 Cytoplasmic;

1199 Cytoplasmic;

319 Cytoplasmic;

191 Extracellular;

295 Cytoplasmic;

310 Cytoplasmic;

953 Cytoplasmic;

558 Extracellular;

343 Cytoplasmic;

230 Extracellular;

277 Cytoplasmic;

366 Cytoplasmic;

452 Cytoplasmic;

262 Cytoplasmic;

167 Cytoplasmic;

457 Cytoplasmic;

161 Cytoplasmic;

191 Cytoplasmic;

376 Cytoplasmic;

280 Membrane;

479 Cytoplasmic;

832 Membrane;

350 Membrane;

270 Membrane;

144 Cytoplasmic;

241 Membrane;

153 Cytoplasmic;

409 Cytoplasmic;

308 Cytoplasmic;

64 Cytoplasmic;

471 Membrane;

293 Membrane;

387 Cytoplasmic;

321 Membrane;

290 Cytoplasmic;

323 Cytoplasmic;

298 Membrane;

301 Cytoplasmic;

84 Extracellular;

199 Cytoplasmic;

313 Cytoplasmic;

401 Cytoplasmic;

232 Cytoplasmic;

358 Cytoplasmic;

433 Extracellular;

506 Membrane;

466 Membrane;

984 Cytoplasmic;

92 Extracellular;

694 Cytoplasmic;

286 Cytoplasmic;

796 Membrane;

275 Cytoplasmic;

349 Membrane;

301 Cytoplasmic;

321 Membrane;
No

No

No

No

No

No

No

No

No

No

No

No

No

No

Yes

No

No

No

Yes

No

No

No

No

No

No

No

No

No

No

No

No

No

Yes

No

No

No

No

No

No

No

No

No

No

No

No

Yes

No

No

No

No

No

No

No

No

No

No

No

No

No

Yes

No

No

No

No

No

No

Yes 


\section{Anexo 1}

793 D9QA86 Iron ABC transporter permease 794 D9QCK6 Ferredoxin/ferredoxin-NADP reductase 795 D9QC50 ATP-dependent helicase dinG-like protein 796 D9QC82 ATP-binding/permease protein cydD

797 D9QE82 Transcription termination/antitermination protein NusG 798 D9Q9D0 Dolichyl-phosphate-mannose-protein mannosyltransferase 799 D9QC66 Uncharacterized protein 800 D9QET5 Lipoprotein LpqB 801 D9QBP1 N-acetyl glucosamine related protein 802 D9Q9G1 Multicopper oxidase 803 D9QAT5 Threonine--tRNA ligase 804 D9QCQ0 Uncharacterized protein 805 D9QBA5 Uncharacterized protein 806 D9QEX4 Uncharacterized protein 807 D9Q9A9 Nucleotidyltransferase substrate binding domain protein 808 D9QAZ0 Uncharacterized protein 809 D9QD84 Iron siderophore binding protein 810 D9QEX8 Trypsin

811 D9Q9B9 Molybdenum cofactor biosynthesis protein B 812 D9QC12 ABC transporter ATP-binding protein 813 D9QA04 2-hydroxyhepta-2,4-diene-1,7-dioate isomerase 814 D9QB17 Riboflavin biosynthesis protein 815 D9QDB2 LPXTG domain-containing protein 816 D9QDW3 $\mathrm{Na}(+) / \mathrm{H}(+)$ antiporter subunit $\mathrm{E}$ 817 D9QA17 D-alanine--D-alanine ligase 818 D9QBI2 Glyoxalase/bleomycin resistance protein/dioxygenase 819 D9QDL0 DNA-3-methyladenine glycosylase 1 820 D9QCS8 Oxidoreductase 821 D9QDG2 Chromosome partitioning protein parA 822 F9Y363 Uncharacterized protein

823 D9QD34 ABC transporter ATP-binding protein 824 D9QC30 HTH-type transcriptional regulator EthR 825 D9QA22 ATP-dependent DNA helicase 826 D9QCV9 Glycosyltransferase

827 D9QDQ9 tRNA-specific adenosine deaminase 828 D9QB34 Methylated-DNA--protein-cysteinemethyltransferase 829 D9QCS6 Phosphate transporter 830 D9QDV0 Uncharacterized protein 831 D9QC85 tRNA-dihydrouridine synthase 832 D9QBC2 Uncharacterized protein 833 D9QD86 Serine/threonine-protein kinase 834 D9QCJ9 ABC superfamily ATP binding cassette transporter protein 835 D9QA94 UPF0225 protein 836 D9QBK1 Uncharacterized protein

837 D9QAX5 Phosphoenolpyruvate-protein phosphotransferase

838 D9QEB8 30 S ribosomal protein S10

839 D9QC06 Nitroreductase

840 D9QD60 DNA gyrase subunit B

841 D9QC29 Bacterioferritin comigratory protein

842 D9QAA4 DEAD-box helicase

843 D9QD39 Cation transport protein

844 D9QE22 Deoxyribose-phosphate aldolase

845 F9Y381 Uncharacterized protein

846 D9QAC0 Precorrin-3B synthase

847 D9QAF4 Phosphatidylethanolamine-binding protein

848 D9Q984 Uncharacterized protein

849 D9QBZ3 Pirin C-terminal domain-containing protein

850 D9QCR2 Membrane protein

851 D9QDY6 Uncharacterized protein

852 D9QAS2 Holliday junction ATP-dependent DNA helicase RuvA

853 D9QEB4 Uncharacterized protein

$854 \mathrm{D} 9 \mathrm{QCl} 5 \mathrm{Na}(+) / \mathrm{H}(+)$ antiporter subunit $\mathrm{C}$

855 D9QCV4 Uncharacterized protein

856 D9QBX2 50 S ribosomal protein L27

857 F9Y350 Uncharacterized protein

858 D9Q9X5 Aspartyl/glutamyl-tRNA(Asn/Gln) amidotransferase subun 859 D9QDW6 $\mathrm{Na}(+) / \mathrm{H}(+)$ antiporter subunit $A$

ciuC
CpC231_1826
dinG
cydD
nusG
CpC231_0673

CpC231_1680 Ipq $\bar{B}$

CpC231_1501

CpC231_0705 thrs

CpC231_1871

CpC231_1360

CpC231_0560

CpC231_0652

CpC231_1241

fag $\bar{D}$

sprT

moaB

CpC231_1626

mhpD

$\mathrm{ribF}$

CpC231_2048

mrpE

ddl

CpC231_1438

$\operatorname{tag} \mathrm{A}$

CpC231_1902

parA

CpC231_1042a

CpC231_2011

ethR

recG

CpC231_1934

$\operatorname{tad} A$

ada

pitB

CpC231_0178

CpC231_1700

CpC231_1377

pknB

CpC231_1819

CpC231_0992

CpC231_1460

ptsl

rpsJ

CpC231_1620

gyr $\bar{B}$

bcp

deaD2

CpC231_2016

deoC

CpC231_1753a

cobG

CpC231_1054

CpC231_0627

CpC231_1607

CpC231_1885

CpC231_0215

ruvA

CpC231_0345

$\mathrm{mrp} \overline{\mathrm{C}} 1$

CpC231_1929

rpmA

CpC231_0691a

gatC

mrpA
343 Membrane;

450 Cytoplasmic;

664 Cytoplasmic;

522 Membrane;

276 Cytoplasmic;

577 Membrane;

144 Cytoplasmic;

561 Extracellular;

273 Cytoplasmic;

547 Cytoplasmic;

689 Cytoplasmic;

304 Cytoplasmic;

225 Membrane;

51 Extracellular; 298 Cytoplasmic; 450 Cytoplasmic; 350 Membrane;

224 Membrane;

212 Cytoplasmic;

307 Cytoplasmic;

265 Cytoplasmic;

332 Cytoplasmic;

62 Extracellular;

139 Membrane;

363 Cytoplasmic;

164 Membrane;

220 Cytoplasmic;

170 Cytoplasmic

330 Cytoplasmic;

32 Extracellular;

292 Cytoplasmic;

217 Cytoplasmic;

704 Membrane;

401 Cytoplasmic;

158 Cytoplasmic;

173 Cytoplasmic;

534 Membrane;

233 Cytoplasmic;

384 Cytoplasmic;

332 Extracellular:

664 Membrane;

309 Cytoplasmic;

129 Cytoplasmic;

59 Cytoplasmic

567 Cytoplasmic;

101 Cytoplasmic;

492 Cytoplasmic

681 Cytoplasmic;

159 Cytoplasmic;

435 Membrane;

67 Cytoplasmic;

197 Cytoplasmic;

37 Extracellular

438 Cytoplasmic;

178 Extracellular;

59 Cytoplasmic;

336 Cytoplasmic;

202 Extracellular;

166 Membrane;

203 Membrane;

153 Cytoplasmic;

160 Membrane;

62 Cytoplasmic;

88 Cytoplasmic;

97 Cytoplasmic;

97 Cytoplasmic;

989 Membrane;

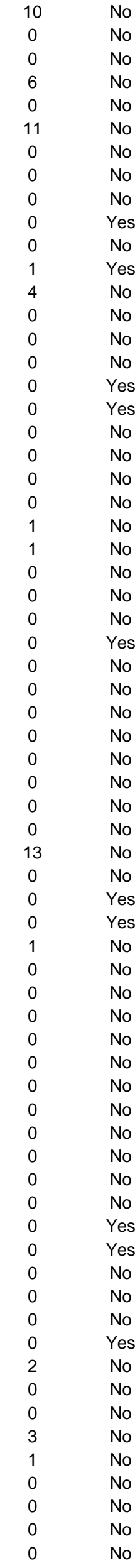




\section{Anexo 1}

860 D9Q9L4 MutT-like protein

861 F9Y333 Uncharacterized protein

862 D9QAP6 Alanine--tRNA ligase

863 D9QB36 Cob (I) yrinic acid a,c-diamide adenosyltransferase

864 D9QAV0 Uncharacterized protein

865 D9QEP6 Uncharacterized protein

866 D9QAL6 Ribosomal RNA small subunit methyltransferase B

867 D9Q9G7 Transcriptional regulator, MazG family

868 D9QDB0 ABC-type antimicrobial peptide transport system, ATPase

869 D9QEM0 Hemin-binding periplasmic protein hmuT

870 D9QCP6 Sortase A

871 D9Q934 Uncharacterized protein

872 D9QE13 Uncharacterized protein

873 D9Q9X2 DNA polymerase III subunit epsilon

874 D9QA34 30S ribosomal protein S1

875 D9QDE7 Predicted Na+-dependent transporter

876 D9QAV1 Uncharacterized protein

877 D9Q915 TetR family transcriptional regulator

878 D9QCNO Uncharacterized protein

879 D9QCE3 Uncharacterized protein

880 D9QA68 ADP-ribose pyrophosphatase (ADPRase)

881 D9QAR7 Oligopeptide-binding protein oppA

882 D9QDM9 Uncharacterized protein

883 D9QBB6 L-threonine dehydratase

884 D9QCG9 Rhodanese-related sulfurtransferase

885 D9QAH8 UPF0210 protein CpC231

886 D9Q9M3 GTP-binding protein TypA/BipA

887 D9QAD7 tRNA (adenine(58)-N(1))-methyltransferase Trml

888 D9QDX2 Uncharacterized metallophosphoesterase ykuE

889 D9Q9H6 Transcription elongation factor GreA

890 D9QBP0 Acyl carrier protein

891 D9Q9S1 Uncharacterized protein

892 D9QB00 Transcriptional regulator ClgR

893 D9QAl1 Uncharacterized protein

894 D9Q9Y3 Iron(3+)-hydroxamate-binding protein fhuD

895 D9QA23 Biotin/lipoyl attachment protein

896 D9QE34 Sensory transduction protein regX3

897 D9QC15 Uncharacterized protein

898 D9QCW6 Uncharacterized protein

899 D9QC71 LPxTG domain-containing protein

900 D9QDB7 Glucosamine-6-phosphate deaminase

901 D9QCF1 SPFH domain/Band 7 family protein

902 D9QEE4 50S ribosomal protein L18

903 D9QDQ6 Pyridoxal 5;

904 D9Q9W4 NUDIX hydrolase

905 D9QC43 Ribonuclease PH

906 D9Q9P0 Uncharacterized protein

907 D9QA78 Cytidylate kinase

908 D9QDG3 Ribosomal RNA small subunit methyltransferase G

909 D9QDU6 Aspartate-semialdehyde dehydrogenase

910 D9Q945 Carbonic anhydrase

911 D9Q9F2 Short chain dehydrogenase

912 D9QAX2 Uncharacterized protein

913 D9QET0 Uncharacterized protein

914 D9QEQ3 Uncharacterized protein

915 D9QBC5 DNA polymerase IV

916 D9QD87 Serine/threonine-protein kinase

917 D9Q9T9 Homoserine kinase

918 D9QCL2 Uncharacterized protein

919 D9QDP4 O-antigen export system ATP-binding protein R

920 D9Q985 Uncharacterized protein

921 D9Q9A8 TetR family regulatory protein

922 D9QCM1 Cytochrome c nitrate reductase, small subunit

923 D9QCV8 Uncharacterized protein

924 D9QDT7 Deoxyribose-phosphate aldolase

925 D9QCG7 D-alanyl-D-alanine carboxypeptidase

926 D9QBC8 Antigen 84

\begin{tabular}{|c|c|c|c|}
\hline mutT1 & 128 Cytoplasmic; & 0 & No \\
\hline CpC231_0021b & 32 Extracellular; & 0 & Yes \\
\hline alas & 890 Cytoplasmic; & 0 & No \\
\hline cobO & 206 Cytoplasmic; & 0 & No \\
\hline СpC231_1200 & 165 Membrane; & 2 & No \\
\hline СpC231_0482 & 52 Cytoplasmic; & 0 & No \\
\hline fmu & 504 Cytoplasmic; & 0 & No \\
\hline CpC231_0711 & 205 Cytoplasmic; & 0 & No \\
\hline CpC231_2046 & 227 Membrane; & 0 & No \\
\hline hmuT & 351 Cytoplasmic; & 0 & Yes \\
\hline srtA & 296 Membrane; & 2 & No \\
\hline CpC231_0573 & 87 Cytoplasmic; & 0 & No \\
\hline CpC231_0242 & 71 Extracellular; & 0 & No \\
\hline dnaQ2 & 232 Cytoplasmic; & 0 & No \\
\hline rpsA & 487 Cytoplasmic; & 0 & No \\
\hline CpC231_2083 & 322 Membrane; & 10 & No \\
\hline СpC231_1201 & 97 Cytoplasmic; & 0 & No \\
\hline tetR2 & 209 Cytoplasmic; & 0 & No \\
\hline CpC231_1850 & 187 Membrane; & 2 & No \\
\hline CpC231_1762 & 56 Extracellular; & 0 & No \\
\hline nudF & 222 Cytoplasmic; & 0 & No \\
\hline орpA4 & 546 Cytoplasmic; & 0 & Yes \\
\hline СpC231_0104 & 74 Cytoplasmic; & 0 & No \\
\hline ilvA & 434 Cytoplasmic; & 0 & No \\
\hline CpC231_1789 & 94 Cytoplasmic; & 0 & No \\
\hline CpC231_1078 & 454 Cytoplasmic; & 0 & No \\
\hline typ $\bar{A}$ & 636 Cytoplasmic; & 0 & No \\
\hline $\operatorname{pimT}$ & 278 Cytoplasmic; & 0 & No \\
\hline ykuE & 312 Cytoplasmic; & 0 & Yes \\
\hline greA & 173 Cytoplasmic; & 0 & No \\
\hline acp & 101 Cytoplasmic; & 0 & No \\
\hline CpC231_0815 & 194 Membrane; & 0 & Yes \\
\hline $\operatorname{clg} \bar{R}$ & 129 Cytoplasmic; & 0 & No \\
\hline CpC231_1081 & 51 Extracellular; & 0 & No \\
\hline fhuD & 355 Extracellular; & 0 & Yes \\
\hline yngHB & 74 Cytoplasmic; & 0 & No \\
\hline regX3 & 231 Cytoplasmic; & 0 & No \\
\hline СpC231_1629 & 39 Extracellular; & 0 & No \\
\hline CpC231_1941 & 115 Membrane; & 4 & No \\
\hline CpC231_1686 & 725 Extracellular; & 0 & Yes \\
\hline nag $B$ & 259 Cytoplasmic; & 0 & No \\
\hline CpC231_1770 & 314 Membrane; & 2 & No \\
\hline $\mathrm{rpI} \overline{\mathrm{R}}$ & 135 Cytoplasmic; & 0 & No \\
\hline $\mathrm{pdxT}$ & 188 Cytoplasmic; & 0 & No \\
\hline CpC231_0859 & 268 Cytoplasmic; & 0 & No \\
\hline $\mathrm{rph}$ & 247 Cytoplasmic; & 0 & No \\
\hline CpC231_0784 & 55 Cytoplasmic; & 0 & No \\
\hline $\mathrm{cmk}$ & 238 Cytoplasmic; & 0 & No \\
\hline gidB & 223 Cytoplasmic; & 0 & No \\
\hline asd & 343 Cytoplasmic; & 0 & No \\
\hline cynT & 240 Cytoplasmic; & 0 & Yes \\
\hline CpC231_0696 & 284 Cytoplasmic; & 0 & No \\
\hline CpC231_1223 & 138 Cytoplasmic; & 1 & No \\
\hline CpC231_0516 & 117 Cytoplasmic; & 0 & No \\
\hline CpC231_0489 & 82 Extracellular; & 0 & No \\
\hline $\operatorname{din} \bar{B}$ & 464 Cytoplasmic; & 0 & No \\
\hline pknA & 506 Membrane; & 1 & No \\
\hline thrB & 307 Cytoplasmic; & 0 & No \\
\hline CpC231_1832 & 55 Extracellular; & 1 & No \\
\hline $\mathrm{rfb} \overline{\mathrm{D}}$ & 301 Membrane; & 6 & No \\
\hline CpC231_0628 & 92 Cytoplasmic; & 0 & No \\
\hline amtR & 227 Cytoplasmic; & 0 & No \\
\hline nrfC & 161 Extracellular; & 1 & No \\
\hline CpC231_1933 & 489 Membrane; & 12 & No \\
\hline $\operatorname{deo} \bar{C}$ & 221 Cytoplasmic; & 0 & No \\
\hline pbp4 & 394 Membrane; & 0 & \\
\hline ag84 & 338 Cytoplasmic; & 0 & \\
\hline
\end{tabular}


Anexo 1

927 D9Q9K8 Uncharacterized protein

CpC231_0752

928 D9QA01 Predicted signal-transduction protein containing cAMP-bin CpC231 0898

929 D9QD81 ATP binding cytoplasmic membrane protein

fag $\bar{C}$

930 D9QE19 Uncharacterized protein

CpC231 0248

931 D9QC09 Uncharacterized protein

932 D9Q9F6 Peptidyl-tRNA hydrolase 1

CpC231_1623

pth1

933 D9QCJ3 Transcriptional regulator, Fis family

CpC231 1813

934 D9QA08 Uncharacterized protein

935 D9QAD9 RecB family nuclease

936 D9QAW7 Alkyl hydroperoxide reductase subunit $\mathrm{C}$

CpC231_0905

recB

ahpC

937 D9QBR2 DNA repair protein $\mathrm{RecO}$

938 D9QD92 Uncharacterized protein

939 D9Q9L8 Oligopeptide transport ATP-binding protein OppD

940 D9QCI9 $\mathrm{Na}(+) / \mathrm{H}(+)$ antiporter subunit $\mathrm{G}$

941 D9QBZ2 Uncharacterized protein

942 D9Q9B6 Two component system response regulator

943 D9QAQ6 L-serine dehydratase

944 D9QDM2 Uncharacterized protein

945 D9Q9J6 Exodeoxyribonuclease 7 small subunit

946 D9QBQ5 Uncharacterized protein

947 D9QD93 CAAX amino terminal protease family

948 D9QAS1 Holliday junction ATP-dependent DNA helicase RuvB

949 D9QCS7 Uncharacterized protein

950 D9QE69 O-succinylbenzoic acid--CoA ligase

951 D9Q987 Glutaredoxin

$\mathrm{recO}$

CpC231_0037

oppD2

mrpG1

CpC231_1606

tcsR4

sdaB

CpC231_0097

xse $\bar{B}$

CpC231_1515

CpC231_0038

ruvB

CpC231_1901

menE

CpC231_0630

952 D9QDM7 Decaprenylphosphoryl-D-2-keto erythropentose reductase CpC231_0102

953 D9QAH9 Uncharacterized protein

954 D9QD94 Uncharacterized protein

CpC231_1079

СpC231 0039

955 D9QAW9 Uncharacterized protein

956 D9QCU0 Urease subunit beta

957 D9QB64 PTS system mannose-specific ElIBCA component

958 D9QDL1 Short-chain dehydrogenase/reductase yusR

959 D9QC03 Uncharacterized protein

960 D9QC22 Oligoribonuclease

961 D9QAT8 Copper resistance protein CopC

962 D9QE50 Delta-aminolevulinic acid dehydratase

963 D9QBH5 Adenosylcobinamide-GDP ribazoletransferase

964 D9QAV6 Uncharacterized protein

965 D9Q9U7 Uncharacterized protein

966 D9QCJ4 Peptide deformylase

967 D9Q967 Superoxide dismutase [Cu-Zn]

968 D9Q9P3 Alpha-acetolactate decarboxylase

969 D9QB54 30 S ribosomal protein S2

970 D9QDA8 Uncharacterized protein

971 D9QBV7 LysE type translocator

972 D9QCB3 Trk system potassium uptake protein trkH

973 D9QEN3 Uncharacterized protein

CpC231_1220

ureB

manP

yusR

CpC231_1617

orn

copC

hemB

cobs

CpC231_1207

CpC231_0842

def

sodC

alsD

rpsB

CpC231_2044

CpC231_1571

trkH

974 D9QCX5 Uncharacterized protein

975 D9Q9K4 Phosphonoacetate hydrolase

976 D9QDE4 Tryptophan synthase beta chain

977 D9QBN8 Pyruvate dehydrogenase E1 component

978 D9QC34 Two-component system sensor kinase protein

979 D9QEE0 L-asparaginase

CpC231_0469

CpC231_1950

phnA

$\operatorname{trpB}$

aceE

tcsS5

ansA

980 D9QDQ0 Glyoxalase/Bleomycin resistance protein/Dihydroxybiphen! CpC231_0126

981 D9QCH3 Multiple antibiotic resistance protein marR

marR2

982 D9Q911 Uncharacterized protein

983 D9QEJ8 Phage shock protein C

984 D9QAF5 Fructose-specific phosphotransferase enzyme IIA compon

985 D9QCP2 Gram-positive anchor

986 D9Q9F8 Pullulanase

987 D9QAS8 6-carboxyhexanoate--CoA ligase

988 D9QDI5 Biotin synthase

989 D9Q966 Acetyl-CoA carboxylase carboxyl transferase

990 F9Y371 Uncharacterized protein

991 D9QER1 Uncharacterized protein

992 D9QBE5 Uncharacterized protein

993 D9QAR5 GTP pyrophosphokinase

CpC231_0725

psp $\bar{C}$

levD

CpC231 1863

pulA

biow

bioB

accDA

CpC231_1417a

CpC231_0497

CpC231 1400

relA

308 Membrane;

637 Membrane;

288 Membrane;

116 Extracellular;

326 Membrane;

135 Cytoplasmic;

92 Cytoplasmic;

469 Extracellular;

303 Cytoplasmic;

198 Cytoplasmic;

242 Cytoplasmic;

317 Cytoplasmic;

558 Membrane;

120 Membrane;

258 Extracellular;

230 Cytoplasmic;

468 Cytoplasmic;

180 Membrane;

98 Cytoplasmic;

175 Extracellular;

237 Membrane;

365 Cytoplasmic;

37 Extracellular;

375 Cytoplasmic;

84 Extracellular;

253 Cytoplasmic;

75 Cytoplasmic;

176 Membrane;

342 Membrane;

103 Cytoplasmic;

677 Membrane;

233 Membrane;

50 Extracellular;

219 Cytoplasmic;

190 Extracellular;

335 Cytoplasmic;

273 Membrane;

79 Cytoplasmic;

144 Membrane;

197 Cytoplasmic;

206 Extracellular;

246 Cytoplasmic;

276 Cytoplasmic;

33 Extracellular;

215 Membrane;

444 Membrane;

411 Cytoplasmic;

473 Membrane;

98 Cytoplasmic;

416 Cytoplasmic;

911 Cytoplasmic;

368 Membrane;

358 Cytoplasmic;

267 Cytoplasmic;

146 Cytoplasmic;

166 Cytoplasmic;

350 Membrane;

229 Cytoplasmic;

271 Membrane;

624 Extracellular;

243 Cytoplasmic;

331 Cytoplasmic;

391 Membrane:

53 Cytoplasmic;

67 Cytoplasmic;

104 Extracellular;

759 Cytoplasmic;

\begin{tabular}{|c|c|}
\hline 4 & No \\
\hline 0 & No \\
\hline 0 & No \\
\hline 2 & No \\
\hline 0 & No \\
\hline 0 & No \\
\hline 0 & No \\
\hline 0 & Yes \\
\hline 0 & No \\
\hline 0 & No \\
\hline 0 & No \\
\hline 0 & No \\
\hline 0 & No \\
\hline 3 & No \\
\hline 0 & Yes \\
\hline 0 & No \\
\hline 0 & No \\
\hline 0 & Yes \\
\hline 0 & No \\
\hline 1 & No \\
\hline 7 & No \\
\hline 0 & No \\
\hline 1 & No \\
\hline 0 & No \\
\hline 0 & No \\
\hline 0 & No \\
\hline 2 & No \\
\hline 2 & No \\
\hline 6 & No \\
\hline 0 & No \\
\hline 10 & No \\
\hline 0 & Yes \\
\hline 0 & No \\
\hline 0 & No \\
\hline 1 & Yes \\
\hline 0 & No \\
\hline 7 & No \\
\hline 0 & No \\
\hline 4 & No \\
\hline 0 & No \\
\hline 0 & Yes \\
\hline 0 & No \\
\hline 0 & No \\
\hline 0 & No \\
\hline 6 & No \\
\hline 9 & No \\
\hline 0 & No \\
\hline 11 & No \\
\hline 0 & No \\
\hline 0 & No \\
\hline 0 & No \\
\hline 6 & No \\
\hline 0 & Yes \\
\hline 0 & No \\
\hline 0 & No \\
\hline 0 & No \\
\hline 4 & No \\
\hline 0 & No \\
\hline 1 & Yes \\
\hline 0 & No \\
\hline 0 & No \\
\hline 0 & No \\
\hline 0 & No \\
\hline 0 & No \\
\hline 2 & No \\
\hline 0 & No \\
\hline 0 & No \\
\hline
\end{tabular}




\section{Anexo 1}

994 D9QCM8 ABC transporter ATP-binding protein YxIF 995 D9QBX9 Uncharacterized protein 996 D9QEV7 Uncharacterized protein 997 F9Y342 Uncharacterized protein 998 D9QCM7 Uncharacterized transmembrane protein yxIG 999 D9QEL6 Uncharacterized protein 1000 D9QDX6 Uncharacterized protein 1001 D9QED4 Uncharacterized protein 1002 D9QAE9 Aldo/keto reductase family oxidoreductase 1003 D9QA00 3-isopropylmalate dehydrogenase 1004 D9QAC7 Dipeptidase pepE

1005 D9QE68 1,4-dihydroxy-2-naphthoate octaprenyltransferase 1006 D9QAX0 ATP-dependent RNA helicase hrpA

1007 D9QCY0 Glycosyltransferase

1008 D9QBJ3 rRNA biogenesis protein rrp5

1009 D9QEF8 L,D-transpeptidase catalytic domain, region YkuD 1010 D9QC44 Metal-dependent hydrolase 1011 D9QDX1 Uncharacterized protein

1012 D9QEE7 50 S ribosomal protein L15

1013 D9QC37 Uncharacterized protein

1014 D9QDM4 Glycine betaine-binding protein

1015 D9QDC8 CAAX amino terminal protease

1016 D9QBL1 Uncharacterized protein

1017 D9QDA0 Uncharacterized protein

1018 F9Y330 Uncharacterized protein

1019 D9QAD4 Prokaryotic ubiquitin-like protein Pup

1020 D9QEU7 Cys-tRNA(Pro)/Cys-tRNA(Cys) deacylase

1021 D9QED3 Uncharacterized protein

1022 D9QEJ9 Two-component system sensor kinase

1023 D9QBV6 30S ribosomal protein S20

1024 D9QA13 3-isopropylmalate dehydratase small subunit

1025 D9QER4 Uncharacterized protein

1026 D9QBL6 MutT/NUDIX family protein

1027 D9QAJ9 OxPP cycle protein opcA

1028 D9QBJ1 Phage-associated protein

1029 D9QDX5 Transcriptional regulator WhiB

1030 D9QEA0 Uncharacterized protein

1031 D9QA19 Thiamine-monophosphate kinase

1032 D9QE23 Uncharacterized protein

1033 D9QAE6 Uncharacterized protein

1034 D9QEN7 HTH-type transcriptional regulator

1035 D9QAJ8 Glucose-6-phosphate 1-dehydrogenase

1036 D9Q975 Multidrug resistance protein norM

1037 D9QD27 Probable queuosine precursor transporter

1038 D9QDQ7 Prephenate dehydrogenase

1039 D9QEJ7 Uncharacterized protein

1040 D9QEU3 Stearoyl-CoA 9-desaturase

1041 D9QCY7 Spermidine/putrescine import ATP-binding protein PotA

1042 D9QAP3 Endolytic murein transglycosylase

1043 D9QDV1 Uncharacterized protein

1044 D9QEE2 30S ribosomal protein S8

1045 D9QBI1 Glycine cleavage system $\mathrm{H}$ protein

1046 D9Q937 Histidinol-phosphatase

1047 D9QAQ5 NADPH-dependent FMN reductase

1048 D9QCA1 Protein Nrdl

1049 D9Q969 2,5-diketo-D-gluconic acid reductase A

1050 D9QAM6 Orotidine 5;

1051 D9QBV8 Ankyrin domain-containing protein

1052 D9QC48 ATP-dependent Clp protease adapter protein ClpS

1053 F9Y368 Uncharacterized protein

1054 D9Q990 3;

1055 D9QDT9 Uncharacterized protein

1056 D9QEE6 50 S ribosomal protein L30

1057 D9QBN3 Low molecular weight protein-tyrosine-phosphatase

1058 D9QCA6 Phosphoribosylformylglycinamidine synthase subunit PurS

1059 D9QDA1 DNA protection during starvation protein

1060 D9QDD0 Aldose 1-epimerase

\begin{tabular}{|c|c|c|}
\hline yxIF & 271 Membrane; & 0 \\
\hline CpC231_1593 & 142 Membrane; & 4 \\
\hline CpC231_0543 & 279 Cytoplasmic; & 0 \\
\hline CpC231_0558a & 152 Membrane; & 2 \\
\hline$y x \overline{I G}$ & 226 Membrane; & 5 \\
\hline CpC231_0450 & 108 Membrane; & 3 \\
\hline CpC231_0205 & 51 Extracellular; & 0 \\
\hline СpC231_0365 & 39 Extracellular; & 0 \\
\hline CpC231_1049 & 302 Cytoplasmic; & 0 \\
\hline leu $\bar{B}$ & 339 Cytoplasmic; & 0 \\
\hline pepE & 380 Cytoplasmic; & 0 \\
\hline menA & 291 Membrane; & 9 \\
\hline hrpA & 1332 Cytoplasmic; & 0 \\
\hline glfT1 & 663 Cytoplasmic; & 0 \\
\hline CpC231_1449 & 140 Cytoplasmic; & 0 \\
\hline СpC231_0391 & 246 Extracellular; & 0 \\
\hline CpC231_1658 & 265 Cytoplasmic; & 0 \\
\hline CpC231_0199 & 159 Extracellular; & 0 \\
\hline $\mathrm{rplO}$ & 148 Cytoplasmic; & 0 \\
\hline CpC231_1651 & 252 Cytoplasmic; & 0 \\
\hline opuAC & 291 Cytoplasmic; & 0 \\
\hline CpC231_2064 & 209 Membrane; & 7 \\
\hline CpC231_1470 & 44 Extracellular; & 0 \\
\hline CpC231_2036 & 257 Membrane; & 5 \\
\hline CpC231_0006a & 28 Extracellular; & 0 \\
\hline pup & 64 Extracellular; & 0 \\
\hline ybaK & 167 Cytoplasmic; & 0 \\
\hline CpC231_0364 & 53 Cytoplasmic; & 0 \\
\hline tcsS3 & 398 Membrane; & 6 \\
\hline rpsT & 87 Cytoplasmic; & 0 \\
\hline leuD & 196 Cytoplasmic; & 0 \\
\hline CpC231_0500 & 36 Extracellular; & 0 \\
\hline CpC231_1475 & 178 Cytoplasmic; & 0 \\
\hline CpC231_1099 & 319 Cytoplasmic; & 0 \\
\hline CpC231_1447 & 130 Extracellular; & 0 \\
\hline whiB & 115 Cytoplasmic; & 0 \\
\hline CpC231_0330 & 58 Cytoplasmic; & 1 \\
\hline thiL & 326 Cytoplasmic; & 0 \\
\hline CpC231_0252 & 282 Membrane; & 1 \\
\hline CpC231_1046 & 145 Cytoplasmic; & 0 \\
\hline СpC231_0473 & 158 Membrane; & 0 \\
\hline$z w \bar{f}$ & 531 Cytoplasmic; & 0 \\
\hline norm & 472 Membrane; & 12 \\
\hline CpC231_2004 & 258 Membrane; & 6 \\
\hline $\operatorname{tyr} \bar{A}$ & 337 Cytoplasmic; & 1 \\
\hline CpC231_0431 & 149 Cytoplasmic; & 0 \\
\hline $\operatorname{des} \mathrm{A} 3$ & 424 Cytoplasmic; & 0 \\
\hline potA & 258 Membrane; & 0 \\
\hline yceG & 382 Extracellular; & 1 \\
\hline CpC231_0179 & 68 Extracellular; & 0 \\
\hline $\mathrm{rps} \overline{\mathrm{H}}$ & 132 Cytoplasmic; & 0 \\
\hline gcvH & 128 Cytoplasmic; & 0 \\
\hline hisN & 268 Cytoplasmic; & 0 \\
\hline CpC231_1155 & 178 Membrane; & 0 \\
\hline nrdl & 141 Cytoplasmic; & 0 \\
\hline $\mathrm{dkgA}$ & 286 Cytoplasmic; & 0 \\
\hline pyrF & 279 Cytoplasmic; & 0 \\
\hline CpC231_1572 & 133 Cytoplasmic; & 0 \\
\hline $\mathrm{clp} \overline{\mathrm{S}}$ & 126 Cytoplasmic; & 0 \\
\hline CpC231_1158a & 57 Extracellular; & 0 \\
\hline cys $\bar{Q}$ & 294 Cytoplasmic; & 0 \\
\hline CpC231_0167 & 518 Extracellular; & 2 \\
\hline $\mathrm{rpmD}$ & 61 Cytoplasmic; & 0 \\
\hline ptpA & 141 Cytoplasmic; & 0 \\
\hline purs & 79 Cytoplasmic; & 0 \\
\hline dps & 163 Cytoplasmic; & 0 \\
\hline CpC231_2066 & 179 Membrane; & 0 \\
\hline
\end{tabular}


Anexo 1

1061 D9Q9K3 Uncharacterized protein 1062 D9QES9 Uncharacterized protein 1063 D9Q9K2 Uncharacterized protein 1064 F9Y373 Uncharacterized protein 1065 D9QAP5 Uncharacterized protein 1066 D9QCT0 Uncharacterized protein 1067 D9Q9C5 Molybdopterin molybdenumtransferase 1068 F9Y354 Uncharacterized protein 1069 D9Q980 Oligopeptide-binding protein oppA 1070 D9QAH3 1-deoxy-D-xylulose-5-phosphate synthase 1071 D9QCD9 Uncharacterized protein $1072 \mathrm{D} 9 \mathrm{QCl} 8 \mathrm{Na}(+) / \mathrm{H}(+)$ antiporter subunit $\mathrm{F}$

1073 D9QAV5 Type III restriction endonuclease, res subunit 1074 D9QAE2 Aspartate ammonia-lyase

1075 D9QCM3 Uncharacterized protein 1076 D9QCR3 Uncharacterized protein 1077 D9QAY6 Uncharacterized protein 1078 D9QD14 Abi family protein

1079 D9QD96 Zinc ABC transporter substrate-binding protein 1080 D9QC62 Protein Nrdl

1081 D9QEN9 Aminobenzoyl-glutamate utilization protein B 1082 D9QAY9 Uncharacterized protein 1083 D9QB69 30S ribosomal protein S16 1084 F9Y358 Uncharacterized protein 1085 D9QB92 Indole-3-glycerol phosphate synthase 1086 D9Q991 ATP-dependent helicase Ihr 1087 D9QCN3 Fructose-bisphosphate aldolase class 2 1088 D9QE30 Long-chain-fatty-acid--CoA ligase 1089 D9Q9Y7 Lysine exporter protein 1090 F9Y375 Uncharacterized protein 1091 D9Q961 Uncharacterized protein 1092 D9Q979 Alpha-ketoglutarate-dependent taurine dioxygenase 1093 D9QC75 Uncharacterized protein 1094 D9QE78 L-lactate dehydrogenase 1095 D9QCW3 Uncharacterized protein 1096 D9QAS6 Acyl-CoA thioesterase II 1097 D9QDL7 Uncharacterized protein 1098 D9QAA7 Magnesium/cobalt transporter CorA $1099 \mathrm{D} 9 \mathrm{Q} 974 \mathrm{Na}(+) / \mathrm{H}(+)$ antiporter-like protein

1100 D9QE67 Uncharacterized protein

1101 D9QD02 Uncharacterized protein 1102 D9QCD1 Cysteine--tRNA ligase

1103 D9QCE8 Hydrolase, alpha/beta fold family 1104 D9Q9H5 Uncharacterized protein

1105 D9QBN5 Cobalamin biosynthesis protein CobD

1106 D9QBN2 Phosphoglycolate phosphatase

1107 D9QCN5 tRNA/rRNA methyltransferase

1108 D9QDD8 Phytoene Dehydrogenase (Desaturase) 1109 D9QEW6 Endopeptidase La

1110 D9QBG1 Cell-wall peptidase NIpC/P60 protein

1111 D9QE33 Signal-transduction histidine kinase senX3

1112 D9QBX3 50 S ribosomal protein L21

1113 D9QB30 Uncharacterized protein

1114 D9QDZ8 Cold-shock protein

1115 D9QC99 Amidophosphoribosyltransferase 1116 D9QAB1 MFS family major facilitator transporter 1117 D9QEQ6 Biotin-(Acetyl-CoA carboxylase) ligase 1118 D9QCJ1 Putative glutamate--cysteine ligase 2 1119 D9QD46 Single-stranded DNA-binding protein 1120 D9QBW0 Competence protein ComE-like protein 1121 D9Q9V5 ATP synthase epsilon chain 1122 D9Q9G9 Enolase 1123 D9QDG9 $\mathrm{Fe}(3+)$ dicitrate transport system permease protein fecD 1124 D9QE53 Uroporphyrinogen decarboxylase 1125 D9QDD5 UDP-N-acetylglucosamine diphosphorylase 1126 D9QA54 Ornithine carbamoyltransferase 1127 D9QB09 Ribonuclease J

\begin{tabular}{|c|c|c|}
\hline СpC231_0747 & 179 Cytoplasmic; & 0 \\
\hline СpC231_0515 & 57 Extracellular; & 0 \\
\hline СpC231_0746 & 87 Cytoplasmic; & 0 \\
\hline CpC231_1467a & 31 Extracellular; & 0 \\
\hline СpC231_1145 & 36 Extracellular; & 0 \\
\hline CpC231_1904 & 218 Cytoplasmic; & 2 \\
\hline moes & 421 Cytoplasmic; & 0 \\
\hline CpC231_0886a & 55 Extracellular; & 0 \\
\hline оррА-2 & 510 Extracellular; & 0 \\
\hline CpC231_1073 & 195 Cytoplasmic; & 1 \\
\hline CpC231_1758 & 235 Extracellular; & 1 \\
\hline $\mathrm{mrp} \overline{\mathrm{F}} 1$ & 90 Membrane; & 3 \\
\hline CpC231_1206 & 569 Cytoplasmic; & 0 \\
\hline $\operatorname{asp} \bar{A}$ & 476 Cytoplasmic; & 0 \\
\hline CpC231_1843 & 284 Cytoplasmic; & 0 \\
\hline СpC231_1886 & 379 Extracellular; & 0 \\
\hline СpC231_1237 & 174 Membrane; & 0 \\
\hline CpC231_1990 & 290 Cytoplasmic; & 0 \\
\hline $\mathrm{fec} \overline{\mathrm{B}}$ & 332 Extracellular; & 0 \\
\hline nrdl & 145 Membrane; & 0 \\
\hline abgB & 398 Cytoplasmic; & 0 \\
\hline CpC231_1240 & 234 Cytoplasmic; & 0 \\
\hline $\operatorname{rps} \bar{P}$ & 154 Cytoplasmic; & 0 \\
\hline CpC231_0969a & 31 Cytoplasmic; & 0 \\
\hline $\operatorname{trp} \bar{C} 2$ & 273 Cytoplasmic; & 0 \\
\hline Ihr & 1673 Cellwall; & 0 \\
\hline $\mathrm{fbaA}$ & 344 Cytoplasmic; & 0 \\
\hline IcfA1 & 506 Membrane; & 2 \\
\hline lysE & 243 Membrane; & 6 \\
\hline CpC231_1487a & 106 Extracellular; & 0 \\
\hline CpC231_0602 & 300 Cytoplasmic; & 0 \\
\hline $\operatorname{tau} \bar{D}$ & 322 Cytoplasmic; & 0 \\
\hline CpC231_1690 & 50 Cytoplasmic; & 0 \\
\hline Idh & 320 Membrane; & 0 \\
\hline CpC231_1938 & 219 Cytoplasmic; & 0 \\
\hline tesB & 298 Cytoplasmic; & 0 \\
\hline CpC231_0092 & 331 Cytoplasmic; & 0 \\
\hline $\operatorname{cor} \bar{A}$ & 356 Cytoplasmic; & 2 \\
\hline CpC231_0616 & 424 Membrane; & 13 \\
\hline CpC231_0296 & 111 Membrane; & 2 \\
\hline CpC231_1977 & 374 Cellwall; & 1 \\
\hline cys $\bar{S}$ & 465 Cytoplasmic; & 0 \\
\hline pldB1 & 261 Cytoplasmic; & 0 \\
\hline CpC231_0719 & 146 Extracellular; & 0 \\
\hline $\operatorname{cob} \bar{D}$ & 287 Membrane; & 5 \\
\hline pgp & 214 Cytoplasmic; & 0 \\
\hline CpC231_1855 & 223 Cytoplasmic; & 0 \\
\hline crtle & 543 Extracellular; & 0 \\
\hline Ion & 351 Cytoplasmic; & 0 \\
\hline CpC231_1416 & 334 Extracellular; & 0 \\
\hline $\operatorname{sen} \times 3$ & 412 Membrane; & 1 \\
\hline rplU & 101 Cytoplasmic; & 0 \\
\hline CpC231_1282 & 245 Membrane; & 0 \\
\hline $\operatorname{csp} \bar{A}$ & 67 Cytoplasmic; & 0 \\
\hline purF & 520 Cytoplasmic; & 0 \\
\hline CpC231_1010 & 461 Membrane; & 12 \\
\hline bir $\bar{A}$ & 281 Cytoplasmic; & 0 \\
\hline CpC231_1811 & 372 Cytoplasmic; & 0 \\
\hline $\mathrm{ssb} 1$ & 189 Extracellular; & 0 \\
\hline comE & 555 Membrane; & 12 \\
\hline atpC & 123 Cytoplasmic; & 0 \\
\hline eno & 425 Cytoplasmic; & 0 \\
\hline fecD & 374 Membrane; & 10 \\
\hline hemE & 371 Cytoplasmic; & 0 \\
\hline CpC231_2071 & 304 Cytoplasmic; & 0 \\
\hline $\arg \bar{F}$ & 333 Cytoplasmic; & 0 \\
\hline $\mathrm{rnj}$ & 683 Cytoplasmic; & 0 \\
\hline
\end{tabular}




\section{Anexo 1}

1128 D9QEF1 Maltose transport system permease

1129 F9Y370 Uncharacterized protein

1130 D9QBN7 Uncharacterized protein

1131 D9QA24 Ribosomal RNA small subunit methyltransferase D

1132 F9Y382 Uncharacterized protein

1133 D9Q9W5 Uncharacterized protein

1134 D9QAC9 Sec-independent protein translocase protein TatC

1135 D9QA26 Probable membrane transporter protein

1136 D9QAF6 Dihydroxyacetone kinase family protein

1137 D9Q914 Major facilitator superfamily permease

1138 D9Q9M8 N-succinyldiaminopimelate aminotransferase

1139 D9QC24 L,D-transpeptidase YkuD

1140 D9QAB5 RNA polymerase-binding protein RbpA

1141 D9QBM8 Bifunctional RNase $\mathrm{H} /$ acid phosphatase

1142 D9QBX4 Ribonuclease E/G family

1143 D9QCZ0 Peptidoglycan recognition protein

1144 D9QC25 Oxidoreductase

1145 D9QA55 Arginine repressor

1146 D9Q9T4 Lactate utilization protein A

1147 D9QE75 Uncharacterized protein

1148 D9Q9H0 Septum formation initiator protein

1149 D9QCU8 Uncharacterized protein

1150 D9QBT1 Uncharacterized protein

1151 D9QBB3 Ribosome-associated heat shock protein/S4

1152 D9QEL8 Cell-surface hemin receptor

1153 D9QDS8 Uncharacterized protein

1154 D9QEP5 Sulfurtransferase

1155 D9QDH8 Protein dipZ

1156 F9Y359 Uncharacterized protein

1157 D9QCF6 Pantoate--beta-alanine ligase

1158 D9QE36 Ppx/GppA phosphatase family

1159 D9QDD9 Tryptophan-specific permease, 5-methyltryptophan resista

1160 D9QDM3 Uncharacterized protein

1161 D9Q9X7 Mycothiol acetyltransferase

1162 D9QAT7 Lipoprotein

1163 D9Q9C7 Uncharacterized protein

1164 D9QAR9 Protein translocase subunit SecD

1165 D9QBT7 Uncharacterized protein

1166 D9QA48 Phenylalanine--tRNA ligase alpha subunit

1167 D9QBK9 Uncharacterized protein htaC

1168 D9Q944 Uncharacterized protein

1169 D9QC80 Cytochrome d ubiquinol oxidase subunit 1

1170 D9QAL5 Ribulose-phosphate 3-epimerase

1171 D9QEW1 NADH pyrophosphatase

1172 D9QDF4 Uncharacterized protein

1173 F9Y357 Uncharacterized protein

1174 D9QAB6 Polyprenol-phosphate-mannose synthase domain 1

1175 D9QDB9 N-acylglucosamine-6-phosphate 2-epimerase

1176 F9Y337 Uncharacterized protein

1177 D9QDJ0 Lysozyme M1

1178 D9QAZ8 Cobalt transport protein cbiQ

1179 D9QBB5 Uncharacterized protein

1180 D9Q9Q3 Uncharacterized protein

1181 D9QAN2 Epimerase family protein yfcH

1182 D9QCY6 UDP-galactopyranose mutase

1183 D9Q942 Cell division protein FtsX

1184 D9QC45 Glutamate racemase

1185 D9QEP3 Uncharacterized protein

1186 D9QCT7 Urease accessory protein UreF

1187 D9QBM5 Uncharacterized protein

1188 D9QBF2 Alpha mannopyranosyltransferase

1189 D9QC47 Uncharacterized protein

1190 D9QEW0 Trk system potassium uptake protein trkA

1191 D9QCN9 Uncharacterized protein

1192 D9QEC2 50S ribosomal protein L2

1193 D9QCG8 Inorganic pyrophosphatase

1194 D9QB65 Uncharacterized protein
malG

CpC231_1199a

CpC231_1497

rsmD

CpC231_1864a

CpC231_0860

tatC

CpC231_0923

dhat

CpC231_0728

dapC

ykuD

rbpA

CpC231_1488

rne

CpC231 1965

CpC231_1639

$\arg R$

lutA

CpC231_0304

CpC231 0714

CpC231_1922

CpC231_1542

CpC231_1368

htaB

CpC231_0155

cysA

dipZ

CpC231_0987a

panC

gppA1

trpF

CpC231_0098

$\mathrm{msh}$

CpC231_1187

CpC231_0670

$\sec D$

CpC231_1549

phes

CpC231_1468

CpC231_0584

cydA

rpe

nudC

CpC231 2090

CpC231_0938a

ppm1

nanE

CpC231_0416a

CpC231_0064

bioN

CpC231_1370

CpC231_0797

CpC231_1132

glf

$\mathrm{fts} X$

murl

CpC231_0479

ureF

CpC231_1485

mptA

CpC231_1661

trkA

CpC231_1860

rplB

ppa

CpC231_1319
292 Membrane;

56 Extracellular;

145 Cytoplasmic;

192 Cytoplasmic;

28 Extracellular;

403 Cytoplasmic;

362 Membrane;

247 Membrane;

215 Cytoplasmic;

566 Membrane;

364 Cytoplasmic;

396 Extracellular;

130 Cytoplasmic;

385 Cytoplasmic;

1134 Cellwall;

675 Extracellular;

332 Cytoplasmic;

163 Cytoplasmic;

261 Cytoplasmic;

151 Membrane;

180 Membrane;

221 Membrane

222 Membrane;

124 Cytoplasmic;

167 Membrane;

78 Cytoplasmic;

292 Cytoplasmic;

545 Membrane;

48 Cytoplasmic;

222 Cytoplasmic;

290 Cytoplasmic;

160 Membrane;

300 Membrane;

164 Extracellular;

201 Membrane;

387 Cytoplasmic;

622 Membrane;

182 Membrane;

351 Cytoplasmic;

299 Extracellular;

41 Extracellular;

507 Membrane;

224 Cytoplasmic;

219 Membrane;

948 Cellwall;

36 Extracellular;

265 Cytoplasmic

229 Cytoplasmic;

33 Cytoplasmic;

389 Extracellular;

204 Membrane;

211 Cytoplasmic;

220 Membrane;

459 Membrane;

411 Cytoplasmic;

300 Membrane;

297 Membrane;

128 Cytoplasmic;

228 Cytoplasmic;

61 Cytoplasmic;

490 Membrane;

178 Cytoplasmic;

359 Membrane;

31 Extracellular;

280 Cytoplasmic;

158 Cytoplasmic;

134 Cytoplasmic;
No

No

No

No

No

No

No

No

No

No

Yes

No

No

No

Yes

No

No

No

No

No

No

No

No

No

No

No

No

No

No

No

No

No

Yes

No

No

No

No

Yes

No

No

No

No

Yes

No

No

No

No

Yes

No

No

Yes

No

No

No

No

No

No

No

No

No

No

No

No

No

No 


\section{Anexo 1}

1195 D9QDC5 Oligopeptide transport ATP-binding protein OppF 1196 D9Q9Q6 Uncharacterized protein

1197 F9Y331 Uncharacterized protein 1198 D9QEY2 Uncharacterized protein 1199 D9Q9H9 Uncharacterized protein 1200 D9QB73 Signal recognition particle receptor FtsY 1201 D9Q9H4 Uncharacterized protein

1202 D9QC02 Single-strand binding protein 1203 D9QD75 Uncharacterized protein 1204 D9QD44 Uncharacterized protein 1205 D9QD78 CRISPR-associated protein Cas5 1206 D9QBE3 Ribosomal RNA small subunit methyltransferase $\mathrm{H}$ 1207 D9QAB2 Uncharacterized protein 1208 D9QCZ5 Uncharacterized protein 1209 D9Q9W6 Electron transfer flavo protein subunit beta 1210 D9QEF4 Glycerol-3-phosphate-transporting ATPase 1211 D9QBV9 DNA polymerase III subunit delta 1212 D9QBF1 Geranylgeranyl pyrophosphate synthase 1213 D9QAV7 Uncharacterized protein 1214 D9QAU3 Uncharacterized protein 1215 D9QCH5 Uncharacterized protein 1216 D9QE28 Uncharacterized protein 1217 D9QC98 Phosphoribosylformylglycinamidine cyclo-ligase 1218 D9QCP5 Uncharacterized protein 1219 D9QCY5 Glycerol-3-phosphate transporter 1220 D9QBW7 Phosphoglycerate dehydrogenase 1221 D9Q9C0 Uncharacterized protein 1222 D9QBF3 Transcription regulator

1223 D9QAS0 Preprotein translocase subunit YajC 1224 D9QCB6 Uncharacterized protein 1225 D9QA87 Iron ABC transporter ATP-binding protein 1226 D9QD05 Glycerophosphoryl diester phosphodiesterase 1227 D9QBQ8 HTH-type transcriptional regulator 1228 F9Y360 Uncharacterized protein 1229 D9QCE2 Uncharacterized protein 1230 D9QAU1 Peptide-methionine (R)-S-oxide reductase 1231 D9Q9R4 Uncharacterized protein 1232 D9QDY0 Uncharacterized protein 1233 D9QE62 ABC transporter ATP-binding protein 1234 D9Q9N9 Uncharacterized protein 1235 D9Q9B2 50 S ribosomal protein L33 1236 D9QCQ2 Uncharacterized protein 1237 D9QDC1 GntR family regulatory protein 1238 D9QDH5 Anti-sigma factor 1239 D9QE77 Demethylmenaquinone methyltransferase 1240 D9QA72 Dethiobiotin synthase 1241 D9QCG0 2-amino-4-hydroxy-6-hydroxymethyldihydropteridine pyropl 1242 D9QAD2 Protein pafB 1243 D9QDR4 Gluconate permease 1244 D9Q9K6 ABC transporter ATP-binding protein 1245 D9QC36 Uncharacterized protein 1246 D9QDB1 ABC transporter inner membrane protein 1247 D9QA02 DNA polymerase III subunit epsilon 1248 D9QD89 Cell division protein $\mathrm{ftsW}$ 1249 D9QEL9 Cell-surface hemin receptor 1250 D9QA98 MerR family transcriptional regulator 1251 D9QEN6 Uracil phosphoribosyltransferase 1252 D9QCX7 Uncharacterized protein 1253 D9QDJ1 Inositol-3-phosphate synthase 1254 D9Q9X9 Uncharacterized protein 1255 D9QCQ7 Secretion protein HlyD 1256 D9QA09 Biotin synthase 1257 D9QD38 Thioredoxin 1258 D9Q9C4 UTP--glucose-1-phosphate uridylyltransferase 1259 D9QDI6 Uncharacterized protein

1260 D9Q9D9 4-diphosphocytidyl-2-C-methyl-D-erythritol kinase 1261 D9QEV5 Uncharacterized protein

\begin{tabular}{|c|c|c|c|}
\hline oppF & 277 Cytoplasmic; & 0 & No \\
\hline СpC231_0800 & 275 Membrane; & 2 & No \\
\hline СpC231_0019a & 35 Extracellular; & 0 & Yes \\
\hline СpC231_0568 & 60 Extracellular; & 0 & No \\
\hline СpC231_0723 & 95 Cytoplasmic; & 0 & No \\
\hline $\mathrm{fts} \bar{Y}$ & 548 Cytoplasmic; & 1 & No \\
\hline CpC231_0718 & 273 Membrane; & 7 & No \\
\hline СpC231_1616 & 186 Extracellular; & 0 & No \\
\hline СpC231 0020 & 52 Extracellular; & 0 & No \\
\hline CpC231_2021 & 76 Extracellular; & 1 & No \\
\hline $\operatorname{cas} \overline{5}$ & 117 Cytoplasmic; & 0 & No \\
\hline mraW & 351 Cytoplasmic; & 0 & No \\
\hline CpC231_1011 & 66 Membrane; & 2 & No \\
\hline CpC231_1970 & 338 Extracellular; & 0 & Yes \\
\hline etf $\bar{B}$ & 264 Cytoplasmic; & 0 & No \\
\hline malk & 378 Cytoplasmic; & 0 & No \\
\hline holA & 324 Cytoplasmic; & 0 & No \\
\hline idsA & 372 Cytoplasmic; & 0 & No \\
\hline CpC231_1208 & 168 Cytoplasmic; & 2 & No \\
\hline СpC231_1193 & 202 Cytoplasmic; & 0 & No \\
\hline CpC231_1795 & 54 Extracellular; & 0 & No \\
\hline СpC231_0257 & 167 Cytoplasmic; & 0 & No \\
\hline pur̄ & 353 Cytoplasmic; & 0 & No \\
\hline CpC231_1866 & 33 Extracellular; & 0 & Yes \\
\hline glpT1 & 461 Membrane; & 12 & No \\
\hline CpC231_1581 & 304 Cytoplasmic; & 0 & No \\
\hline CpC231_0663 & 69 Cytoplasmic; & 0 & No \\
\hline CpC231_1408 & 122 Cytoplasmic; & 0 & No \\
\hline $\sec \overline{\mathrm{N}}$ & 111 Membrane; & 1 & No \\
\hline CpC231_1732 & 205 Membrane; & 0 & No \\
\hline $\operatorname{ciu} \bar{D}$ & 273 Membrane; & 0 & No \\
\hline glpQ & 239 Cytoplasmic; & 0 & No \\
\hline CpC231_1518 & 133 Cytoplasmic; & 0 & No \\
\hline CpC231_0987b & 52 Cytoplasmic; & 0 & No \\
\hline СpC231_1761 & 433 Membrane; & 11 & No \\
\hline $\mathrm{msr} \bar{B}$ & 136 Cytoplasmic; & 0 & No \\
\hline CpC231_0808 & 102 Membrane; & 2 & No \\
\hline СpC231_0209 & 71 Extracellular; & 1 & No \\
\hline СpC231_0291 & 256 Membrane; & 0 & No \\
\hline CpC231_0783 & 95 Membrane; & 1 & No \\
\hline $\mathrm{rpmG}$ & 54 Cytoplasmic; & 0 & No \\
\hline CpC231_1873 & 251 Extracellular; & 1 & No \\
\hline CpC231_2057 & 258 Cytoplasmic; & 0 & No \\
\hline cskE & 214 Cytoplasmic; & 1 & No \\
\hline menG & 232 Cytoplasmic; & 0 & No \\
\hline bioD & 201 Membrane; & 0 & Yes \\
\hline folK & 151 Cytoplasmic; & 0 & No \\
\hline pafB & 329 Cytoplasmic; & 0 & No \\
\hline gntP & 462 Membrane; & 13 & No \\
\hline CpC231_0750 & 564 Membrane; & 6 & No \\
\hline CpC231_1650 & 343 Membrane; & 10 & No \\
\hline CpC231_2047 & 350 Membrane; & 4 & No \\
\hline dnaQ3 & 172 Cytoplasmic; & 0 & No \\
\hline $\mathrm{ftsW}$ & 457 Membrane; & 12 & No \\
\hline htaA & 615 Extracellular; & 1 & Yes \\
\hline merR2 & 250 Cytoplasmic; & 0 & No \\
\hline upp & 211 Cytoplasmic; & 0 & No \\
\hline CpC231_1952 & 641 Membrane; & 11 & No \\
\hline ino 1 & 361 Cytoplasmic; & 0 & No \\
\hline CpC231_0874 & 120 Extracellular; & 4 & No \\
\hline hly $\bar{D}$ & 563 Extracellular; & 0 & No \\
\hline bioB2 & 334 Cytoplasmic; & 0 & No \\
\hline $\operatorname{trxA1}$ & 122 Cytoplasmic; & 0 & No \\
\hline galU & 318 Cytoplasmic; & 0 & No \\
\hline CpC231_0060 & 84 Cytoplasmic; & 0 & No \\
\hline isp $\bar{E}$ & 319 Cytoplasmic; & 0 & No \\
\hline СpC231_0541 & 75 Extracellular; & 0 & No \\
\hline
\end{tabular}


Anexo 1

1262 D9QAT9 Riboflavin biosynthesis protein RibD

1263 D9QA03 Uncharacterized protein

1264 F9Y348 Uncharacterized protein

1265 D9QEB6 Uncharacterized protein

1266 D9Q9B1 30S ribosomal protein S14

1267 D9QE11 Surface layer protein A

1268 D9QA82 Esterase

1269 D9QAG4 Uncharacterized protein

1270 D9QD15 MazG nucleotide pyrophosphohydrolase

1271 D9QED0 Oligopeptide transport ATP-binding protein

1272 F9Y384 Uncharacterized protein

1273 D9QER9 Uncharacterized protein

1274 D9QDH9 Uncharacterized protein

1275 D9QBG5 Ubiquinol-cytochrome c reductase iron-sulfur subunit

1276 D9QD57 Beta sliding clamp

1277 D9Q9R9 Glyoxalase/Bleomycin resistance protein/Dihydroxybiphen

1278 D9QC87 Uncharacterized protein

1279 D9QC68 HTH-type transcriptional regulator CmtR

1280 D9QE59 Cytochrome c-type biogenesis protein CcdA

1281 D9QC19 Uncharacterized protein

1282 D9Q9Y6 Aldo-keto reductase

1283 D9QE51 Uncharacterized protein

1284 D9QCZ2 1-acyl-sn-glycerol-3-phosphate acyltransferase

1285 D9QB46 Zinc metalloprotease

1286 D9QES2 Transcriptional regulator WhiB

1287 D9QAR4 Uncharacterized protein

1288 D9Q9B3 50 S ribosomal protein L28

1289 D9QBF9 Glucose kinase

1290 D9QDP9 PtsGHI operon antiterminator

1291 D9QCA9 Uncharacterized protein

1292 D9QCJ5 Acetyltransferase

1293 D9Q9N5 Succinyl-diaminopimelate desuccinylase

1294 D9QEH3 ESAT-6-like protein

1295 D9QAG0 Dehydrogenase/oxidoreductase

1296 D9QBQ9 Ferric uptake regulatory protein

1297 D9QC60 Ferritin

1298 D9QD91 FHA domain-containing protein

1299 D9QA69 Tyrosine recombinase XerD

1300 D9QB23 Ribosome-binding factor A

1301 D9QAL9 Probable primosomal protein N;

1302 D9QET9 Uncharacterized protein

1303 D9QCV6 Acyltransferase

1304 D9Q9T1 Uncharacterized protein

1305 D9QDV7 Spermidine/putrescine-binding periplasmic protein

1306 D9QBP3 Beta-lactamase transpeptidase-like protein

1307 D9QC76 Cysteine synthase

1308 D9QDK2 Uncharacterized protein

1309 D9QCD4 Transcriptional regulator

1310 D9QDS0 Uncharacterized protein

1311 D9QBG8 Cytochrome c oxidase polypeptide 4

1312 D9Q993 DNA glycosylase

$1313 \mathrm{D} 9 \mathrm{CCl} 7 \mathrm{Na}(+) / \mathrm{H}(+)$ antiporter subunit $\mathrm{E}$

1314 D9QD48 Uncharacterized protein

1315 D9QEU8 RNA polymerase sigma factor

1316 D9QAH7 UPF0237 protein CpC231

1317 D9QA70 Chromosome partitioning ATPase protein

1318 D9QDV8 Glycerol-3-phosphate transporter

1319 D9QBU8 Uncharacterized protein

1320 D9Q9H7 Uncharacterized protein

1321 D9QBQ4 Uncharacterized protein

1322 D9QDK3 Ammonia monooxygenase

1323 D9QC16 Carbon starvation protein A

1324 D9QBD1 Polyphenol oxidase

1325 F9Y374 Uncharacterized protein

1326 D9QDI4 Peptidase family M20/M25/M40

1327 D9QCX2 Cutinase

1328 D9Q9U0 Uncharacterized protein

\begin{tabular}{|c|c|c|c|}
\hline CpC231_1189 & 265 Extracellular; & 0 & No \\
\hline СpC231_0900 & 107 Membrane; & 1 & No \\
\hline СpC231_0599a & 32 Extracellular; & 0 & No \\
\hline СpC231_0347 & 112 Cytoplasmic; & 0 & No \\
\hline $\operatorname{rps} \bar{N}$ & 101 Cytoplasmic; & 0 & No \\
\hline slpA & 359 Extracellular; & 0 & Yes \\
\hline CpC231_0980 & 414 Extracellular; & 4 & No \\
\hline CpC231_1064 & 170 Membrane; & 5 & No \\
\hline $\operatorname{mazG}$ & 106 Cytoplasmic; & 0 & No \\
\hline oppDF1 & 690 Membrane; & 0 & No \\
\hline CpC231_1964a & 40 Cytoplasmic; & 0 & No \\
\hline CpC231_0505 & 34 Extracellular; & 0 & No \\
\hline СpC231_0053 & 253 Cytoplasmic; & 0 & No \\
\hline qcré & 406 Membrane; & 3 & No \\
\hline dnaN & 395 Cytoplasmic; & 0 & No \\
\hline CpC231_0813 & 148 Cytoplasmic; & 0 & No \\
\hline CpC231_1702 & 67 Extracellular; & 0 & No \\
\hline $\mathrm{cmt} \overline{\mathrm{R}}$ & 132 Cytoplasmic; & 0 & No \\
\hline $\operatorname{ccdA}$ & 268 Membrane; & 6 & No \\
\hline CpC231_1633 & 44 Extracellular; & 0 & No \\
\hline yghz & 379 Cytoplasmic; & 0 & No \\
\hline CpC231_0280 & 193 Membrane; & 2 & No \\
\hline $\mathrm{plsC} 1$ & 282 Cytoplasmic; & 0 & No \\
\hline CpC231_1299 & 404 Membrane; & 4 & No \\
\hline whi $\bar{B}$ & 99 Cytoplasmic; & 0 & No \\
\hline CpC231_1164 & 113 Extracellular; & 1 & Yes \\
\hline $\mathrm{rpmB}$ & 78 Cytoplasmic; & 0 & No \\
\hline glk & 317 Cytoplasmic; & 0 & No \\
\hline glcT & 282 Cytoplasmic; & 0 & No \\
\hline CpC231_1725 & 69 Extracellular; & 0 & No \\
\hline CpC231_1815 & 320 Cytoplasmic; & 0 & No \\
\hline dap $\bar{E}$ & 357 Cytoplasmic; & 0 & No \\
\hline $\mathrm{CpC2310406}$ & 94 Extracellular; & 0 & No \\
\hline CpC231_1060 & 490 Cytoplasmic; & 0 & No \\
\hline furB $\bar{B}$ & 141 Cytoplasmic; & 0 & No \\
\hline $\mathrm{ftn}$ & 173 Cytoplasmic; & 0 & No \\
\hline CpC231_0036 & 159 Membrane; & 1 & No \\
\hline xerD $\bar{D}$ & 310 Cytoplasmic; & 0 & No \\
\hline rbfA & 145 Cytoplasmic; & 0 & No \\
\hline priA & 681 Cytoplasmic; & 0 & No \\
\hline CpC231_0525 & 177 Membrane; & 0 & No \\
\hline СpC231_1931 & 363 Membrane; & 10 & No \\
\hline СpC231_0826 & 114 Cytoplasmic; & 0 & Yes \\
\hline $\operatorname{pot} \bar{D}$ & 333 Extracellular; & 0 & Yes \\
\hline bla & 269 Membrane; & 0 & No \\
\hline cysK & 311 Cytoplasmic; & 0 & No \\
\hline CpC231_0077 & 278 Cytoplasmic; & 0 & No \\
\hline $\operatorname{car} \bar{D}$ & 193 Cytoplasmic; & 0 & No \\
\hline CpC231_0146 & 189 Cytoplasmic; & 0 & No \\
\hline $\operatorname{cta} \bar{F}$ & 143 Membrane; & 4 & No \\
\hline nei & 257 Cytoplasmic; & 0 & No \\
\hline mrpE1 & 171 Membrane; & 4 & No \\
\hline CpC231_2025 & 60 Extracellular; & 2 & No \\
\hline $\operatorname{sig} \overline{\mathrm{H}}$ & 223 Cytoplasmic; & 0 & No \\
\hline CpC231_1077 & 89 Extracellular; & 0 & No \\
\hline soj & 289 Cytoplasmic; & 0 & No \\
\hline glpT & 465 Membrane; & 12 & No \\
\hline CpC231_1560 & 43 Extracellular; & 0 & No \\
\hline CpC231_0721 & 150 Membrane; & 1 & No \\
\hline СpC231_1514 & 142 Cytoplasmic; & 0 & No \\
\hline$a b r \bar{B}$ & 360 Membrane; & 10 & No \\
\hline pcsA & 761 Membrane; & 16 & No \\
\hline CpC231_1386 & 239 Cytoplasmic; & 0 & No \\
\hline CpC231_1472a & 35 Extracellular; & 0 & No \\
\hline CpC231_0058 & 445 Cytoplasmic; & 0 & No \\
\hline CpC231_1947 & 308 Cytoplasmic; & 1 & No \\
\hline $\mathrm{CpC} 2310835$ & 221 Cytoplasmic; & 0 & No \\
\hline
\end{tabular}


Anexo 1

1329 D9Q916 Uncharacterized protein 1330 F9Y353 Uncharacterized protein 1331 D9QDI7 Metallopeptidase MepB $1332 \mathrm{D} 9 \mathrm{QDZ3}$ Bacterial type II secretion system protein $\mathrm{F}$ domain protein 1333 D9QBY0 Bifunctional protein folC 1334 D9Q9R1 Uncharacterized protein 1335 F9Y332 Uncharacterized protein 1336 D9QBS4 Uncharacterized protein 1337 D9QBM7 Ribonuclease R

1338 D9QC90 Phosphate-binding protein PstS 1339 D9QCU2 Uncharacterized protein 1340 D9QCG3 GTP cyclohydrolase 1 1341 D9QCG5 Hypoxanthine phosphoribosyltransferase 1342 D9QE94 Uncharacterized protein 1343 D9QA15 Uncharacterized protein 1344 D9QBH2 Uncharacterized protein 1345 D9QBT4 Uncharacterized protein 1346 D9QDL3 Uncharacterized protein yaaA 1347 D9QC59 Uncharacterized protein 1348 D9QBI5 Uncharacterized protein 1349 F9Y351 Uncharacterized protein 1350 D9Q9E0 ABC transporter ATP-binding protein 1351 D9QBG2 Uncharacterized protein 1352 D9QDJ2 $\mathrm{Fe}(2+) / \mathrm{Mn}(2+)$ transporter pcl1 1353 D9QC93 Diacylglycerol kinase, catalytic region 1354 D9QDU4 Aspartokinase

1355 D9Q9R0 Uncharacterized protein 1356 D9QCV2 VanW family protein 1357 D9Q9V3 ATP synthase gamma chain 1358 F9Y366 Uncharacterized protein 1359 D9Q9E9 Uncharacterized protein 1360 D9QBZ0 Uncharacterized protein 1361 D9QES1 Uncharacterized protein 1362 D9QBJ4 Uncharacterized protein 1363 D9QEJ1 RNA polymerase sigma-D factor 1364 D9Q9V6 Uncharacterized protein 1365 D9QBM0 Uncharacterized protein 1366 D9QDU3 Uncharacterized protein 1367 D9QDW1 $\mathrm{Na}(+) / \mathrm{H}(+)$ antiporter subunit $\mathrm{G}$ 1368 D9QB03 Putative membrane protein 1369 D9QCU7 Hydrolase/acyltransferase 1370 D9Q9Z1 Low molecular weight protein antigen 6 1371 D9Q9Y0 Uncharacterized protein 1372 D9QAA0 MerR family transcriptional regulator 1373 D9QDF8 Thioredoxin

1374 D9QE46 Glutaredoxin-like domain protein

1375 D9Q9N0 Uncharacterized protein

1376 D9QDJ9 Uncharacterized protein

1377 D9QE31 D-inositol-3-phosphate glycosyltransferase

1378 D9QE39 Uncharacterized protein

1379 D9QAR6 Adenine phosphoribosyltransferase

1380 D9QCW9 Propionyl-CoA carboxylase beta chain 5

1381 D9QDE9 Branched-chain amino acid transport protein 1382 D9QDE8 Uncharacterized protein

1383 D9QD59 Uncharacterized protein

1384 D9QEF2 Protein traX

1385 D9QCK0 7,8-dihydro-8-oxoguanine-triphosphatase 1386 D9QAL0 Uncharacterized protein

1387 D9QE02 DNA polymerase III subunit gamma/tau 1388 D9QDV4 Uncharacterized protein 1389 D9QB89 Uncharacterized protein 1390 D9QDP1 Periplasmic zinc-binding protein troA 1391 D9QAH1 Invasion-associated protein p60 1392 D9QBS9 Isopentenyl-diphosphate Delta-isomerase 1393 D9QC86 Phosphate uptake regulator 1394 D9Q9U3 Peptide chain release factor 1 1395 D9QA40 DoxX family protein

\begin{tabular}{|c|c|c|}
\hline СpC231_0730 & 111 Cytoplasmic; & 0 \\
\hline СpC231_0852a & 94 Cytoplasmic; & 0 \\
\hline mepB & 143 Extracellular; & 0 \\
\hline gspF & 207 Membrane; & 2 \\
\hline folc & 520 Cytoplasmic; & 0 \\
\hline CpC231_0805 & 177 Cytoplasmic; & 0 \\
\hline CpC231_0021a & 34 Extracellular; & 0 \\
\hline CpC231_1535 & 46 Extracellular; & 1 \\
\hline $\mathrm{rnr}$ & 461 Cytoplasmic; & 0 \\
\hline pstS & 368 Extracellular; & 0 \\
\hline CpC231_1916 & 396 Membrane; & 10 \\
\hline fole & 187 Cytoplasmic; & 0 \\
\hline hpt & 193 Cytoplasmic; & 0 \\
\hline CpC231_0324 & 653 Cellwall; & 1 \\
\hline CpC231_0912 & 40 Extracellular; & 0 \\
\hline CpC231_1427 & 243 Membrane; & 2 \\
\hline $\mathrm{yvb} \overline{\mathrm{T}}$ & 331 Cytoplasmic; & 0 \\
\hline yaaA & 96 Cytoplasmic; & 0 \\
\hline CpC231_1673 & 57 Cytoplasmic; & 1 \\
\hline CpC231_1441 & 256 Membrane; & 2 \\
\hline CpC231_0691b & 40 Cytoplasmic; & 0 \\
\hline СpC231_0683 & 604 Cytoplasmic; & 0 \\
\hline CpC231_1417 & 209 Extracellular; & 0 \\
\hline CpC231_0066 & 245 Membrane; & 5 \\
\hline CpC231_1709 & 344 Cytoplasmic; & 0 \\
\hline lys $\bar{C}$ & 429 Cytoplasmic; & 0 \\
\hline CpC231_0804 & 262 Cytoplasmic; & 0 \\
\hline CpC231_1927 & 553 Extracellular; & 1 \\
\hline $\operatorname{atp} \bar{G}$ & 326 Cytoplasmic; & 0 \\
\hline CpC231_1057a & 42 Extracellular; & 0 \\
\hline CpC231_0693 & 217 Membrane; & 6 \\
\hline CpC231_1604 & 39 Cytoplasmic; & 0 \\
\hline CpC231_0507 & 100 Extracellular; & 0 \\
\hline CpC231_1450 & 79 Cytoplasmic; & 0 \\
\hline $\operatorname{sig} \bar{D}$ & 196 Cytoplasmic; & 0 \\
\hline СpC231_0851 & 164 Membrane; & 1 \\
\hline CpC231_1479 & 86 Extracellular; & 0 \\
\hline CpC231_0171 & 281 Membrane; & 9 \\
\hline $\mathrm{mrp} \overline{\mathrm{G}}$ & 102 Membrane; & 3 \\
\hline CpC231_1255 & 26 Extracellular; & 0 \\
\hline СpC231_1921 & 203 Cytoplasmic; & 0 \\
\hline $\operatorname{cfp} \overline{6}$ & 179 Membrane; & 2 \\
\hline CpC231_0875 & 48 Extracellular; & 0 \\
\hline merR3 & 185 Cytoplasmic; & 0 \\
\hline $\operatorname{trxA1}$ & 107 Cytoplasmic; & 0 \\
\hline CpC231_0275 & 84 Cytoplasmic; & 0 \\
\hline CpC231_0774 & 390 Cytoplasmic; & 0 \\
\hline CpC231_0074 & 556 Cytoplasmic; & 0 \\
\hline $\operatorname{mshA}$ & 420 Cytoplasmic; & 0 \\
\hline CpC231_0268 & 62 Extracellular; & 0 \\
\hline apt & 201 Cytoplasmic; & 0 \\
\hline accD & 515 Cytoplasmic; & 0 \\
\hline azID & 117 Membrane; & 4 \\
\hline CpC231_2084 & 104 Cytoplasmic; & 0 \\
\hline CpC231_0004 & 190 Cytoplasmic; & 0 \\
\hline $\operatorname{traX}$ & 247 Membrane; & 8 \\
\hline mutT & 192 Cytoplasmic; & 0 \\
\hline СpC231_1110 & 188 Cytoplasmic; & 2 \\
\hline dnaX & 400 Cytoplasmic; & 0 \\
\hline CpC231_0182 & 317 Cytoplasmic; & 0 \\
\hline CpC231_1344 & 191 Membrane; & 1 \\
\hline $\operatorname{tro} \bar{A}$ & 330 Extracellular; & 0 \\
\hline CpC231_1071 & 580 Extracellular; & 0 \\
\hline idi & 184 Cytoplasmic; & 0 \\
\hline phoU & 250 Cytoplasmic; & 0 \\
\hline prfA & 356 Cytoplasmic; & 0 \\
\hline doxX & 269 Cytoplasmic; & 0 \\
\hline
\end{tabular}


Anexo 1

1396 D9QBW8 Uncharacterized protein 1397 D9Q9E6 Enoyl-CoA hydratase

1398 D9QBT5 Endonuclease

1399 D9QD74 Rhomboid family protein

1400 D9QD77 Uncharacterized protein

1401 D9QD47 30S ribosomal protein S6

1402 D9Q983 Oligopeptide transport ATP-binding protein OppD

1403 D9QDY9 Uncharacterized protein

1404 D9QC55 Uncharacterized protein

1405 D9QD42 Replicative DNA helicase

1406 D9QBA7 TetR family transcriptional regulator

1407 D9QDN2 Uncharacterized protein

1408 D9QBB2 Uncharacterized protein

1409 D9QAV4 Uncharacterized protein

1410 D9QBZ1 Uncharacterized protein

1411 D9QBB7 DNA-directed DNA polymerase

1412 D9QCL7 Cytochrome c biogenesis protein resC

1413 D9QDU9 Uncharacterized protein

1414 D9QEL4 Putative tRNA (cytidine(34)-2;

1415 D9QE65 Cytochrome $c$ biogenesis protein CcsA

1416 D9Q9J0 Phosphinothricin acetyltransferase YwnH

1417 D9QDL9 Glycerol uptake facilitator protein

1418 D9QAA8 Methyltransferase type 11

1419 D9QCH6 Polyphosphate kinase 2

1420 D9QDT4 Deoxyribonucleoside regulator

1421 D9QAT3 CDP-diacylglycerol--inositol 3-phosphatidyltransferase

1422 D9QCE4 ATP-dependent Clp protease ATP-binding subunit

1423 D9QB81 Uncharacterized protein

1424 D9Q9M9 Uncharacterized protein

1425 D9Q9V4 ATP synthase subunit beta

1426 D9QCC4 Uncharacterized protein

1427 D9QDC2 Oligopeptide-binding protein oppA

1428 D9QBM4 Chad domain-containing protein

1429 F9Y340 Uncharacterized protein

1430 D9Q956 Uncharacterized protein

1431 D9QB59 Uncharacterized protein

1432 D9QB52 Uridylate kinase

1433 D9QB21 Multidrug resistance protein norM

1434 D9QDZ2 Uncharacterized protein

1435 D9QEM8 Uncharacterized protein

1436 D9Q9Q5 ABC transporter domain-containing ATP-binding protein

1437 D9QB71 Bifunctional uridylyltransferase/uridylyl-removing enzyme

1438 D9QBH6 Branched-chain-amino-acid aminotransferase

1439 D9QA97 Oxoglutarate dehydrogenase inhibitor

1440 D9QA56 Argininosuccinate synthase

1441 D9QC78 Acetyltransferase

1442 D9QA65 DNA repair protein $\mathrm{RecN}$

1443 D9QAP2 Shikimate dehydrogenase

1444 D9Q949 $\mathrm{Fe}(3+)$ dicitrate transport ATP-binding protein FecE

1445 D9QA52 Acetylglutamate kinase

1446 D9QBZ4 Ribose-5-phosphate isomerase B

1447 D9Q9R2 Aldose 1-epimerase

1448 D9QAG9 Uncharacterized protein

1449 D9QC27 Antibiotic biosynthesis monooxygenase

1450 D9QE42 Uncharacterized protein

1451 D9QAU2 Chlorite dismutase

1452 D9QEV0 Transcriptional regulator WhiB

1453 D9QA31 Uncharacterized protein

1454 D9QB12 4-hydroxy-tetrahydrodipicolinate reductase

1455 D9QCU9 Uncharacterized protein

1456 D9QDW4 $\mathrm{Na}(+) / \mathrm{H}(+)$ antiporter subunit $\mathrm{D}$

1457 D9QBL7 Uncharacterized protein

1458 D9QD26 TetR family transcriptional regulator

1459 D9QAD5 Proteasome accessory factor PafA2

1460 D9QDZ6 Uncharacterized protein

1461 D9QB47 1-deoxy-D-xylulose 5-phosphate reductoisomerase

1462 D9Q9L2 Cobalt transport protein CbiQ

\begin{tabular}{|c|c|c|c|}
\hline CpC231_1582 & 115 Membrane; & 4 & No \\
\hline echA & 355 Cytoplasmic; & 0 & No \\
\hline CpC231_1547 & 395 Cytoplasmic; & 0 & No \\
\hline ybh $\bar{B}$ & 256 Membrane; & 7 & No \\
\hline CpC231_0022 & 42 Extracellular; & 1 & No \\
\hline $\mathrm{rps} \overline{\mathrm{F}}$ & 95 Cytoplasmic; & 0 & No \\
\hline oppD1 & 480 Membrane; & 0 & No \\
\hline СpC231_0218 & 71 Extracellular; & 0 & No \\
\hline CpC231_1669 & 74 Extracellular; & 0 & No \\
\hline $\mathrm{dna} \overline{\mathrm{B}}$ & 492 Cytoplasmic; & 0 & No \\
\hline tetR & 205 Cytoplasmic; & 0 & No \\
\hline CpC231_0107 & 295 Cytoplasmic; & 0 & No \\
\hline CpC231_1367 & 41 Extracellular; & 0 & No \\
\hline CpC231_1205 & 173 Membrane; & 2 & No \\
\hline CpC231_1605 & 83 Cytoplasmic; & 0 & No \\
\hline dnaE & 1186 Cytoplasmic; & 0 & No \\
\hline resC & 269 Membrane; & 8 & No \\
\hline CpC231_0177 & 39 Cytoplasmic; & 0 & No \\
\hline spou & 176 Cytoplasmic; & 0 & No \\
\hline $\operatorname{ccs} A$ & 333 Membrane; & 8 & No \\
\hline ywnH & 186 Cytoplasmic; & 0 & No \\
\hline glpF & 257 Membrane; & 6 & No \\
\hline CpC231_1007 & 195 Cytoplasmic; & 0 & No \\
\hline CpC231_1796 & 301 Cytoplasmic; & 0 & No \\
\hline deo $\bar{R}$ & 312 Cytoplasmic; & 0 & No \\
\hline pgsA & 229 Membrane; & 6 & No \\
\hline $\mathrm{clpC}$ & 885 Cytoplasmic; & 0 & No \\
\hline CpC231_1335 & 244 Cytoplasmic; & 0 & No \\
\hline CpC231_0773 & 185 Membrane; & 4 & No \\
\hline $\operatorname{atp} \bar{D}$ & 481 Cytoplasmic; & 0 & No \\
\hline CpC231_1743 & 118 Cytoplasmic; & 0 & No \\
\hline оррА̄7 & 540 Extracellular; & 0 & Yes \\
\hline CpC231_1484 & 551 Cytoplasmic; & 0 & No \\
\hline CpC231_0441a & 160 Cytoplasmic; & 0 & Yes \\
\hline CpC231_0597 & 175 Membrane; & 1 & No \\
\hline CpC231_1313 & 101 Cytoplasmic; & 0 & No \\
\hline pyrH & 243 Cytoplasmic; & 0 & No \\
\hline norM & 451 Membrane; & 12 & No \\
\hline CpC231_0221 & 251 Membrane; & 4 & No \\
\hline CpC231_0464 & 59 Cytoplasmic; & 2 & No \\
\hline CpC231_0799 & 1231 Cellwall; & 12 & No \\
\hline$g \ln \bar{D}$ & 745 Cytoplasmic; & 0 & No \\
\hline ilvE & 366 Cytoplasmic; & 0 & No \\
\hline odhl & 143 Cytoplasmic; & 0 & No \\
\hline $\arg G$ & 399 Cytoplasmic; & 0 & No \\
\hline CpC231_1693 & 100 Cytoplasmic; & 0 & No \\
\hline $\mathrm{rec} \overline{\mathrm{N}}$ & 582 Cytoplasmic; & 0 & No \\
\hline aroE1 & 307 Extracellular; & 0 & Yes \\
\hline fecE & 251 Cytoplasmic; & 0 & No \\
\hline $\operatorname{argB}$ & 311 Cytoplasmic; & 0 & No \\
\hline rpiB & 157 Cytoplasmic; & 0 & No \\
\hline yihR & 295 Cytoplasmic; & 0 & No \\
\hline CpC231_1069 & 260 Cytoplasmic; & 0 & No \\
\hline CpC231_1641 & 116 Cytoplasmic; & 0 & No \\
\hline CpC231_0271 & 33 Cytoplasmic; & 0 & No \\
\hline CpC231_1192 & 259 Cytoplasmic; & 0 & No \\
\hline whiB & 86 Cytoplasmic; & 0 & No \\
\hline CpC231_0928 & 313 Membrane; & 9 & No \\
\hline $\operatorname{dap} B$ & 248 Cytoplasmic; & 0 & No \\
\hline CpC231_1923 & 77 Cytoplasmic; & 0 & No \\
\hline $\operatorname{mrp} \bar{D}$ & 512 Membrane; & 14 & No \\
\hline CpC231_1476 & 46 Extracellular; & 0 & No \\
\hline $\mathrm{mcbR}$ & 208 Cytoplasmic; & 0 & No \\
\hline pafA1 & 510 Cytoplasmic; & 0 & No \\
\hline CpC231_0225 & 88 Cytoplasmic; & 0 & Yes \\
\hline$d x r^{-}$ & 388 Membrane; & 0 & Yes \\
\hline $\mathrm{cbiQ}$ & 251 Membrane; & 7 & No \\
\hline
\end{tabular}




\section{Anexo 1}

1463 D9QAE3 Anaerobic C4-dicarboxylate transporter 1464 D9QC21 Short chain dehydrogenase

1465 D9QDG4 Inner membrane protein translocase component YidC 1466 D9QEX5 Uncharacterized protein

$\begin{array}{ll}1466 \text { D9QEX5 Uncharacterized protein } & \text { CpC231_0561 } \\ 1467 \text { D9QE90 ABC-type metal ion transport system, periplasmic compon } & \text { CpC231_0320 }\end{array}$ 1468 D9Q9P7 RNA polymerase sigma factor SigE

1469 D9QDC7 Uncharacterized protein

1470 D9QEY4 L-asparagine permease

1471 D9Q9D7 Resuscitation-promoting factor RpfB

1472 D9QAY4 GTPase HfIX

1473 D9QBV4 Elongation factor 4

1474 D9QCM9 YxIE

1475 D9QE95 Uncharacterized protein

1476 D9QAP7 Uncharacterized AAA domain-containing protein Rv2559c/

1477 D9QB02 Phosphatidylglycerophosphate synthase

1478 D9QBE7 Uncharacterized protein

1479 D9QBU3 Uncharacterized protein

1480 D9QC70 Uncharacterized protein

1481 D9QDW2 $\mathrm{Na}(+) / \mathrm{H}(+)$ antiporter subunit $\mathrm{F}$

1482 D9QEK8 Uncharacterized protein

1483 D9QBP2 Uncharacterized protein

1484 D9QA99 Uncharacterized protein

1485 D9QAV3 RNA polymerase sigma factor SigA

1486 D9QA30 Serine/threonine-protein kinase PknD

1487 D9QD11 Superoxide dismutase

1488 D9QCW8 DedA family protein

1489 F9Y380 Uncharacterized protein

1490 F9Y329 Uncharacterized protein

1491 D9QAM8 Carbamoyl-phosphate synthase small chain

1492 D9QBG7 Cytochrome c oxidase subunit III

1493 D9QBX1 GTPase Obg

1494 F9Y334 Uncharacterized protein

1495 D9QC05 Uncharacterized protein ycaO

1496 D9QCY9 ABC transporter substrate-binding lipoprotein yvrC

1497 D9QD28 Transglycosylase associated protein

1498 D9QEB3 Uncharacterized protein

1499 D9QBP5 Uncharacterized protein

1500 D9QBT3 Branched-chain amino acid transport system carrier proteil

1501 D9QDF3 MutT/NUDIX family protein

1502 D9QBA0 Uncharacterized protein

1503 D9QDY5 Alpha/beta hydrolase family

1504 D9QC97 Uncharacterized protein

1505 D9QEU6 Putative SOS response-associated peptidase

1506 D9QBS1 Uncharacterized protein

1507 D9QBB4 Uncharacterized protein

1508 D9QD30 Uncharacterized protein

1509 D9QEL0 Manganese ABC transporter ATP-binding protein

1510 D9QAQ8 MaoC-like dehydratase

1511 D9QAS7 Uncharacterized protein

1512 F9Y386 Uncharacterized protein

1513 D9QC92 Uncharacterized protein

1514 D9QBI6 Uncharacterized protein

1515 D9QAD3 Pup--protein ligase

1516 D9QBK3 Uncharacterized protein

1517 D9QC26 Isochorismatase family protein yddQ

1518 D9QBE8 Uncharacterized protein

1519 D9QAT6 Dyp-type peroxidase family protein

1520 D9QDP8 Sodium-dependent dicarboxylate transporter sdcS

1521 D9QCC1 Uncharacterized protein

1522 D9Q9N7 Dihydropteroate synthase

1523 D9QD51 Penicillin-binding protein

1524 D9QB85 Uncharacterized protein

1525 D9Q940 Topology modulation protein

1526 D9QDS6 Galactonate operon transcriptional repressor

1527 D9Q976 Cystathionine beta-synthase

1528 D9QCH1 Uncharacterized protein

1529 D9QDK7 Ascorbate-specific permease IIC component ulaA
dcuA

CpC231_1635

yidC1

sigE

CpC231_2063

ansP

rpfB

hfIX

lepA

yxIE

CpC231_0325

CpC231_1147

pgsA1

CpC231_1402

CpC231_1555

$\mathrm{mrpF}$

CpC231_0442

CpC231_1502

CpC231_0997

sigA

pknD

sodA

$\operatorname{ded} A$

CpC231 0001a

carA

ctaE

obgE

CpC231_0021c

ycaO

yvrC

CpC231_2005

CpC231_0344

CpC231_1505

brn $\bar{Q}$

CpC231_2089

CpC231_1355

$\mathrm{mhpC}$

CpC231_1713

CpC231_0532

CpC231_1532

CpC231_1369

CpC231_2007

$\mathrm{mntB}$

CpC231_1158

CpC231_1177

CpC231_2024a

CpC231_1708

CpC231_1442

pafA

CpC231_1462

yddQ

CpC231_1403

CpC231_1186

sdcS

CpC231_1739

folP

pbp1A

CpC231_1340

flaR

dgoR

cbs

CpC231_1791

ulaA
CpC231_1685

CpC231_1684a
435 Membrane;

267 Cytoplasmic;

318 Membrane;

98 Cytoplasmic;

541 Cytoplasmic;

213 Cytoplasmic;

139 Extracellular;

479 Membrane;

383 Extracellular;

546 Cytoplasmic;

615 Cytoplasmic;

90 Membrane;

313 Membrane;

445 Membrane;

197 Membrane;

140 Cytoplasmic;

44 Extracellular;

82 Extracellular;

88 Membrane;

24 Extracellular;

120 Cytoplasmic;

202 Cytoplasmic;

517 Cytoplasmic;

298 Membrane;

213 Extracellular;

213 Membrane;

110 Extracellular;

48 Extracellular;

410 Cytoplasmic;

196 Membrane;

508 Cytoplasmic;

48 Extracellular;

512 Cytoplasmic;

337 Cytoplasmic;

85 Membrane;

183 Membrane;

80 Extracellular;

439 Membrane;

368 Cytoplasmic;

67 Extracellular;

305 Membrane;

108 Extracellular;

219 Extracellular;

226 Cytoplasmic;

77 Extracellular;

47 Extracellular;

240 Cytoplasmic;

181 Extracellular;

491 Membrane;

82 Cytoplasmic;

262 Extracellular;

157 Membrane;

485 Cytoplasmic;

66 Cytoplasmic;

204 Cytoplasmic;

37 Extracellular;

436 Extracellular;

524 Membrane;

294 Cytoplasmic;

285 Cytoplasmic;

721 Extracellular;

143 Cytoplasmic;

157 Cytoplasmic;

234 Cytoplasmic;

356 Cytoplasmic;

63 Cytoplasmic;

513 Membrane;

\begin{tabular}{|c|c|}
\hline 13 & \\
\hline 0 & \\
\hline 5 & \\
\hline 0 & \\
\hline 0 & \\
\hline 0 & \\
\hline 0 & \\
\hline 12 & \\
\hline 1 & \\
\hline 0 & \\
\hline 0 & \\
\hline 2 & \\
\hline 1 & \\
\hline 0 & \\
\hline 6 & \\
\hline 0 & \\
\hline 0 & \\
\hline 0 & \\
\hline 3 & \\
\hline 0 & \\
\hline 0 & \\
\hline 0 & \\
\hline 0 & \\
\hline 0 & \\
\hline 0 & \\
\hline 5 & \\
\hline 1 & \\
\hline 0 & \\
\hline 0 & \\
\hline 5 & \\
\hline 0 & \\
\hline 0 & \\
\hline 0 & \\
\hline 0 & \\
\hline 3 & \\
\hline 2 & \\
\hline 0 & \\
\hline 12 & \\
\hline 0 & \\
\hline 2 & \\
\hline 0 & \\
\hline 0 & \\
\hline 0 & \\
\hline 0 & \\
\hline 2 & \\
\hline 0 & \\
\hline 0 & \\
\hline 0 & \\
\hline 9 & \\
\hline 0 & \\
\hline 0 & \\
\hline 3 & \\
\hline 0 & \\
\hline 0 & \\
\hline 0 & \\
\hline 0 & \\
\hline 0 & \\
\hline 15 & \\
\hline 0 & \\
\hline 0 & \\
\hline 1 & \\
\hline 0 & \\
\hline 0 & \\
\hline 0 & \\
\hline 0 & \\
\hline 0 & \\
\hline 11 & \\
\hline
\end{tabular}


Anexo 1

1530 F9Y372 RNA polymerase factor sigma 70 1531 D9QEK7 Uncharacterized protein

1532 D9QAF7 Dihydroxyacetone kinase subununit 1533 D9QDZ5 Uncharacterized protein

1534 D9Q9F1 Peptide chain release factor 3

1535 D9QER6 Uncharacterized protein

1536 D9QE25 Formate acetyltransferase

1537 D9QCL6 Thiol-disulfide oxidoreductase resA

1538 D9QAN4 Transcription antitermination protein NusB

1539 D9QEI8 tRNA N6-adenosine threonylcarbamoyltransferase

1540 D9QAZ1 Uncharacterized protein

1541 D9QC61 Ribonucleoside-diphosphate reductase

1542 D9QA76 Segregation and condensation protein B

1543 D9QD22 Uncharacterized protein

1544 D9QBS7 Carboxylic ester hydrolase

1545 D9QD12 Flavin reductase

1546 D9QAJ2 Nod factor export ATP-binding protein I

1547 D9QCC0 Corynomycolyl transferase

1548 D9QBC4 L-asparaginase

1549 F9Y347 Uncharacterized protein

1550 D9QBK5 Uncharacterized protein

1551 D9Q9U1 Long-chain-fatty-acid--CoA ligase

1552 D9QD06 Nucleoside transporter

1553 D9QD50 Uncharacterized protein

1554 D9Q9E2 Uncharacterized protein

1555 D9QD79 Insertion element protein

1556 D9Q9C8 Oxidoreductase mhqP

1557 D9QES3 Uncharacterized protein

$1558 \mathrm{D} 9 \mathrm{QCl} 6 \mathrm{Na}(+) / \mathrm{H}(+)$ antiporter subunit $\mathrm{D}$

1559 D9Q9P8 Anti-sigma factor

1560 D9QDT5 Purine-nucleoside phosphorylase

1561 D9QBC9 YggT

1562 D9QBK6 Uncharacterized protein

1563 D9QEC7 50 S ribosomal protein L29

1564 D9QAN9 Shikimate kinase

1565 D9QDA7 Uncharacterized protein

1566 D9QEW5 Uncharacterized protein

1567 D9QDI8 AMP nucleosidase

1568 F9Y367 Uncharacterized protein

1569 D9QA25 Phosphopantetheine adenylyltransferase

1570 D9QEX7 Copper-containing nitrite reductase

1571 D9Q941 Cell division ATP-binding protein FtsE

1572 D9QAP0 Chorismate synthase

1573 D9QDL6 Uncharacterized protein

1574 D9Q9S3 Helicase helZ

1575 D9Q9V9 Uncharacterized protein

1576 D9QAN3 Uncharacterized protein

1577 D9QEX1 Abi-like protein

1578 D9QD88 Penicillin-binding protein A

1579 D9QBE1 Penicillin-binding protein

1580 D9QBY3 TetR-family regulatory protein

1581 D9QB44 Secreted penicillin-binding protein

1582 D9QDZ4 Uncharacterized protein

1583 D9QAC6 Oxidoreductase

1584 D9QEF7 Neuraminidase (Sialidase)

1585 D9QAW2 UDP-glucose 4-epimerase

1586 D9Q9W9 Spermidine synthase

1587 D9QEK6 D-methionine-binding lipoprotein metQ

1588 D9QCW2 tRNA (guanine-N(7)-)-methyltransferase

1589 D9QAH5 HTH-type transcriptional repressor AcnR

1590 D9QCB2 Trk system potassium uptake protein trkA

1591 D9QAYO Phosphocarrier protein HPr

1592 D9QE66 Uncharacterized protein

1593 D9QD33 Uncharacterized protein

1594 D9QEX0 Transcription regulator BetR, N-terminal

1595 D9QD66 Uncharacterized protein

1596 D9QCH7 Cell wall channel

\begin{tabular}{|c|c|c|c|}
\hline CpC231_1451 & 183 Cytoplasmic; & 0 & No \\
\hline CpC231_0441 & 134 Cytoplasmic; & 1 & No \\
\hline dhak & 345 Cytoplasmic; & 0 & No \\
\hline CpC231_0224 & 90 Extracellular; & 0 & Yes \\
\hline $\operatorname{prf\overline {C}}$ & 544 Cytoplasmic; & 0 & No \\
\hline CpC231_0502 & 225 Cytoplasmic; & 0 & No \\
\hline $\mathrm{pfl}$ & 83 Cytoplasmic; & 0 & No \\
\hline resA & 174 Cytoplasmic; & 0 & Yes \\
\hline nusB & 208 Cytoplasmic; & 0 & No \\
\hline tsaD & 351 Cytoplasmic; & 0 & No \\
\hline CpC231_1243 & 223 Membrane; & 2 & No \\
\hline $\mathrm{nrd} \overline{\mathrm{E}}$ & 719 Cytoplasmic; & 0 & No \\
\hline $\operatorname{scpB}$ & 207 Cytoplasmic; & 0 & No \\
\hline CpC231_1999 & 190 Extracellular; & 0 & Yes \\
\hline CpC231_1538 & 423 Extracellular; & 0 & No \\
\hline CpC231_1988 & 194 Cytoplasmic; & 0 & No \\
\hline nodl & 318 Membrane; & 0 & No \\
\hline CpC231_1737 & 393 Extracellular; & 0 & Yes \\
\hline ans $\bar{A}$ & 358 Cytoplasmic; & 0 & No \\
\hline CpC231_0595a & 47 Extracellular; & 0 & No \\
\hline CpC231_1464 & 57 Extracellular; & 0 & No \\
\hline IcfA2 & 577 Membrane; & 0 & No \\
\hline yutK & 404 Membrane; & 10 & No \\
\hline CpC231_2027 & 28 Extracellular; & 0 & No \\
\hline CpC231_0685 & 92 Extracellular; & 0 & Yes \\
\hline CpC231_0024 & 346 Membrane; & 0 & No \\
\hline $\mathrm{mhqP}$ & 137 Membrane; & 4 & No \\
\hline CpC231_0509 & 151 Cytoplasmic; & 0 & No \\
\hline $\mathrm{mrpD} 1$ & 556 Membrane; & 14 & No \\
\hline cseE & 143 Cytoplasmic; & 0 & No \\
\hline deoD & 238 Membrane; & 0 & No \\
\hline yggT & 98 Membrane; & 2 & No \\
\hline CpC231_1465 & 61 Extracellular; & 0 & No \\
\hline $\mathrm{rpmC}$ & 76 Cytoplasmic; & 0 & No \\
\hline aroK & 198 Cytoplasmic; & 0 & No \\
\hline CpC231_2043 & 39 Extracellular; & 0 & No \\
\hline CpC231_0551 & 462 Membrane; & 0 & No \\
\hline$a m \bar{n}$ & 471 Cytoplasmic; & 0 & No \\
\hline CpC231_1133a & 134 Cytoplasmic; & 0 & No \\
\hline $\operatorname{coa} \bar{D}$ & 162 Cytoplasmic; & 0 & No \\
\hline aniA & 877 Membrane; & 13 & No \\
\hline $\mathrm{ftsE}$ & 229 Cytoplasmic; & 0 & No \\
\hline aroC & 428 Cytoplasmic; & 0 & No \\
\hline CpC231_0091 & 81 Extracellular; & 0 & No \\
\hline hel' & 1031 Membrane; & 0 & No \\
\hline CpC231_0854 & 122 Cytoplasmic; & 0 & Yes \\
\hline CpC231_1133 & 157 Extracellular; & 0 & No \\
\hline CpC231_0557 & 278 Cytoplasmic; & 0 & No \\
\hline $\operatorname{pbp} \bar{A}$ & 486 Extracellular; & 0 & Yes \\
\hline $\mathrm{ftsl}$ & 627 Membrane; & 1 & No \\
\hline CpC231_1597 & 252 Cytoplasmic; & 0 & No \\
\hline $\mathrm{pbp} \bar{B}$ & 613 Extracellular; & 0 & Yes \\
\hline CpC231_0223 & 64 Extracellular; & 1 & No \\
\hline CpC231_1025 & 246 Membrane; & 0 & No \\
\hline $\operatorname{nan} \bar{H}$ & 694 Cytoplasmic; & 1 & Yes \\
\hline galE & 327 Cytoplasmic; & 0 & Yes \\
\hline speE & 289 Cytoplasmic; & 0 & No \\
\hline metQ1 & 334 Membrane; & 1 & No \\
\hline $\operatorname{trmB}$ & 269 Cytoplasmic; & 0 & No \\
\hline acnR & 192 Cytoplasmic; & 0 & No \\
\hline trkA & 218 Membrane; & 0 & No \\
\hline $\mathrm{ptsH}$ & 88 Cytoplasmic; & 0 & No \\
\hline CpC231_0295 & 101 Membrane; & 0 & Yes \\
\hline CpC231_2010 & 349 Membrane; & 10 & No \\
\hline betR & 56 Cytoplasmic; & 0 & No \\
\hline CpC231_0011 & 259 Membrane; & 9 & No \\
\hline porH & 60 Extracellular; & 0 & No \\
\hline
\end{tabular}




\section{Anexo 1}

1597 D9QC14 Uncharacterized protein

1598 D9Q9B4 50S ribosomal protein L31 type B

1599 D9QCE0 Carbonic anhydrase

1600 D9QBZ5 DSBA oxidoreductase

1601 D9QA28 ABC transporter ATP-binding protein

1602 D9Q9G6 L-Lysine transport protein

1603 D9QBB9 Uncharacterized protein

1604 D9QE16 Succinate dehydrogenase cytochrome b556 subunit 1605 D9QCP1 Uncharacterized protein

1606 D9QC40 Uncharacterized protein

1607 D9Q9X4 Uncharacterized protein

1608 D9QAU8 Uncharacterized protein

1609 D9QBE2 Uncharacterized protein

1610 D9QB98 Imidazole glycerol phosphate synthase subunit HisH

1611 D9Q9Q8 Carboxylic ester hydrolase

1612 D9QDH3 Major Facilitator Superfamily (MFS)

1613 D9QEA4 Anaerobic ribonucleoside-triphosphate reductase activatin

1614 D9QB16 Pyrimidine-specific ribonucleoside hydrolase rihA

1615 D9QEV4 ATP-dependent RNA helicase rhIE

1616 F9Y376 Uncharacterized protein

1617 D9QAA1 Uncharacterized protein

1618 D9QC73 Cob(I)yrinic acid a,c-diamide adenosyltransferase 1619 D9Q9Q1 Uncharacterized protein

1620 D9QA07 Poly(3-hydroxybutyrate) depolymerase

1621 D9QE89 Uncharacterized protein

1622 D9QB48 Uncharacterized protein

1623 D9QD03 Uncharacterized protein

1624 D9QEG7 Uncharacterized protein

1625 D9QAZ6 Biotin transporter BioY

1626 D9QAC3 Precorrin-6A reductase

1627 D9QDP3 O-antigen export system, ATP-binding protein

1628 D9QDG6 Ribonuclease P protein component

1629 D9QD45 50 S ribosomal protein L9

1630 D9Q9T5 L-lactate permease

1631 D9QCJ2 Uncharacterized protein

1632 F9Y352 Uncharacterized protein

1633 D9QB38 Magnesium chelatase

1634 F9Y355 Uncharacterized protein

1635 D9QCY3 LPXTG domain-containing protein

1636 F9Y378 Hemoglobin-like protein

1637 D9QEB7 Uncharacterized protein

1638 D9QCA0 Uncharacterized protein

1639 D9QDK1 Uncharacterized protein

1640 D9Q955 Cold shock protein B

1641 D9QBH7 Probable cytosol aminopeptidase

1642 D9QDL4 Antigen Cfp30B

1643 D9QC10 YcaO-like family protein

1644 D9QBQ0 Uncharacterized protein

1645 D9QAU7 Uncharacterized protein

1646 D9QB70 Signal recognition particle protein

1647 D9QC64 50S ribosomal protein L36

1648 D9QES7 Mannose-6-phosphate isomerase manA

1649 D9QDE0 Anthranilate synthase component I

1650 D9QCL1 Disulfide bond formation protein, DsbB family

1651 D9QB75 Chromosome partition protein Smc

1652 D9QEM4 Isocitrate dehydrogenase [NADP]

1653 D9QCH2 Secretory lipase

1654 D9QA79 GTPase Der

1655 D9QCK9 Formate-dependent phosphoribosylglycinamide formyltran:

1656 D9QCl1 Acetyl-CoA acetyltransferase

1657 D9Q9A7 Citrate lyase subunit beta

1658 D9QAP9 Aspartate--tRNA(Asp/Asn) ligase

1659 D9QBT6 Ectoine, glycine betaine and proline transport system mem

1660 D9QEV6 Uncharacterized protein

1661 D9QEE9 Maltotriose-binding protein

1662 D9Q9K5 ABC transporter ATP-binding protein

1663 D9QBD4 UDP-N-acetylmuramate--L-alanine ligase

CpC231_1628
rpmE
bca
CpC231_1609
atrC
lysl
CpC231_1374
sdhC

CpC231_1862

CpC231_1654

CpC231_0869

CpC231_1198

CpC231_1397

his $\overline{\mathrm{H}}$

lipT

CpC231_0047

$\operatorname{nrdG}$

rihA

rhIE

CpC231_1596a

CpC231_0999

yvqK

CpC231_0795

IpqC

CpC231_0319

CpC231_1301

CpC231_1978

CpC231 0400

bioY

cobK

rfbE

rnpA

rpll

lutP

CpC231_1812

CpC231_0709a

CpC231_1290

CpC231_0928a

CpC231_1958

glbO

CpC231_0348

CpC231_1716

CpC231_0076

$\mathrm{cspB}$

pepB

cfp30B

CpC231_1624

CpC231_1510

CpC231_1197

ffh

rpmJ

manA

trpE

dsbB

smc

icd

lipY

engA

purT

CpC231_1801

citE

aspS

ectP

CpC231_0542

malE

CpC231_0749

murC
50 Extracellular;

88 Cytoplasmic;

209 Cytoplasmic;

206 Cytoplasmic;

257 Cytoplasmic;

496 Membrane;

179 Cytoplasmic;

252 Membrane;

403 Membrane;

148 Cytoplasmic;

220 Cytoplasmic;

267 Cytoplasmic;

235 Cytoplasmic;

210 Cytoplasmic;

532 Cytoplasmic;

424 Membrane;

193 Cytoplasmic;

321 Cytoplasmic;

441 Cytoplasmic;

55 Cytoplasmic;

476 Extracellular;

190 Cytoplasmic;

199 Cytoplasmic;

377 Cytoplasmic;

317 Extracellular;

141 Cytoplasmic;

666 Extracellular;

140 Membrane;

197 Membrane;

226 Cytoplasmic;

264 Cytoplasmic;

118 Cytoplasmic;

150 Cytoplasmic;

550 Membrane;

183 Extracellular;

36 Extracellular;

360 Membrane;

39 Cytoplasmic; 1029 Cellwall;

130 Cytoplasmic;

155 Cytoplasmic;

145 Cytoplasmic;

118 Membrane;

130 Cytoplasmic;

505 Cytoplasmic;

274 Cytoplasmic;

491 Membrane;

85 Cytoplasmic;

234 Membrane;

535 Cytoplasmic;

40 Cytoplasmic;

385 Cytoplasmic;

535 Cytoplasmic;

496 Membrane;

1160 Cellwall;

736 Cytoplasmic;

415 Extracellular;

540 Cytoplasmic;

354 Cytoplasmic;

178 Extracellular;

297 Cytoplasmic;

600 Cytoplasmic;

610 Membrane;

296 Extracellular;

415 Extracellular;

546 Membrane;

485 Cytoplasmic;
No

No

No

No

No

No

Yes

No

Yes

No

No

No

No

No

No

No

No

No

No

No

No

No

No

No

Yes

No

Yes

No

No

No

No

No

No

No

No

No

No

No

Yes

No

No

No

No

No

No

No

Yes

No

No

No

No

No

No

No

No

No

Yes

No

No

No

No

No

No

No

Yes

No

No 
Anexo 1

1664 D9QE96 DNA-directed RNA polymerase subunit beta 1665 D9QBW9 Transport YidE/YbjL family protein

1666 D9QCC8 Lacl-family transcriptional regulator 1667 D9QCK4 Acetate kinase

1668 D9QEK0 Two-component system transcriptional regulatory protein 1669 D9QCG4 ATP-dependent zinc metalloprotease FtsH

1670 D9QA53 Acetylornithine aminotransferase

1671 D9QCU6 Lysine--tRNA ligase

1672 D9QDU5 Surface antigen

1673 D9QEF9 Translation initiation factor IF-1

1674 D9QEG6 Uncharacterized protein

1675 D9QBU4 Proline iminopeptidase

1676 D9Q964 Citrate synthase

1677 D9QCV7 Uncharacterized protein

1678 D9QBY1 Valine--tRNA ligase

1679 D9QDQ5 Pyridoxal 5;

1680 D9QDB8 N-acetylglucosamine-6-phosphate deacetylase

1681 D9Q963 Phosphoserine aminotransferase

1682 D9QE21 Uncharacterized protein

1683 D9QDT6 MFS-type drug efflux transporter

1684 D9QD19 LSR2-like protein

1685 D9QCW7 Uncharacterized protein

1686 F9Y349 Uncharacterized protein

1687 D9QCC6 Uncharacterized protein

1688 D9Q9T2 Uncharacterized protein

1689 D9QAM5 Uncharacterized protein

1690 D9QCX6 Trehalose corynomycolyl transferase B

1691 D9QAM1 Coenzyme A biosynthesis bifunctional protein CoaBC

1692 D9QD18 Uncharacterized protein

1693 D9QAY7 Diaminopimelate epimerase

1694 D9QC63 Glutaredoxin-like protein $\mathrm{nrdH}$

1695 D9QCT8 Urease accessory protein UreE

1696 D9Q9T0 Uncharacterized protein

1697 D9QDX3 Uncharacterized protein yqeY

1698 F9Y369 Uncharacterized protein

1699 D9QEN0 Ribonuclease BN-like family

1700 D9QET7 Ribosome hibernation promoting factor

1701 D9Q968 Uncharacterized protein

1702 D9Q939 Peptide chain release factor 2

1703 D9QAB8 FxsA cytoplasmic membrane protein

1704 D9QDP6 Quinone oxidoreductase 1

1705 D9QCA3 Hemolysin III-like protein

1706 D9QCQ5 Macrolide export ATP-binding/permease protein macB

1707 D9QB25 Predicted nucleic-acid-binding protein implicated in transcr

1708 D9QBG3 Uncharacterized protein

1709 D9QCQ1 Sodium/glutamate symporter

1710 D9QC54 Uncharacterized protein

1711 D9Q9K7 UvrABC system protein A

1712 D9QBU2 Oligopeptide transport ATP-binding protein OppD

1713 F9Y338 Uncharacterized protein

1714 D9Q9C3 5-formyltetrahydrofolate cyclo-ligase

1715 D9QD97 Uncharacterized protein

1716 D9Q9V2 ATP synthase subunit alpha

1717 D9QBX5 Uncharacterized protein

1718 F9Y335 Uncharacterized protein

1719 D9Q9P1 Ribosomal RNA methyltransferase

1720 D9QE91 Uncharacterized protein

1721 D9QAF2 Uncharacterized protein

1722 D9QED9 L-serine dehydratase 1

1723 D9Q9H1 Uncharacterized protein

1724 D9QD95 Transcription regulator padR

1725 D9QDN1 Uncharacterized protein

1726 D9QC01 ABC transporter ATP-binding protein

1727 D9QD04 SEC-C domain-containing protein

1728 D9QC81 Cytochrome d ubiquinol oxidase subunit 2

1729 D9QC39 Caax amino protease

1730 D9QE49 Uroporphyrinogen-III synthase

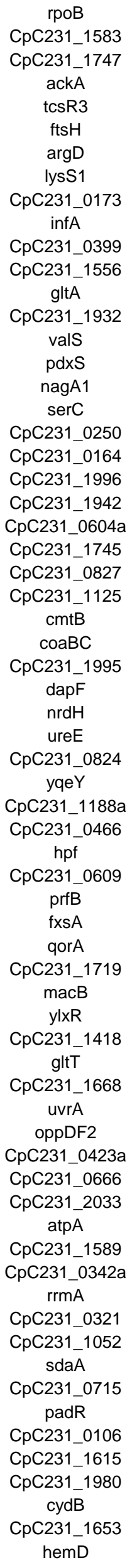

1178 Cytoplasmic;

530 Membrane;

363 Cytoplasmic;

400 Cytoplasmic;

225 Cytoplasmic;

667 Membrane;

416 Cytoplasmic;

1083 Membrane;

1071 Cellwall;

72 Cytoplasmic;

452 Membrane;

423 Cytoplasmic;

431 Cytoplasmic;

396 Membrane;

911 Cytoplasmic;

323 Cytoplasmic;

383 Cytoplasmic;

377 Membrane;

96 Membrane;

459 Membrane;

106 Cytoplasmic;

209 Extracellular;

34 Extracellular;

159 Membrane;

209 Cytoplasmic;

42 Extracellular;

341 Extracellular;

417 Cytoplasmic;

210 Cytoplasmic;

297 Cytoplasmic;

77 Cytoplasmic;

158 Cytoplasmic;

119 Cytoplasmic;

153 Cytoplasmic;

117 Extracellular;

361 Membrane;

222 Cytoplasmic;

53 Extracellular;

366 Cytoplasmic;

176 Membrane;

319 Cytoplasmic;

225 Membrane;

423 Membrane;

124 Cytoplasmic;

34 Extracellular;

449 Membrane;

46 Extracellular;

734 Membrane;

477 Membrane;

63 Cytoplasmic;

205 Cytoplasmic;

157 Membrane;

542 Cytoplasmic;

57 Extracellular;

34 Extracellular;

288 Cytoplasmic;

344 Extracellular;

62 Cytoplasmic;

458 Cytoplasmic;

188 Cytoplasmic;

107 Cytoplasmic;

176 Cytoplasmic;

570 Cytoplasmic;

303 Cytoplasmic;

327 Membrane;

220 Membrane;

562 Cytoplasmic;

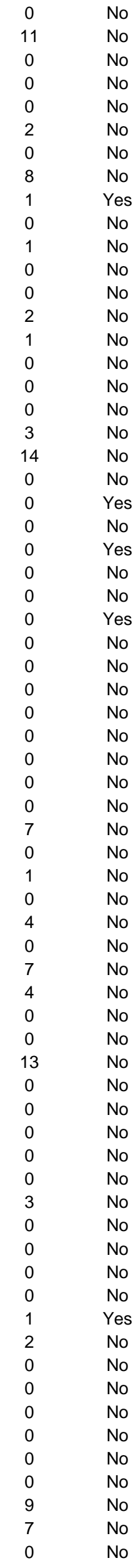


Anexo 1

1731 D9QCL3 Uncharacterized protein

1732 D9QCX4 Trehalose corynomycolyl transferase C

1733 D9QBI8 Uncharacterized protein

1734 D9QCM0 Cytochrome c-552

1735 D9QEH9 Uncharacterized protein

1736 D9QD17 RecB family nuclease

1737 D9QDU7 RNA polymerase sigma factor

1738 D9Q962 Uncharacterized protein

1739 D9QBF7 Acyltransferase

1740 F9Y344 Uncharacterized protein

1741 D9QBT2 Uncharacterized protein

1742 D9QE81 Protein translocase subunit SecE

1743 D9QAH6 Glutamine amidotransferase class-I

1744 D9QDF2 tRNA nucleotidyltransferase

1745 D9QBF8 1-acyl-sn-glycerol-3-phosphate acyltransferase

1746 D9QDE3 N-(5;

1747 D9QC00 Thioesterase

1748 D9QAY3 Pyrimidine permease rutG

1749 D9QDG5 Putative membrane protein insertion efficiency factor

1750 D9QB87 Metal-dependentamidase/aminoacylase/carboxypeptidase

1751 D9Q9L3 Uncharacterized protein

1752 D9QB26 Transcription termination/antitermination protein NusA

1753 D9Q9U5 tRNA threonylcarbamoyladenosine biosynthesis protein $\mathrm{Yv}$

1754 D9QAQ4 HTH-type transcriptional repressor KstR

1755 D9QBM9 Zn-ribbon protein

1756 D9Q943 SsrA-binding protein

1757 D9Q9T8 Homoserine dehydrogenase

1758 D9QCE9 Caax amino protease family

1759 D9QBN0 GTP cyclohydrolase 1 type 2 homolog

1760 D9QCI0 Thiol dipeptidase

1761 D9QBH8 Oxidoreductase

1762 D9QDR6 Zinc-binding alcohol dehydrogenase

1763 D9QEH5 50 S ribosomal protein L13

1764 D9QCB8 Response regulator mprA

1765 D9QA27 PhzF family phenazine biosynthesis protein

1766 D9QAQ2 Uncharacterized protein yhgE

1767 D9QCR4 Heat shock protein HspR

1768 D9Q9B5 50 S ribosomal protein L32

1769 D9QE55 3-hydroxyisobutyrate dehydrogenase

1770 D9QDK6 PTS system, IIA component

1771 D9Q936 Uncharacterized protein

1772 D9QC77 Serine acetyltransferase

1773 D9QC28 Uncharacterized protein

1774 D9QAN1 Bifunctional protein PyrR

1775 D9QBQ7 Uncharacterized protein

1776 D9QDJ4 Gamma-type carbonic anhydratase-like protein

1777 D9QBL2 Regulatory protein

1778 D9Q935 Methylmalonyl-CoA carboxyltransferase 1.3S subunit

1779 D9QA81 SAM-dependent methyltransferase

1780 D9QDD4 Uncharacterized protein

1781 D9Q999 Uncharacterized metalloprotease

1782 D9Q9V8 Methylmalonyl-CoA epimerase

1783 D9QDH2 Uncharacterized protein

1784 D9QAR3 Peptidyl-prolyl cis-trans isomerase B

1785 D9QD08 Thymidine phosphorylase

1786 D9QCJ7 Cardiolipin synthase

1787 D9QBU9 Uncharacterized protein

1788 D9QAC2 Precorrin-3B C(17)-methyltransferase

1789 D9QB93 Uncharacterized protein

1790 D9QEM5 Arabinose efflux permease

1791 D9QD62 Uncharacterized protein

1792 D9Q9F7 50 S ribosomal protein L25

1793 D9QD53 Multiple antibiotic resistance protein marR

1794 D9QAE1 Formate--tetrahydrofolate ligase

1795 D9QBV2 ABC transporter ATP-binding protein

1796 D9Q9L9 Trypsin-like serine protease

1797 D9QBJ6 Uncharacterized protein

\begin{tabular}{|c|c|c|c|}
\hline СpC231_1833 & 103 Extracellular; & 0 & No \\
\hline $\mathrm{cmtC}$ & 644 Extracellular; & 0 & Yes \\
\hline CpC231_1444 & 81 Membrane; & 2 & No \\
\hline$n r f \bar{A}$ & 483 Cytoplasmic; & 1 & No \\
\hline CpC231_0412 & 387 Membrane; & 0 & No \\
\hline $\operatorname{rec} \bar{B}$ & 520 Cytoplasmic; & 0 & No \\
\hline sigC & 187 Cytoplasmic; & 0 & No \\
\hline CpC231_0603 & 361 Cytoplasmic; & 0 & No \\
\hline СpC231_1412 & 368 Membrane; & 10 & No \\
\hline СpC231 0569a & 30 Extracellular; & 0 & Yes \\
\hline СpC231_1543 & 168 Extracellular; & 0 & Yes \\
\hline $\sec \bar{E}$ & 108 Cytoplasmic; & 1 & No \\
\hline CpC231_1076 & 239 Cytoplasmic; & 0 & No \\
\hline $\mathrm{cca}^{-}$ & 533 Cytoplasmic; & 0 & No \\
\hline plsC & 242 Membrane; & 0 & No \\
\hline $\operatorname{trpC}$ & 495 Membrane; & 0 & No \\
\hline CpC231_1614 & 142 Cytoplasmic; & 0 & No \\
\hline CpC231_1234 & 428 Membrane; & 12 & No \\
\hline CpC231_2101 & 95 Extracellular; & 0 & No \\
\hline$a m i \bar{B}$ & 420 Membrane; & 0 & No \\
\hline CpC231_0757 & 155 Cytoplasmic; & 0 & No \\
\hline nus $\bar{A}$ & 332 Cytoplasmic; & 0 & No \\
\hline ywlC & 216 Cytoplasmic; & 0 & No \\
\hline kstR & 200 Membrane; & 0 & No \\
\hline CpC231_1489 & 238 Cytoplasmic; & 0 & No \\
\hline $\mathrm{smpB}$ & 163 Cytoplasmic; & 0 & No \\
\hline thrA & 449 Cytoplasmic; & 0 & No \\
\hline CpC231_1768 & 220 Membrane; & 7 & No \\
\hline CpC231_1490 & 385 Cytoplasmic; & 0 & No \\
\hline $\operatorname{tpd} \bar{A}$ & 521 Membrane; & 0 & No \\
\hline CpC231_1433 & 131 Cytoplasmic; & 0 & No \\
\hline $\mathrm{idn} \overline{\mathrm{D}}$ & 329 Membrane; & 0 & No \\
\hline rplM & 147 Cytoplasmic; & 0 & No \\
\hline mprA & 237 Cytoplasmic; & 0 & No \\
\hline phzF & 272 Extracellular; & 0 & No \\
\hline CpC231_1152 & 673 Membrane; & 6 & No \\
\hline $\mathrm{hsp} \overline{\mathrm{R}}$ & 133 Cytoplasmic; & 0 & No \\
\hline rpmF & 57 Cytoplasmic; & 0 & No \\
\hline $\mathrm{mmsB}$ & 278 Membrane; & 0 & No \\
\hline sgaA & 271 Cytoplasmic; & 0 & No \\
\hline CpC231_0575 & 394 Extracellular; & 0 & Yes \\
\hline cys $\bar{E}$ & 188 Cytoplasmic; & 0 & No \\
\hline CpC231_1642 & 91 Cytoplasmic; & 1 & No \\
\hline pyr $\bar{R}$ & 221 Cytoplasmic; & 0 & No \\
\hline CpC231_1517 & 65 Cytoplasmic; & 0 & No \\
\hline gca & 185 Cytoplasmic; & 0 & No \\
\hline pfos & 356 Membrane; & 10 & No \\
\hline CpC231_0574 & 120 Cytoplasmic; & 0 & No \\
\hline СpC231_0979 & 279 Extracellular; & 0 & No \\
\hline CpC231_2070 & 378 Cytoplasmic; & 0 & No \\
\hline CpC231_0642 & 237 Extracellular; & 0 & Yes \\
\hline СpC231_0853 & 152 Cytoplasmic; & 0 & No \\
\hline CpC231_0046 & 96 Cytoplasmic; & 0 & No \\
\hline $\mathrm{ppi} \bar{B}$ & 284 Extracellular; & 1 & No \\
\hline deoA & 433 Cytoplasmic; & 0 & No \\
\hline cls & 497 Membrane; & 2 & No \\
\hline CpC231_1561 & 57 Cytoplasmic; & 0 & No \\
\hline cobJ & 501 Cytoplasmic; & 0 & No \\
\hline CpC231_1348 & 213 Membrane; & 3 & Yes \\
\hline araJ & 409 Membrane; & 12 & No \\
\hline CpC231_0007 & 77 Extracellular; & 0 & No \\
\hline $\mathrm{rpl} \bar{Y}$ & 205 Cytoplasmic; & 0 & No \\
\hline marR3 & 176 Membrane; & 0 & No \\
\hline fhs & 550 Cytoplasmic; & 0 & No \\
\hline CpC231_1566 & 209 Cytoplasmic; & 0 & No \\
\hline $\operatorname{spr} \bar{X}$ & 246 Extracellular; & 0 & Yes \\
\hline $\mathrm{CpC} 2311453$ & 75 Cytoplasmic; & 0 & No \\
\hline
\end{tabular}




\section{Anexo 1}

1798 D9Q9D6 TatD family hydrolase 1799 D9QDC0 N-acetylglucosamine kinase

1800 D9QAK1 Protein-export membrane protein secG 1801 D9QC04 Uncharacterized protein

1802 D9QCY4 Glycerophosphoryl diester phosphodiesterase 1803 D9QDI9 Uncharacterized protein

1804 D9QB80 Metal-binding, possibly nucleic acid-binding protein 1805 D9QCF9 Uncharacterized protein 1806 D9QEU0 Haloacid dehalogenase-like hydrolase 1807 F9Y387 Uncharacterized protein 1808 D9QEl1 Abhydrolase domain-containing protein 5 1809 D9QAE0 Virulence-associated protein I

1810 D9QDH6 ECF family sigma factor K

1811 D9Q9M6 Uncharacterized protein

1812 D9QEV1 Uncharacterized protein 1813 D9QD23 Uncharacterized protein

1814 D9QEI7 Ribosomal-protein-alanine $\mathrm{N}$-acetyltransferase

1815 D9Q9N4 2,3,4,5-tetrahydropyridine-2,6-dicarboxylate N-succinyltran 1816 D9Q9C9 Uncharacterized protein

1817 D9Q958 Uncharacterized protein

1818 D9QBJ2 Protein p51

1819 D9QAZ5 Uncharacterized protein 1820 D9Q9M7 Ferredoxin

1821 D9Q9D1 Uncharacterized protein

1822 D9QDB4 Two-component system histidine kinase ChrS

1823 D9Q9S0 Uncharacterized protein

1824 D9QDY7 Uncharacterized protein

1825 D9Q9G8 LpqU family protein

1826 D9QES0 Mannose-1-phosphate guanylyltransferase

1827 D9QB49 Uncharacterized protein

1828 D9QA66 Thiamin pyrophosphokinase, catalytic domain-containing $\mathrm{r}$ 1829 D9QAU4 Ribonuclease D

1830 D9QEW3 Uncharacterized protein

1831 D9QAG7 NfeD-like protein

1832 D9QBM3 Uncharacterized protein

1833 D9QDX7 RutC family protein yabJ

1834 D9QEQ0 Maf-like protein CpC231

1835 D9QCQ8 Uncharacterized protein

1836 D9QEW4 Uncharacterized protein

1837 D9QDY4 Trypsin-like serine protease

1838 D9QBR1 Isoprenyl transferase

1839 D9QAS5 Uncharacterized protein

1840 D9QE92 Manganese transport system ATP-binding protein MntB

1841 D9Q9G4 TetR family transcriptional regulator

1842 D9Q9N2 2,3,4,5-tetrahydropyridine-2,6-dicarboxylate N-succinyltran

1843 D9QCE7 Inosine-uridine preferring nucleoside hydrolase

1844 D9Q9K0 Uncharacterized protein

1845 D9Q9J4 Fructose-1,6-bisphosphatase

1846 D9QAM3 Guanylate kinase

1847 D9QCY2 Membrane-associated phospholipid phosphatase

1848 D9QAQ0 Zinc metallopeptidase

1849 D9Q9Z4 Acetolactate synthase 3 regulatory subunit

1850 D9QCR1 Alcohol dehydrogenase GroES-like protein

1851 D9QD80 Phospholipase D

1852 D9QAG8 Uncharacterized protein

1853 F9Y336 Uncharacterized protein

1854 D9QCW5 Uncharacterized protein

1855 D9QCX3 Uncharacterized protein

1856 D9QC67 Uncharacterized protein

1857 D9QB68 Cupin domain-containing protein

1858 D9QDG7 50 S ribosomal protein L34

1859 D9Q9J3 Fumarate hydratase class II

1860 D9Q9U2 Transcription termination factor Rho

1861 D9QCL5 Uncharacterized protein

1862 D9QEI5 Uncharacterized protein

1863 D9QB51 Ribosome-recycling factor

1864 D9QEN5 Uncharacterized protein

\begin{tabular}{|c|c|c|}
\hline tatD & 280 Cytoplasmic; & 0 \\
\hline nanK & 297 Cytoplasmic; & 0 \\
\hline $\sec G$ & 78 Membrane; & 2 \\
\hline CpC231_1618 & 584 Membrane; & 0 \\
\hline$g \mid p \bar{Q}$ & 365 Cytoplasmic; & 0 \\
\hline CpC231_0063 & 474 Extracellular; & 0 \\
\hline CpC231_1334 & 175 Cytoplasmic; & 0 \\
\hline CpC231_1779 & 148 Membrane; & 4 \\
\hline CpC231_0526 & 136 Cytoplasmic; & 0 \\
\hline СpC231_2063a & 77 Cytoplasmic; & 0 \\
\hline CpC231_0414 & 280 Membrane; & 0 \\
\hline vapl & 100 Cytoplasmic; & 0 \\
\hline sigK & 183 Cytoplasmic; & 0 \\
\hline CpC231_0770 & 133 Membrane; & 4 \\
\hline CpC231_0537 & 140 Membrane; & 3 \\
\hline CpC231_2000 & 50 Extracellular; & 1 \\
\hline riml- & 163 Cytoplasmic; & 0 \\
\hline dapD1 & 304 Cytoplasmic; & 0 \\
\hline CpC231_0672 & 221 Membrane; & 4 \\
\hline СpC231_0599 & 244 Cytoplasmic; & 0 \\
\hline CpC231_1448 & 337 Cytoplasmic; & 0 \\
\hline CpC231_1247 & 70 Cytoplasmic; & 0 \\
\hline $\mathrm{fdx} \overline{\mathrm{A}}$ & 105 Cytoplasmic; & 0 \\
\hline СpC231_0674 & 70 Extracellular; & 0 \\
\hline chrS & 424 Membrane; & 6 \\
\hline СpC231_0814 & 156 Membrane; & 4 \\
\hline CpC231_0216 & 221 Cytoplasmic; & 0 \\
\hline $\mathrm{Ipq} \overline{\mathrm{U}}$ & 261 Extracellular; & 1 \\
\hline manc & 362 Cytoplasmic; & 0 \\
\hline CpC231_1303 & 144 Membrane; & 2 \\
\hline СpC231_0964 & 397 Cytoplasmic; & 1 \\
\hline rnd & 401 Cytoplasmic; & 0 \\
\hline СpC231 0549 & 283 Cytoplasmic; & 0 \\
\hline CpC231_1067 & 142 Membrane; & 2 \\
\hline CpC231_1483 & 314 Membrane; & 0 \\
\hline yabJ & 152 Cytoplasmic; & 0 \\
\hline maf & 209 Cytoplasmic; & 0 \\
\hline CpC231_1880 & 55 Cytoplasmic; & 0 \\
\hline CpC231_0550 & 183 Cytoplasmic; & 0 \\
\hline htrA $\overline{2}$ & 399 Membrane; & 4 \\
\hline upps2 & 245 Cytoplasmic; & 0 \\
\hline CpC231_1175 & 46 Extracellular; & 1 \\
\hline $\mathrm{mnt} \overline{\mathrm{B}}$ & 257 Membrane; & 0 \\
\hline tetR1 & 215 Cytoplasmic; & 0 \\
\hline dapD & 324 Cytoplasmic; & 0 \\
\hline iunH2 & 330 Cytoplasmic; & 0 \\
\hline СpC231_0744 & 524 Membrane; & 10 \\
\hline $\operatorname{glp} \bar{X}$ & 336 Cytoplasmic; & 0 \\
\hline gmk & 191 Cytoplasmic; & 0 \\
\hline СpC231_1957 & 168 Membrane; & 4 \\
\hline CpC231_1150 & 297 Extracellular; & 1 \\
\hline ilvH & 174 Membrane; & 0 \\
\hline $\operatorname{adh} A$ & 385 Cytoplasmic; & 0 \\
\hline pld & 307 Extracellular; & 0 \\
\hline CpC231_1068 & 280 Cytoplasmic; & 0 \\
\hline CpC231_0370a & 41 Extracellular; & 0 \\
\hline СpC231_1940 & 349 Membrane; & 10 \\
\hline CpC231_1948 & 175 Extracellular; & 0 \\
\hline CpC231_1681 & 138 Cytoplasmic; & 0 \\
\hline CpC231_1322 & 193 Membrane; & 0 \\
\hline rpmi & 47 Cytoplasmic; & 0 \\
\hline fumC & 467 Cytoplasmic; & 0 \\
\hline rho & 714 Cytoplasmic; & 0 \\
\hline CpC231_1835 & 85 Extracellular; & 0 \\
\hline CpC231_0418 & 158 Membrane; & 0 \\
\hline frr & 185 Cytoplasmic; & 0 \\
\hline СpC231_0471 & 89 Cytoplasmic; & 0 \\
\hline
\end{tabular}


Anexo 1

1865 D9QCW0 SAM-dependent methyltransferase 1866 D9QDS9 Uncharacterized protein

1867 D9Q9S8 Multiple antibiotic resistance protein marR 1868 D9QB82 Alanine dehydrogenase 1869 D9QDT0 Cobyric acid synthase 1870 D9QA80 Anaerobic C4-dicarboxylate transporter 1871 D9QAQ7 Citrate lyase subunit beta-like protein 1872 D9QDQ1 Nitric-oxide reductase, cytochrome b-containing subunit I 1873 D9QB05 TerC family

1874 F9Y339 Uncharacterized protein

1875 D9Q9L1 HMP/thiamine import ATP-binding protein

1876 D9QAA2 UPF0053 protein

1877 D9QCW4 Transmembrane transport protein MmpL

1878 F9Y343 Uncharacterized protein

1879 D9QC41 Uncharacterized protein

1880 D9QD37 Phage shock protein A

1881 D9QCG1 7,8-dihydroneopterin aldolase

1882 D9QB18 tRNA pseudouridine synthase $B$

1883 D9QCC5 Trehalose-6-phosphate synthase

1884 D9QD10 Peptide methionine sulfoxide reductase MsrA

1885 D9QEK2 Sucrase ferredoxin-like protein

1886 D9QE63 ABC-type transporter

1887 D9QBW1 DNA uptake protein, SLBB domain protein

1888 D9QCU3 Uncharacterized protein

1889 D9Q9S7 Metabolite transport protein ycel

1890 D9QB61 Signal peptidase I

1891 D9QEU4 Ribosome biogenesis GTPase RsgA

1892 D9QD85 Cell division protein CrgA

1893 D9QD69 Periplasmic binding protein/Lacl transcriptional regulator

1894 F9Y383 Uncharacterized protein

1895 D9Q9S2 Sodium/proline symporter

1896 F9Y362 Uncharacterized protein

1897 D9QB32 Uncharacterized protein

1898 D9QCC9 Poly(3-hydroxyalkanoate) depolymerase

1899 D9QCF8 Uncharacterized protein

1900 D9QEI3 UPF0079 ATP-binding protein

1901 D9Q9M1 Uncharacterized protein

1902 D9QE58 Thiol-disulfide isomerase/thioredoxin

1903 D9QAN6 Uncharacterized peptidase yqhT, Metallopeptidase family

1904 D9QBD5 UDP-N-acetylglucosamine--N-acetylmuramyl-(pentapeptid

1905 F9Y361 Uncharacterized protein

1906 D9QE44 Thiol:disulfide interchange protein DsbD

1907 D9QEH8 Uncharacterized protein

1908 D9QAB0 Cyclopropane fatty acid synthase

1909 D9QC17 Uncharacterized protein

1910 D9QAK8 Nucleotide-binding protein CpC231

1911 D9QBY9 Uncharacterized protein

1912 D9QEM3 Uncharacterized protein

1913 D9Q9Q2 Magnesium transporter mgtE

1914 D9QE98 Two-component system sensor kinase protein

1915 D9QA92 Uncharacterized protein

1916 F9Y356 Uncharacterized protein

1917 D9QC33 Uncharacterized protein

1918 D9QEJ4 Inosine-5;

1919 D9QCT1 Transcriptional regulatory protein

1920 D9QE12 Uncharacterized protein

1921 D9QBX6 Uncharacterized protein

1922 D9QCV0 dCTP deaminase

1923 D9QDU2 Uncharacterized protein

1924 D9QCF7 Uncharacterized protein

1925 D9QEX9 Uncharacterized protein

1926 D9QA47 rRNA methyltransferase

1927 D9QBR5 CBS domain-containing protein

1928 D9QC20 Mycocerosic acid synthase

1929 D9QDY3 Uncharacterized Nudix hydrolase nudL

1930 D9Q9P6 O-methyltransferase

1931 D9QBZ9 Uncharacterized protein
CpC231 1935

CpC231_0156

marR1

ald

cobQ

dcuB

CpC231_1157

norB

terC

CpC231_0423b

ykoD

CpC231_1001

$\mathrm{mmpL}$

CpC231_0560a

CpC231_1655

pspA1

folB

truB

ots A

mrsA

CpC231 0436

CpC231_0292

CpC231_1575

CpC231_1917

ycel

lepB

rsgA

crgA

CpC231_0014

CpC231_1890a putP

CpC231_0993a

CpC231_1284

CpC231_1748

CpC231_1778 ydiB

CpC231_0765 $\operatorname{ccs} \mathrm{X}$

CpC231_1136 murG

CpC231_0989a dsbD

CpC231_0411 ufaA

CpC231_1631

CpC231_1108

CpC231_1603

$\mathrm{htaC}$

mgtE2

cstS

CpC231_0990

CpC231_0931a

CpC231_1647

guaB2

CpC231_1905

CpC231_0241

CpC231_1590

dcd

CpC231_0170

CpC231_1777

CpC231_0565

tsn $R$

CpC231_1525

mas

nudL

CpC231_0790

CpC231_1613
53 Extracellular;

41 Extracellular;

158 Cytoplasmic;

369 Membrane;

250 Cytoplasmic;

461 Membrane;

300 Cytoplasmic;

766 Membrane;

331 Membrane;

30 Extracellular;

466 Membrane;

350 Membrane;

874 Membrane;

56 Cytoplasmic;

119 Membrane;

295 Cytoplasmic;

105 Cytoplasmic;

303 Membrane;

491 Cytoplasmic;

224 Cytoplasmic;

290 Cytoplasmic;

328 Cytoplasmic;

205 Cytoplasmic;

59 Extracellular;

175 Cytoplasmic;

271 Cytoplasmic;

338 Cytoplasmic;

89 Extracellular;

333 Extracellular;

35 Extracellular;

480 Membrane;

46 Extracellular;

377 Cytoplasmic;

285 Extracellular;

174 Membrane;

164 Cytoplasmic;

177 Cytoplasmic;

194 Membrane;

363 Cytoplasmic;

361 Cytoplasmic;

58 Extracellular;

274 Membrane;

99 Cytoplasmic;

435 Cytoplasmic;

66 Extracellular;

299 Cytoplasmic;

44 Extracellular;

302 Extracellular;

430 Cytoplasmic;

382 Membrane;

717 Cellwall;

30 Extracellular;

101 Cytoplasmic;

380 Cytoplasmic;

103 Cytoplasmic;

44 Extracellular;

228 Membrane;

188 Cytoplasmic;

368 Membrane;

128 Cytoplasmic;

218 Extracellular;

289 Cytoplasmic;

441 Membrane;

334 Cytoplasmic;

259 Cytoplasmic;

210 Cytoplasmic;

202 Membrane;
0 No

0 No

0 No

0 No

13

No

No

No

No

No

No

No

No

No

No

No

No

No

No

No

No

Yes

No

No

No

No

No

No

Yes

No

No

No

No

No

No

No

No

Yes

No

No

No

No

No

No

No

No

No

Yes

No

No

No

No

No

No

No

No

No

No

No

No

No

No

No

No

No

No

No 
Anexo 1

1932 D9QBG0 Mannosyltransferase 1933 D9QDV9 Response regulator mprA

1934 D9QAK7 Putative gluconeogenesis factor 1935 D9QA58 Uncharacterized protein

1936 D9Q992 G/U mismatch-specific DNA glycosylase

1937 D9QAE4 ATP phosphoribosyltransferase

1938 D9QBJ0 Uncharacterized protein

1939 D9Q9Z7 Uncharacterized protein

1940 D9QAl8 FeS cluster assembly protein SufD

1941 D9QAW0 RNA polymerase sigma factor

1942 D9QDQ8 Uncharacterized protein

1943 D9QCl2 Uncharacterized protein

1944 D9QBU7 Uncharacterized protein

1945 D9QAW1 Diphtheria toxin repressor

1946 D9QCZ8 Prephenate dehydratase

1947 D9QCX9 Membrane-associated phospholipid phosphatase

1948 D9QAV2 Polyphosphate glucokinase

1949 D9Q9C2 Uncharacterized protein

1950 D9QEA5 Anaerobic ribonucleoside triphosphate reductase

1951 D9Q9E1 Antibiotic biosynthesis monooxygenase

1952 D9Q9S4 Uncharacterized protein

1953 D9QAF3 Uncharacterized protein

1954 D9QBN4 SURF1-like protein

1955 D9QA89 Efflux protein

1956 D9QAM4 Integration host factor MihF

1957 D9QDR5 Gluconokinase

1958 D9QBB0 Glycogen debranching protein

1959 D9QEU1 Uncharacterized protein

1960 D9QAJ7 Transaldolase

1961 D9QDR8 Uncharacterized protein

1962 D9Q9P2 Sucrose-6-phosphate hydrolase

1963 D9QEB5 Uncharacterized protein

1964 D9QAP1 Uncharacterized protein

1965 D9QB76 Acylphosphatase

1966 D9QAZ7 Cobalt import ATP-binding protein CbiO

1967 D9Q9M0 Arsenate reductase

1968 D9QAF1 Dihydroorotate dehydrogenase (quinone)

1969 D9QBW4 Ribosomal silencing factor RsfS

1970 D9QBA9 DNA polymerase III PoIC

1971 D9Q9Q7 Shikimate 5-dehydrogenase

1972 D9QD65 Uncharacterized protein

1973 D9QBZ8 Uncharacterized protein

1974 D9QCJ6 Exodeoxyribonuclease III

1975 D9QEK5 D-methionine-binding lipoprotein metQ

1976 F9Y385 Uncharacterized protein

1977 D9QAY1 Luciferase-like monooxygenase

1978 D9QEH2 Uncharacterized protein

1979 D9Q933 Methylmalonyl-CoA carboxyltransferase 12S subunit 1980 D9Q973 Uncharacterized protein

1981 D9QEW7 Uncharacterized protein

1982 D9QA62 Uncharacterized protein

1983 D9QAW6 Alkyl hydroperoxide reductase AhpD

1984 D9QB50 Phosphatidate cytidylyltransferase

1985 D9QDP2 Phosphatidylglycerophosphatase B

1986 D9QBG9 Cytochrome c oxidase subunit II

1987 D9QCV3 Beta-N-acetylglucosaminidase

1988 D9QDS2 Nucleoid-associated protein CpC231

1989 D9QDA9 Uncharacterized protein

1990 D9QAL8 Peptide deformylase

1991 D9QCB5 HIT family protein

1992 D9QBD0 Cell division protein SepF

1993 D9QEW9 UPF0182 protein CpC231

1994 D9Q9E5 Nicotinamide riboside transporter pnuC

1995 D9Q9D3 Uncharacterized protein

1996 D9QCD7 Uncharacterized protein

1997 D9QAD1 Protein pafC

1998 D9QEH4 ESAT-6-like protein

\begin{tabular}{|c|c|c|c|}
\hline pimB & 376 Cytoplasmic; & 0 & No \\
\hline mprA & 233 Cytoplasmic; & 0 & No \\
\hline CpC231_1107 & 342 Cytoplasmic; & 0 & No \\
\hline СpC231_0956 & 61 Cytoplasmic; & 0 & No \\
\hline mug & 211 Membrane; & 0 & No \\
\hline hisG & 281 Cytoplasmic; & 0 & No \\
\hline CpC231_1446 & 69 Cytoplasmic; & 1 & No \\
\hline CpC231_0894 & 620 Cytoplasmic; & 0 & No \\
\hline sufD & 393 Cytoplasmic; & 0 & No \\
\hline $\operatorname{sig} B$ & 329 Cytoplasmic; & 0 & No \\
\hline СpC231_0134 & 160 Cytoplasmic; & 0 & No \\
\hline CpC231_1802 & 355 Membrane; & 2 & No \\
\hline CpC231_1559 & 71 Extracellular; & 0 & Yes \\
\hline$d t \times R$ & 226 Cytoplasmic; & 0 & No \\
\hline pheA & 269 Cytoplasmic; & 0 & No \\
\hline CpC231_1954 & 168 Membrane; & 1 & No \\
\hline ppgk & 258 Cytoplasmic; & 0 & No \\
\hline CpC231_0665 & 250 Membrane; & 0 & Yes \\
\hline $\mathrm{nrdD}$ & 598 Extracellular; & 0 & No \\
\hline CpC231_0684 & 107 Cytoplasmic; & 0 & No \\
\hline СpC231_0818 & 261 Cytoplasmic; & 0 & No \\
\hline CpC231_1053 & 130 Membrane; & 4 & No \\
\hline CpC231_1494 & 314 Membrane; & 2 & No \\
\hline $\operatorname{ciuF}$ & 430 Membrane; & 12 & No \\
\hline $\operatorname{minF}$ & 107 Cytoplasmic; & 0 & No \\
\hline idnK & 163 Cytoplasmic; & 0 & No \\
\hline $\operatorname{glg} X$ & 211 Membrane; & 0 & No \\
\hline CpC231_0527 & 168 Cytoplasmic; & 0 & No \\
\hline tal & 360 Cytoplasmic; & 0 & No \\
\hline CpC231_0144 & 37 Extracellular; & 0 & Yes \\
\hline $\operatorname{scr} \bar{B}$ & 483 Cytoplasmic; & 0 & No \\
\hline СpC231_0346 & 68 Membrane; & 2 & No \\
\hline CpC231_1141 & 176 Membrane; & 6 & No \\
\hline acyP & 105 Cytoplasmic; & 0 & No \\
\hline bioM & 230 Cytoplasmic; & 0 & No \\
\hline $\operatorname{arsC}$ & 114 Cytoplasmic; & 0 & No \\
\hline pyrD & 348 Cytoplasmic; & 0 & No \\
\hline rsfS & 155 Cytoplasmic; & 0 & No \\
\hline CpC231_1364 & 453 Extracellular; & 0 & No \\
\hline aroE & 271 Membrane; & 0 & No \\
\hline CpC231_0010 & 114 Membrane; & 2 & No \\
\hline CpC231_1612 & 298 Membrane; & 10 & No \\
\hline xthA & 255 Cytoplasmic; & 0 & No \\
\hline metQ & 285 Cytoplasmic; & 0 & Yes \\
\hline CpC231_1989a & 37 Extracellular; & 0 & No \\
\hline CpC231_1232 & 371 Cytoplasmic; & 0 & No \\
\hline СpC231_0405 & 344 Cytoplasmic; & 1 & No \\
\hline СpC231_0572 & 518 Cytoplasmic; & 0 & No \\
\hline CpC231_0615 & 302 Extracellular; & 0 & Yes \\
\hline CpC231_0553 & 234 Extracellular; & 0 & Yes \\
\hline CpC231_0960 & 54 Cytoplasmic; & 0 & No \\
\hline $\operatorname{ahpD}$ & 174 Cytoplasmic; & 0 & No \\
\hline cdsA & 292 Membrane; & 9 & No \\
\hline pgpB & 244 Membrane; & 6 & No \\
\hline $\mathrm{ctaC}$ & 361 Membrane; & 2 & Yes \\
\hline nagA & 371 Extracellular; & 0 & Yes \\
\hline ybaB & 106 Cytoplasmic; & 0 & No \\
\hline CpC231_2045 & 32 Extracellular; & 0 & No \\
\hline def & 169 Cytoplasmic; & 0 & No \\
\hline CpC231_1731 & 141 Cytoplasmic; & 0 & No \\
\hline sepF & 149 Cytoplasmic; & 0 & No \\
\hline CpC231_0555 & 1010 Membrane; & 7 & No \\
\hline pnuC & 236 Membrane; & 7 & No \\
\hline CpC231_0676 & 514 Membrane; & 10 & No \\
\hline СpC231_1756 & 313 Membrane; & 0 & Yes \\
\hline pafC & 329 Cytoplasmic; & 0 & No \\
\hline esxT & 93 Extracellular; & 0 & No \\
\hline
\end{tabular}


Anexo 1

1999 D9QC18 Peptidase, S8A (Subtilisin) family protein 2000 D9Q9G5 Transcription-repair-coupling factor 2001 D9QEB2 Uncharacterized protein 2002 D9QCD6 Uncharacterized protein 2003 D9Q9X0 tRNA-specific 2-thiouridylase MnmA 2004 D9Q9N3 Aromatic amino acid transport protein 2005 D9QBK4 Uncharacterized protein 2006 D9Q9J5 Uncharacterized protein 2007 D9QAT4 Hit (Histidine triad) family protein 2008 D9QCC3 Threonine export carrier 2009 F9Y341 Uncharacterized protein 2010 D9QAJ3 Uncharacterized protein 2011 D9QE41 Uncharacterized protein 2012 D9QEM6 HTH-type transcriptional activator tipA 2013 D9QAH2 Uncharacterized protein 2014 D9QAJ4 Cytochrome oxidase assembly protein 2015 D9Q9F5 Uncharacterized protein 2016 D9QA63 Hemolysin A

2017 F9Y377 Uncharacterized protein 2018 D9QDW5 $\mathrm{Na}(+) / \mathrm{H}(+)$ antiporter subunit $\mathrm{C}$ 2019 D9Q986 Precorrin-6A synthase [deacetylating] 2020 D9QBS5 Uncharacterized protein 2021 D9QEI0 Uncharacterized protein 2022 D9QCN1 Transcription regulator padR 2023 D9QDN0 Uncharacterized protein 2024 D9QE01 Adenylate cyclase 2025 D9QBK2 Uncharacterized protein 2026 D9Q971 Uncharacterized protein 2027 D9Q9I0 Isoprenyl transferase 2028 D9QAX8 PTS system fructose-specific EIIABC component 2029 D9QCJ8 ABC transporter 2030 D9QDR0 Uncharacterized protein 2031 D9QE76 Glycosyl transferase group 1 2032 D9QDI3 Uncharacterized protein 2033 D9QEC4 50 S ribosomal protein L22

2034 D9QDL5 Methylated-DNA--protein-cysteine methyltransferase 2035 D9QC69 Uncharacterized protein

2036 D9QDS4 Inner membrane permease ygbN

2037 D9QCS1 Oligopeptide ABC transporter, ATP-binding protein 2038 D9QC57 Uncharacterized protein

2039 D9QCL0 Purine phosphoribosyltransferase

2040 D9QBI9 Uncharacterized protein

2041 D9QA12 3-isopropylmalate dehydratase large subunit 2042 D9QBS2 Long-chain-fatty-acid-CoA ligase

2043 D9QBL9 Uncharacterized protein

2044 D9QA46 Uncharacterized protein 2045 D9QA18 Uncharacterized protein 2046 D9QCF2 Uncharacterized protein 2047 D9QDJ5 Transcription factor Rok 2048 D9QET3 DNA-binding response regulator mtrA 2049 D9QE06 Glucose-1-phosphate thymidylyltransferase 2050 D9QAG1 Arginine/ornithine transport system ATPase 2051 D9QDJ6 Uncharacterized protein 2052 F9Y345 Uncharacterized protein 2053 D9QE70 1,4-dihydroxy-2-naphthoyl-CoA synthase 2054 D9QC52 Phosphoserine phosphatase

2055 D9QDL2 UPF0145 protein CpC231

2056 D9QCY1 Uncharacterized protein

2057 D9QCZ7 Phosphoglycerate mutase

2058 D9QE24 Pyruvate formate-lyase-activating enzyme 2059 D9QBN1 Aminotransferase

2060 D9QDK9 Alpha-ketoglutarate-dependent dioxygenase AlkB 2061 D9QEH7 Phosphoglucosamine mutase

2062 D9QB66 tRNA (guanine-N(1)-)-methyltransferase

2063 D9QEA9 Elongation factor $\mathrm{G}$

2064 D9QB72 Nitrogen regulatory protein P-II

2065 D9QBC3 Uncharacterized protein

\begin{tabular}{|c|c|c|}
\hline СpC231_1632 & 608 Extracellular; & 0 \\
\hline $\mathrm{mfd}$ & 1264 Cytoplasmic; & 0 \\
\hline СpC231_0343 & 181 Membrane; & 1 \\
\hline CpC231_1755 & 162 Cytoplasmic; & 1 \\
\hline $\mathrm{mnmA}$ & 372 Cytoplasmic; & 0 \\
\hline aroP2 & 454 Membrane; & 12 \\
\hline CpC231_1463 & 62 Cytoplasmic; & 0 \\
\hline СpC231_0739 & 189 Membrane; & 1 \\
\hline СpC231_1184 & 197 Cytoplasmic; & 0 \\
\hline CpC231_1741 & 489 Membrane; & 10 \\
\hline CpC231_0491a & 53 Extracellular; & 0 \\
\hline CpC231_1093 & 266 Membrane; & 6 \\
\hline CpC231_0270 & 40 Extracellular; & 0 \\
\hline tip $\bar{A}$ & 256 Cytoplasmic; & 0 \\
\hline CpC231_1072 & 31 Extracellular; & 0 \\
\hline CpC231_1094 & 331 Membrane; & 8 \\
\hline CpC231_0699 & 57 Cytoplasmic; & 0 \\
\hline tly $\bar{A}$ & 273 Cytoplasmic; & 0 \\
\hline CpC231_1610a & 39 Extracellular; & 0 \\
\hline $\mathrm{mrpC}$ & 151 Membrane; & 3 \\
\hline cobF & 251 Membrane; & 0 \\
\hline CpC231_1536 & 73 Cytoplasmic; & 1 \\
\hline CpC231_0413 & 101 Cytoplasmic; & 0 \\
\hline padR1 & 129 Cytoplasmic; & 0 \\
\hline CpC231_0105 & 153 Membrane; & 1 \\
\hline cya $\bar{A}$ & 505 Membrane; & 6 \\
\hline CpC231_1461 & 72 Cytoplasmic; & 0 \\
\hline CpC231_0612 & 113 Cytoplasmic; & 2 \\
\hline uppS1 & 265 Cytoplasmic; & 0 \\
\hline $\mathrm{pts} F$ & 649 Membrane; & 8 \\
\hline CpC231_1818 & 253 Membrane; & 6 \\
\hline CpC231_0136 & 100 Cytoplasmic; & 0 \\
\hline CpC231_0305 & 354 Cytoplasmic; & 0 \\
\hline CpC231_0057 & 66 Cytoplasmic; & 0 \\
\hline rpIV & 120 Cytoplasmic; & 0 \\
\hline ogt & 96 Cytoplasmic; & 0 \\
\hline СpC231_1684 & 214 Extracellular; & 3 \\
\hline $\operatorname{ygb\overline {N}}$ & 445 Membrane; & 13 \\
\hline oppD3 & 221 Cytoplasmic; & 0 \\
\hline CpC231_1671 & 59 Extracellular; & 0 \\
\hline CpC231_1830 & 159 Cytoplasmic; & 0 \\
\hline СpC231_1445 & 117 Cytoplasmic; & 0 \\
\hline leu $\bar{C}$ & 482 Cytoplasmic; & 0 \\
\hline fadD15 & 611 Cytoplasmic; & 0 \\
\hline CpC231_1478 & 266 Extracellular; & 1 \\
\hline CpC231_0944 & 180 Membrane; & 3 \\
\hline CpC231_0915 & 322 Extracellular; & 1 \\
\hline CpC231_1771 & 66 Cytoplasmic; & 0 \\
\hline CpC231_0070 & 339 Membrane; & 0 \\
\hline $\mathrm{mtr} \overline{\mathrm{A}}$ & 232 Cytoplasmic; & 0 \\
\hline $\mathrm{rfbA}$ & 289 Membrane; & 0 \\
\hline CpC231_1061 & 365 Cytoplasmic; & 0 \\
\hline CpC231_0071 & 31 Extracellular; & 0 \\
\hline CpC231_0580a & 48 Extracellular; & 0 \\
\hline menB & 335 Cytoplasmic; & 0 \\
\hline serB & 427 Cytoplasmic; & 0 \\
\hline CpC231_0087 & 106 Cytoplasmic; & 0 \\
\hline CpC231_1956 & 451 Extracellular; & 1 \\
\hline $\mathrm{pgmB}$ & 218 Cytoplasmic; & 0 \\
\hline pflA & 289 Cytoplasmic; & 0 \\
\hline cobC & 380 Cytoplasmic; & 0 \\
\hline alkB & 247 Membrane; & 0 \\
\hline glmM & 447 Cytoplasmic; & 0 \\
\hline trmD & 289 Cytoplasmic; & 0 \\
\hline fusA & 708 Cytoplasmic; & 0 \\
\hline$g \ln B$ & 112 Cytoplasmic; & 0 \\
\hline CpC231_1378 & 197 Extracellular; & 0 \\
\hline
\end{tabular}


Anexo 1

2066 D9QA90 Uncharacterized protein

2067 D9QA93 Integrase

2068 D9Q917 Transcriptional regulator LysR family

2069 D9Q9S9 Phage shock protein C

2070 D9QD36 Uncharacterized protein

2071 D9QCT5 Urease accessory protein UreD

2072 D9Q954 Resuscitation-promoting factor

2073 D9QDM5 Arabinosyltransferase C

2074 D9Q9M4 Monoacyl phosphatidylinositol tetramannoside-binding pro

2075 D9QDS3 Recombination protein RecR

2076 D9QD35 GntR-family transcriptional regulator

2077 D9QD52 Uncharacterized protein

2078 D9QCH8 Cell wall channel

2079 D9QDR7 Gluconate 5-dehydrogenase

2080 D9QCU5 YibE/F family protein

2081 D9QDQ3 Uncharacterized protein

2082 D9QCB9 TetR-family regulatory protein

2083 D9QBP4 Uncharacterized protein

2084 D9QCX8 4-hydroxybenzoate polyprenyltransferase-related prenyltra

2085 D9QAY5 Uncharacterized protein

2086 D9QA14 Uncharacterized protein

2087 D9QDW9 Protein yhaP

2088 D9QEQ5 Propionyl-CoA carboxylase beta chain 2

2089 D9Q9Z9 D-3-phosphoglycerate dehydrogenase

2090 D9QD32 Uncharacterized protein

CpC231_0988
CpC231_0991
lysR
pspC1
CpC231_2013
ureD
rpfA
embC
IpqW
recR
CpC231_2012
CpC231_2029
CpC231_1798
idnO
CpC231_1919
CpC231_0129
CpC231_1736
CpC231_1504
ubiA
CpC231_1236
CpC231_1084
yhaP
pccB2
serA
CpC231_2009

81 Extracellular;

88 Extracellular;

253 Cytoplasmic;

73 Membrane;

460 Cytoplasmic;

275 Cytoplasmic;

207 Extracellular;

1070 Membrane;

490 Extracellular;

218 Cytoplasmic;

124 Cytoplasmic;

123 Cytoplasmic;

49 Extracellular;

249 Membrane;

510 Membrane;

228 Extracellular;

169 Extracellular;

249 Membrane;

326 Membrane;

252 Membrane;

159 Cytoplasmic;

275 Membrane;

547 Cytoplasmic;

531 Cytoplasmic;

103 Extracellular;
No

No

No

No

No

No

Yes

Yes

No

No

No

No

No

No

No

Yes

No

No

No

No

No

No

No

No

No 
Anexo 2

\begin{tabular}{|c|c|c|c|c|}
\hline \multirow{2}{*}{$\begin{array}{c}\text { \# } \\
\text { Epitope \# }\end{array}$} & \multirow{2}{*}{$\begin{array}{l}\text { Uniprot entry } \\
\text { Epitope name }\end{array}$} & \multicolumn{3}{|c|}{ B-cell Epitopes } \\
\hline & & Epitope sequence & $\begin{array}{l}\text { Position of first aa in } \\
\text { protein sequence }\end{array}$ & $\begin{array}{l}\text { Conservation among } \\
\text { proteomes (\%) }\end{array}$ \\
\hline \multirow{5}{*}{1} & \multirow{5}{*}{ E1_D9Q919 } & SDLPRGDDDD & 81 & 94,3 \\
\hline & & DLPRGDDDDD & 82 & 94,3 \\
\hline & & LPRGDDDDDS & 83 & 94,3 \\
\hline & & RGDDDDDSAL & 84 & 94,3 \\
\hline & & YPKDGPSGNT & 185 & 35,7 \\
\hline \multirow{3}{*}{2} & \multirow{3}{*}{ E5_D9QCl3 } & TQSNTANVNG & 186 & 35,7 \\
\hline & & QPDGSRTLAG & 187 & 35,7 \\
\hline & & ADPQYQRKEF & 612 & 41,4 \\
\hline \multirow{2}{*}{3} & \multirow{2}{*}{ E9_D9QEK9 } & EGESQPEFTH & 128 & 94,3 \\
\hline & & GESQPEFTHD & 129 & 94,3 \\
\hline \multirow[t]{4}{*}{4} & \multirow[t]{4}{*}{ E11_D9QDW8 } & PADAQPTPRA & 406 & 92,9 \\
\hline & & PGKFEQRKGG & 176 & 80,0 \\
\hline & & VTKNKPAPGS & 177 & 51,4 \\
\hline & & TKNKPAPGSI & 178 & 51,4 \\
\hline \multirow[t]{6}{*}{5} & \multirow[t]{6}{*}{ E12_D9QAI2 } & FEPKQTGGFT & 484 & 80,0 \\
\hline & & IPRDRSSETP & 578 & 80,0 \\
\hline & & RDRSSETPLV & 580 & 80,0 \\
\hline & & DRSSETPLVI & 581 & 80,0 \\
\hline & & PVPPTDPWYQ & 323 & 90,0 \\
\hline & & VPPTDPWYQK & 324 & 90,0 \\
\hline \multirow{5}{*}{6} & \multirow{5}{*}{ E19_D9QBT9 } & AEQYPFDPDR & 334 & 90,0 \\
\hline & & PFDPDRARQL & 338 & 90,0 \\
\hline & & FDPDRARQLM & 339 & 90,0 \\
\hline & & DPDRARQLMD & 340 & 90,0 \\
\hline & & SNGQSAAWLG & 189 & 90,0 \\
\hline \multirow[t]{2}{*}{7} & \multirow{2}{*}{ E25_D9QBQ3 } & ARKTTTDHAR & 539 & 52,9 \\
\hline & & RKTTTDHARQ & 340 & 90,0 \\
\hline 8 & E28_D9QAF0 & SGTAEPKRHY & 229 & 88,6 \\
\hline & & NLQDLTDGSA & 46 & 84,3 \\
\hline & & LQDLTDGSAP & 47 & 84,3 \\
\hline & & TSNNADEQAA & 145 & 84,3 \\
\hline 9 & F29 D90חX4 & KKGLSTEQIT & 303 & 84,3 \\
\hline (5) & ELS_LSQU人4 & SYSEKGSFDQ & 488 & 84,3 \\
\hline & & YNTKYNRGSS & 679 & 84,3 \\
\hline & & SDGTPPRRTT & 749 & 80,0 \\
\hline & & DGTPPRRTTS & 750 & 78,6 \\
\hline 10 & E37_D9Q9L5 & TRTPAKDFSS & 321 & 97,1 \\
\hline & & DSSDAPYSAL & 50 & 94,3 \\
\hline & & DPSVNKLKSS & 158 & 94,3 \\
\hline & & SVNKLKSSDV & 160 & 94,3 \\
\hline & & VNKLKSSDVK & 161 & 94,3 \\
\hline & & PTGELPKPES & 225 & 94,3 \\
\hline 11 & E38 D9OB28 & TGELPKPESA & 226 & 94,3 \\
\hline & E30_U9QBD<8 & GELPKPESAY & 227 & 94,3 \\
\hline & & ELPKPESAYE & 228 & 94,3 \\
\hline & & LPKPESAYEL & 229 & 94,3 \\
\hline & & LKKYQQPVDA & 238 & 94,3 \\
\hline & & KKYQQPVDAQ & 239 & 94,3 \\
\hline & & QPVDAQSTAD & 243 & 94,3 \\
\hline & & TNNSYSNNAD & 81 & 54,3 \\
\hline & & NNSYSNNADA & 82 & 54,3 \\
\hline 12 & E50_F9Y379 & QDLTNRGIPD & 153 & 52,9 \\
\hline & & DLTNRGIPDG & 154 & 52,9 \\
\hline & & NRGIPDGPNY & 157 & 55,7 \\
\hline & & PNTAKGKKFS & 9 & 50,0 \\
\hline & & DPASGNRSAQ & 43 & 55,7 \\
\hline 13 & E55_D9QB55 & PASGNRSAQR & 44 & 55,7 \\
\hline & & ASGNRSAQRV & 45 & 55,7 \\
\hline
\end{tabular}


Anexo 2

$\begin{array}{ll}15 & \text { E63_D9QER5 } \\ 16 & \text { E64_D9QBP6 } \\ 17 & \text { E66_D9QDH7 } \\ 18 & \text { E67_D9QD67 } \\ 19 & \text { E70_D9QCT4 } \\ 20 & \text { E72_D9QA91 } \\ 21 & \text { E76_D9QEN1 } \\ 22 & \text { E78_D9QC38 }\end{array}$

KDSTSAKTPP

51,4

TSAKTPPPAA

TWKATSGNHP

SDSSAPAPQN

AAPKPQTHNH

APKPQTHNHP

HREGMDGKDH

DKPETLDPDE

KPETLDPDEK

KTPEIDDRDD

CAKPEEDPYM

AKPEEDPYMV

IDTNRGYDSK

DTNRGYDSKT

TNRGYDSKTD

ERKQGGSYTG

LADPTPRSSA

PSELPTPPTP

PGAPMRTELA

VEGDADPACA

STGEESAGAP

GEESAGAPAV

EESAGAPAVH

ESAGAPAVHD

TSARDGAAKL

SARDGAAKLA

ARDGAAKLAD

RDGAAKLADG

ADGMNQLQAA

DPKAAEFKPE

NFEDLRQNHP

FEDLRQNHPK

EDLRQNHPKA

E90_D9QEE1

LRQNHPKAME

RQNHPKAMEE

QNHPKAMEEN

GSIRQYRVSH

YTWDAQKRRN

TWDAQKRRNF

ESGTQDREVG

PYTEDPPGSL

STYSPEPHSK

TYSPEPHSKE

SPEPHSKEWC

PEPHSKEWCH

SSNPPKTRHP

KSSDTPPVER

SDTPPVERAI

E105_D9QBC2

KQGTFNPTAP

QGTFNPTAPS

FNPTAPSGGE

NPTAPSGGEV

E112_D9QCR2

E114_D9QC71

PEKVTKGETF

SSCTTKPDVQ

NSNTYVGPSN

KIGEYRGFDE

DKDEKVRSIG

PLENPQDIFS

ENPQDIFSFG

NLTNNSAATT

TNNSAATTTG 
Anexo 2

35

36

37

38
E127_D9QBZ2

E125_D9QA08

E136_D9QAT8

E141_D9Q967

E142_D9QEF8

E144_D9QDT9

E154_D9Q980

E158_D9QC90

E159_D9QDD8

E161_D9QB44

E162_D9QDP1

E164_D9QDC2

E167_D9QDV7

E169_D9QEM3

E172_D9QEL9

E178_D9QCH2
GLTGPRPAGA

LTGPRPAGAF

TGPRPAGAFS

EPQPVRDGFY

PQPVRDGFYA

QPVRDGFYAA

GNKSNQQIES

NKSNQQIESD

PLEGQRQAGK

PQATPDTPNY

QATPDTPNYY

ATPDTPNYYP

TPDTPNYYPG

PDTPNYYPGG

TPNYYPGGMV

TSSDGHATRG

DRAEGASTSS

EGASTSSDPN

STSSDPNDAT

TSSDPNDATK

TKDSADKAMT

QERTAPPVVP

PTPPAFDTGS

DSFPSDTSDV

AGPNSNKIGQ

SVNPEDPTKP

VNPEDPTKPE

EDPTKPEPKE

PEPKEPEKPK

YKAEDKGTVV

PVENEDLFTP

TPEVPDDSSF

QTNPAYAAPV

ASAQRDPYKL

AQRDPYKLLP

GTGDPNIDSS

ESGQFYDNTW

KKWNDAAIAQ

DVSSDPTALA

GSAESTAVRT

SIPEGETPLD

GGDPHTYQPS

PDKADTYKTN

SEKKYTRRDF

KSTNATEQKN

STNATEQKNK

NVDRFTRSGN

TRSGNAPSDV

EGKEMTSYKA

DNEKLSFSGK

NSSKDASLGD

SNYADPSSGS

PKTENQTPPS

KTENQTPPSP

ASAKQGDKDD

SAKQGDKDDS

KQGDKDDSEE

TDPDGFYTSI

DNTGIDPIEA

QGKMGSRTVK

GKMGSRTVKQ

GSRTVKQFHR 
Anexo 2

E226_D9QCR3

E229 D9QAT6

DGTWSEWYDT

SEWYDTEPLD

QPAAGQPAAD

TNNVSDFDVV

HYSEGTSYTP

NTPPRGDAPA

TPPRGDAPAP

PPRGDAPAPQ

SSINWKDVKS

GGVMPPSREE

GVMPPSREEL

VMPPSREELL

MPPSREELLA

GYYQRRYVTN

DPTTAESTWA

AEYTKDDRTD

EYTKDDRTDA

EGEYLPSSTK

EYLPSSTKGE

YLPSSTKGEE

LPSSTKGEEK

PSSTKGEEKG

SSRSTSRATT

SRSTSRATTS

RSTSRATTSS

KYCKNTGKKD

FKDSDGKISW

SSERSIALPK

EQTPTASSLA

SQPAPVSAWV

QPAPVSAWVN

TQKDAQGRTI

NSPDVPAESL

PDVPAESLAA

SGAPKPPSAD

GAPKPPSADA

APKPPSADAP

PKPPSADAPS

KPPSADAPSP

PPSADAPSPL

AEPKGSASNN

PQVDAGTVAL

VSGKHRKQTS

EPLKASPGRA

DDPWKDKLQV

EVNKSGAMQV

GKEDQRPAWL

PAFSKDKLDP

TWKDDQGKIT

TPSLEQQDTH

DCLSSRTDAS

DEAKSKEDVY

EAKSKEDVYR

ASAGPRDWLR

SAGPRDWLRP

RDWLRPDATG

DWLRPDATGT

LRPDATGTCE

RPDATGTCEW

PDATGTCEWD

KDLGKGVYGD

AKPTPGESFS 
Anexo 2

E245_D9QC18

72

73

74

75

76
E254_D9QCV3

E257_D9Q954

E258_D9Q973

E262_D9QBC3

E268_D9QEW7
QRQSAAPAGE

SDPKISQDHD

PKISQDHDGR

GNHNPGGGIL

NHNPGGGILS

NRGLRGAEAS

RQPKERSGRE

TGKEQSKQQQ

KEQSKQQQCT

LGAPQNGLPS

GAPQNGLPST

APQNGLPSTL

VDDAQNYAAA

TADWKQGAAG

APPVSPGNPA

PPVSPGNPAP

PVSPGNPAPV

SSDDKGSSSS

SDDKGSSSSS

DDKGSSSSSS

DAAAQPPAPD

AAQPPAPDAP

QPPAPDAPAA

GTAETSSEKT

ETSSEKTKKN

QFDSCDANGV

MACSGEKIGQ

ACSGEKIGQF

CSGEKIGQFQ
85,7

90,0

90,0

90,0

90,0

54,3

90,0

90,0

90,0

77,1

77,1

77,1

98,6

94,3

94,3

94,3

94,3

97,1

95,7

95,7

97,1

97,1

97,1

54,3

88,6

88,6

88,6

88,6

88,6 